\title{
The Scope and Limits of Biological Explanations in \\ Archaeology
}

\section{Benjamin Jeffares}

A thesis submitted to the Victoria University of Wellington in fulfilment of the requirements for the degree of

Master of Arts in Philosophy

2002 


\section{Acknowledgements}

This thesis was only completed due to the patience (and the occasional justifiable impatience) of two individuals: Kim Sterelny, who has mentored greater talents than I, and Robyn Johnston, who not only puts up with me, but provided the necessary snuggles and other nourishment.

Others to thank are fairly numerous. The philosophy department and staff of Victoria University for providing a home, in particular Ken Perszyk for ensuring it was a home with real coffee and James Chase for helping me drink it. My fellow long haul Masters students, Louise Hull (most of the time), and Andy Doube (I'm $\mathrm{f}^{* * * * * *}$, restart?) and the attendees of the student seminars for being peers and providing all that peer review brings. From co-founder Mo, early stalwarts Brett and Russell through to the more recent converts, thank you all to all attendees and I leave the seminars in the fine hands of Jess Hammond and Amy Russell.

The Philosophy Dept "Associates" deserve a mention. Marjan, Russell, Richard, Andy, James, Mel Barrett, Fiona and anyone else who has bought me a drink. Cheers.

For Mum. 


\begin{abstract}
I show how archaeologists have two problems. The construction of scenarios accounting for the raw data of Archaeology, the material remains of the past, and the explanation of pre-history. Within Archaeology, there has been an ongoing debate about how to constrain speculation within both of these archaeological projects, and archaeologists have consistently looked to biological mechanisms for constraints. I demonstrate the problems of using biology, either as an analogy for cultural processes or through direct application of biological principles to material remains. This is done through setting out the requirements of a Darwinian Archaeology, and then measuring various approaches against these requirements.

This approach leads to the conclusion that archaeologist's explanations of the past must include within their formulations an account of human cognitive capacities within their explanatory framework. The limits of our understanding of the human past will be the limits of our understanding of Homo sapiens.
\end{abstract}




\section{Table of Contents}

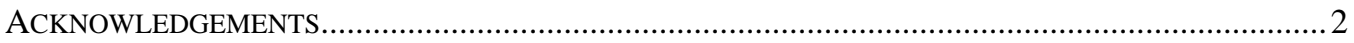

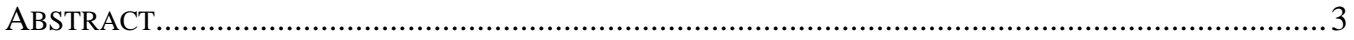

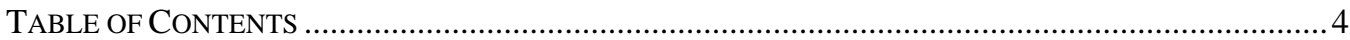

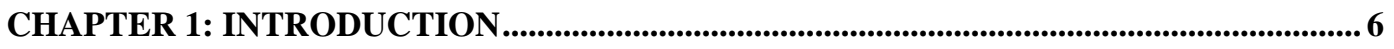

1.1.1. Archaeology and Human Evolution..................................................................... 6

1.1.2. Archaeological Data in Space and Time ............................................................... 9

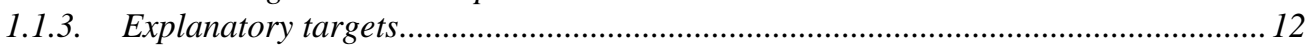

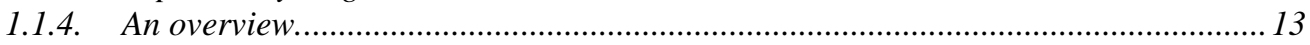

CHAPTER 2: HAWKES' HIERARCHY AND ITS CONTEXT ................................................ 16

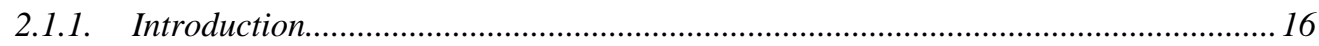

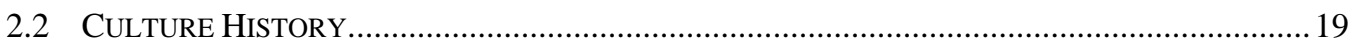

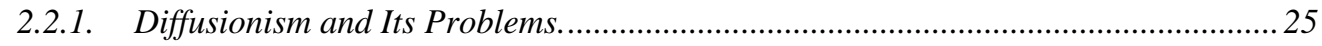

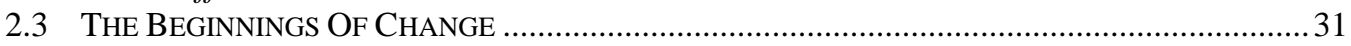

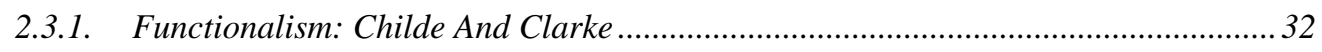

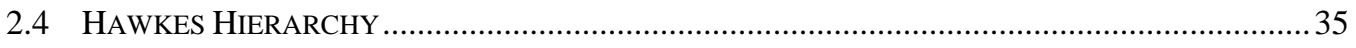

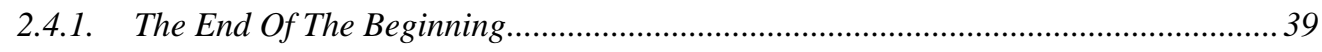

CHAPTER 3: BINFORD AND THE "NEW ARCHAEOLOGY" ............................................... 41

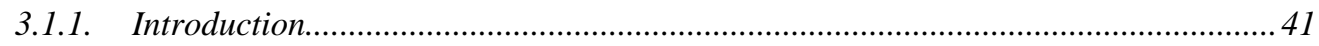

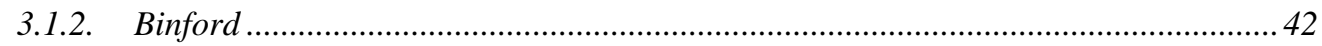

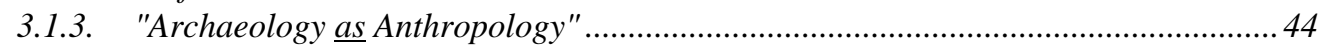

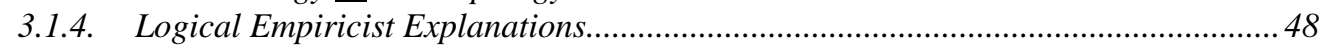

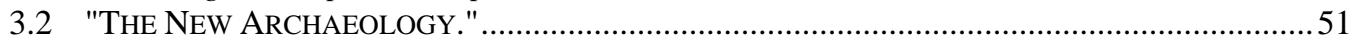

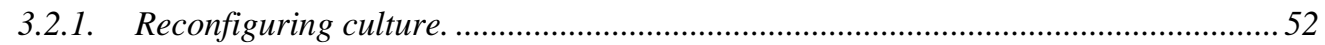

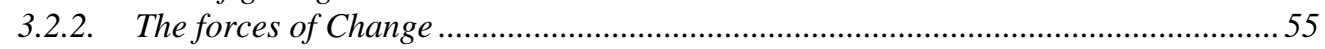

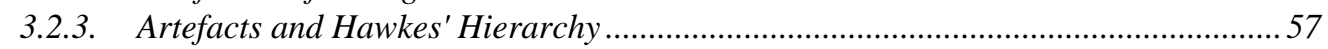

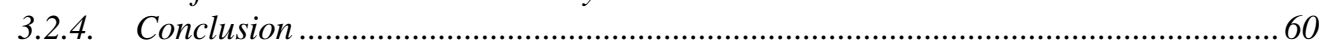

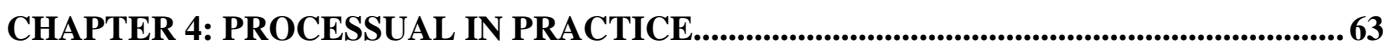

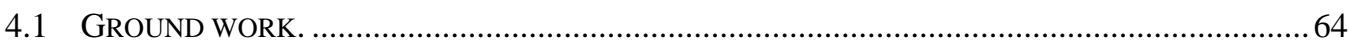

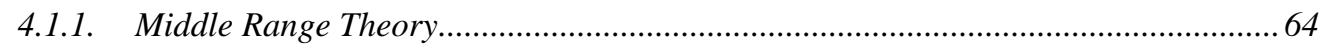

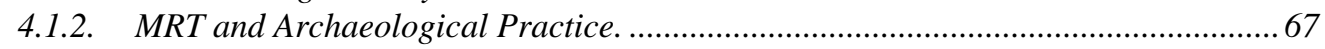

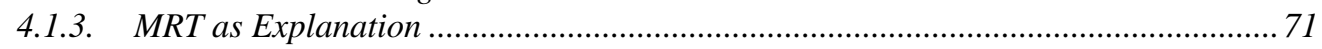

4.2 ARCHAEOLOGICAL EXPLANATION - PARTICULAR AND GENERAL ........................................ 74

4.2.1. Research Projects and Unity ................................................................................ 77

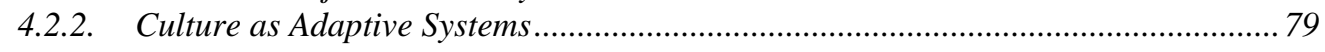

CHAPTER 5: EVOLUTIONARY ARCHAEOLOGY ............................................................. 82

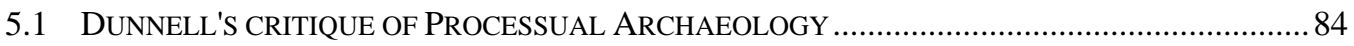

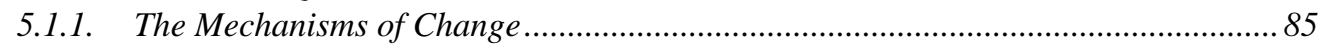

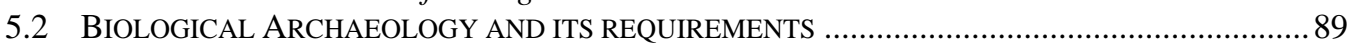

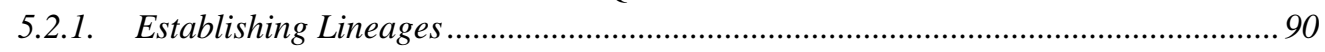

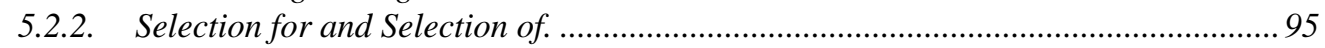


CHAPTER 6: SELECTIONIST ARCHAEOLOGY...........................................................100

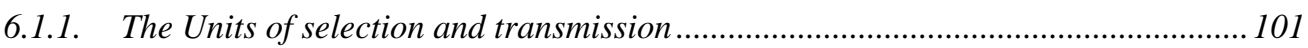

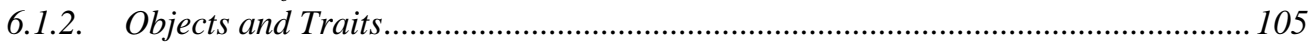

6.1.3. Lineages, style, and traits................................................................................. 109

6.1.4. Separating Style and Function: so how do you tell? ........................................... 112

CHAPTER 7: BEHAVIOURAL ECOLOGY AND ARCHAEOLOGY ..................................115

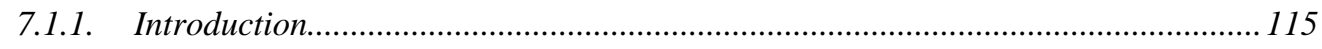

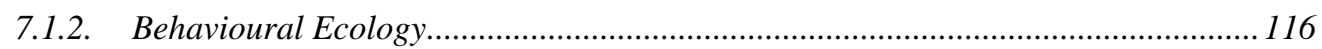

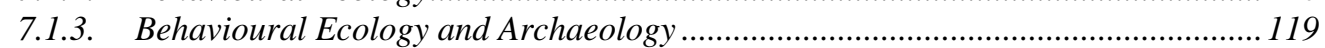

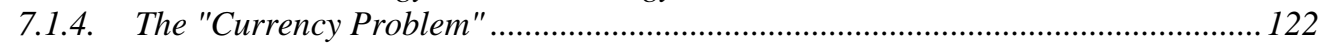

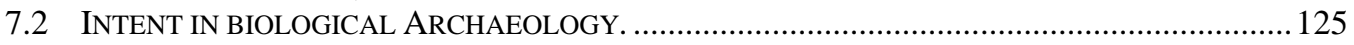

7.2.1. Mithen and the "Eco-psychology of decision making "......................................... 132

7.2.2. The Problems of cognitive Archaeology .............................................................. 135

CHAPTER 8: BIOLOGICAL EXPLANATIONS IN ARCHAEOLOGY ............................. 138

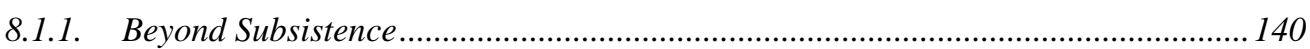

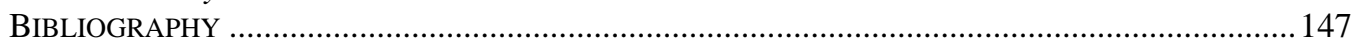




\section{Chapter 1: Introduction}

\subsubsection{Archaeology and Human Evolution}

This thesis is about Archaeology. In particular, it is about archaeological explanations, and how much such explanations can tell us about the past. For it is the remains of our interactions with the physical world - our material culture - that offers the greatest possibilities for insights into the behaviour of our forebears. Other disciplines contribute to our understanding. The work of physical anthropologists and their study of skeletal material should not be underestimated. However, much of the lifeways and the behaviours of human beings are associated with material artefacts. Human beings make stuff to get on in the world. That stuff, be it buildings or cooking pots, can, given the right circumstances, survive as fragments. Given a relationship between artefacts and behaviours, the possibility exists that we can gain an insight into the lifeways, the behaviours, the lives of our ancestors through their material remains.

However, we cannot expect the explanations of the past that Archaeology provides to be complete. There will be limits in what it can reliably tell us. Cultural remains are a decayed by-product of human behaviours. They are not the behaviours themselves. As such, they can only indicate behaviours through interpretation and analysis. This thesis is a working through of the limits of those interpretations. What can artefacts, the archaeological record, reliably tell us, and what is required in order to provide those interpretations with some authority?

Put crudely the issue is this: Can we point to an object made long ago, and in the absence of eyewitnesses and written documents, say with confidence what that object was used for, and the role it played in the life of an individual or a people? At its 
broadest, this thesis addresses that question. What can be said with confidence? What is speculation and how can we tell the difference between them?

In particular, this thesis looks at the relation between statements about the past and biology. For in looking at human evolution its clear that tool using, tool making, is an important component of just what it is that makes hominids, those upright apes, such startling animals. In fact, the first hominid with an alleged association with tools, Homo habilis, was designated "Homo" as opposed to "Australopithecus" precisely because it was presumed to be a toolmaker. Controversially at the time, cultural products, tools and the ability to make and use them, were part of the designation of the "type", Homo habilis. (Lewin, 1997) Type specimens, the reference specimen used by anatomists for the classification of species, traditionally focused on anatomical features. H. habilis included within its type definition the use of tools. Tools, artefacts, extensions of the Homo phenotype, are part of what it is that defines our genus. Consequently, our understanding of human evolution requires an understanding of tools. The study of Physiology and the skeletal remains of hominids were not going to tell the whole story of human evolution. Material culture matters in the success of hominid species.

If tools are going to be part of the biological definition of hominids, and if they are going to make a difference to hominid evolution, then tools and artefacts seem to require some biological context. The contributions tools make to the differential survival of hominids, how they make those contributions and the limits of those contributions all matter in the evolutionary history of human beings.

Equally, tools and material culture become part of the environment for hominids. If tool use enhances survival, an increase in the efficiency of tool use enhances the fitness of individuals, perhaps at the expense of less efficient tool users. The presence of tools and material culture may be an environmental factor crucial to human evolution. So again, there seems to be a need to understand tools in their biological context, and in their impact upon evolutionary events.

The potential for Archaeology to give insights into the biological and evolutionary 
context of artefacts is the focus of this thesis. However, it is worthwhile noting that Archaeology is an extraordinarily diverse discipline. It ranges from the changes in hominid tool use over hundreds of thousands of years to changes in pottery styles over decades. Archaeology as a field of study has the potential to blur into history with extraordinary ease. The cultures that European archaeologists deal with were literate, or contemporaneous with literate societies. Consequently, it is unsurprising that there is a natural relation between Archaeology, classics, history, art history and other humanities. Nor should it be surprising that at least some archaeologists should look to such disciplines for guides to their explanatory project. An archaeologist looking at the remains of Roman mosaics may clearly find productive the tools of art history. An archaeologist looking at Etruscan architecture may find building sciences a useful adjunct to her understanding.

Although the archaeologists whose areas of study blur into humanities and social sciences are of interest, they are not the primary focus of this thesis. Not that they are entirely absent. As I hope to show, the Middle Range Theory that emerged out of the work of Lewis Binford has ramifications for all archaeologists in a way that cuts across different explanatory agendas. However, I will be primarily discussing where Archaeology impacts upon, and blurs into, the work of biologists and scientists. The Archaeology under examination here shares a close relationship with palaeoanthropology, anthropology and the study of hominids as a genus, rather than the study of specific cultures or cultural products such as art.

That said, a broader theory that places Homo sapiens and their cultural products within their ecological and evolutionary context should influence the interpretative endeavours of archaeologists, but that influence is outside of this thesis' scope. This thesis is about the archaeological theorists who look to the natural sciences as a guide to how to do Archaeology, and are in an active partnership with them in understanding the past. 


\subsubsection{Archaeological Data in Space and Time}

I begin with archaeological data. What is it that archaeologists measure and count?

We all at some stage have cleared away the overgrown backyard of our own flats and homes to find half-buried teaspoons, empty bottles and indefinable rusty objects. Archaeology deals with this kind of detritus from human lives. Archaeological sites are merely such human leftovers scaled up in terms of age and frequently in size. Not just the refuse of the previous few tenants, but the remains of entire cultures who once inhabited the land. Archaeologists can be confronted with the remains of entire villages, with the foundations of buildings, places that looked like workshops, dwellings, temples, grave sites and grave goods, rubbish dumps, and the lost objects of generations of people which had lived within a community. Depending on the culture, an archaeologist may even find some teaspoons.

Sometimes the nature of the sites won't be as recognisable as the remains of a village or settled community. Nomadic peoples also leaves traces of their activities that can make it into the archaeological record. A rocky overhang can be reused over centuries by different groups for campfires, animal butchery, and tool making in stone and bone, all of which can leave remains that can survive to our times.

For instance when Ralph Solecki excavated the Shanidar caves of Iraq he found evidence of its use by 'people' back to Neanderthal times. In fact Solecki had to work round the nomadic people who still used the cave as a seasonal shelter in the 1960's (Solecki, 1971). In parts, the sediment that Solecki had to dig through was in places 10 meters thick. And all through that sediment at various layers were objects. Broken pottery, flints, bones, things made by humans and discarded or lost. Solecki was confronted with the results of more than 50,000 years of people breaking things, burying objects and loosing stuff.

From such collections of artefacts, there can be a range of data for the archaeologist. What things were made of, how they were made, whether one object was on top of another. Increasingly archaeologists use a much wider data set than just 
the remains of manufactured culture. The gathering of the data that archaeologists use is a collective endeavour. Chemists, geologists, and other disciplines are all involved in providing information that the archaeologists can work with. Pollen samples, the remains of meals (middens etc), are all included within the basic data of Archaeology.

In Archaeology all this data makes little sense outside of the context of the associated objects. Quite often, the data that archaeologists are most interested in is the configuration of objects. What sits next to what will matter.

Archaeologists face two types of information in the configuration of artefacts and data. On the one hand, there are the configurations through the various layers of deposits. As time passes debris, dirt and sediment is laid down, creating a series of deposits where older layers are beneath more recent. This can be a matter of thousands of years as in the case of the caves of Shanidar, or shorter time-scales. As the archaeologists progress through the layers, so the artefacts change. The excavations of a sequence of archaeological remains at a site in Hissarlik, Turkey, got the designations Troy I through to Troy VII because of changes in artefacts at different depths. (Glyn Edmund Daniel, 1981:p158). There was a discernible difference in the artefact types at each layer over hundreds of years.

So archaeological data can appear to have temporal relations. It can look as though the different artefacts at different layers can reflect sequences, changes in artefact types, from the more recent layers on the surface to the older layers beneath. Archaeological data has a time dimension.

The second kind of data that archaeologists deal with is the configuration of artefacts in space. If a range of artefacts is contemporaneous in time, there may be spatial relations. Again, an example may help. When Graham Avery and his associates excavated through the layers at Die Kelders cave in southern Africa, at a layer they attribute to the Middle Stone Age, they unearthed various stone artefacts and the flakes associated with the manufacturing process. These were associated with the remains of what looked to be dismembered carcasses with bone surface modifications, and the odd fairly robust hominid tooth (Avery et al., 1997). This 
range of artefacts shared a distinctive spatial relationship.

At base then, archaeologists deal with objects and their configurations through time and space. This process of putting individual objects into their spatial and temporal context is a process of enriching the data. The fundamental unadorned data is given a context from which more information can be extracted. From scattered objects, it may be possible to talk of cultures, peoples, settlements and groups.

However, this process of temporal and spatial contextualising is itself a matter of interpretation. It is not always a straightforward process to identify meaningful relations between artefacts. As we shall see as we progress through this thesis, finding a group of artefacts in a contiguous location may not show they were contiguous in use. How they ended up in the same place becomes an issue. So archaeologists have to determine when temporal and spatial relations are meaningful. What counts as "meaningful" is part of the process of Archaeology that we will examine. The site investigated by Avery et al is viewed as meaningful. For the relations between the individual data points, the bones, the stones etc, are thought to represent a prehistoric butchery site. But this is an inference from the configuration of objects to a claim about what they represent. What gives us confidence in such inferences?

The claim about the site in Turkey being the ruins of Troy makes a similar inference from the configuration of artefacts through time. There is an implicit assumption in the designations Troy I through to Troy VII that the different artefacts at different layers bear some kind of relationship with each other beyond that of geographical location. The assumption is that they represent some kind of continuity of a cultural group.

One of the questions we can ask of such interpretations of the raw data is how reliable they are. So in Die Kelders cave example, we can ask, do these things really indicate a group of hominids butchered a carcass here thousands of years ago? Maybe a group of hyenas were responsible for the bones found, and the hominids just made tools here at a later stage. Likewise, we can ask questions about the supposed 
temporal relations of a site such as the one at Hissarlik. Does this site represent a continuity of a culture? And what information do we need to make such a statement?

\subsubsection{Explanatory targets}

Once we have secured our statements about the past such as the presence of a campsite, or the continuity of a community, what can such things tell us about the past?

Archaeologists are not just interested in documenting the past. Archaeologists are often in the business of explaining the past. However, what has counted as an explanation has shifted over the years. A lot depends on what an archaeologist wants to achieve. There have been subtle shifts in the explanatory project of Archaeology. These changes in the explanatory target of Archaeology have attendant changes in the interpretation of Archaeology's raw data and the process of putting it into its temporal and spatial context. Archaeologists want to talk about past events, changes in the lives of extinct groups, and the evolution of human material culture. They want to examine the changes in the way people have lived, and to explain those changes. As a result the process of collecting artefacts, assigning them a location in space and time, and comparing artefacts, is frequently done with explanatory goals in mind. Die Kelders cave is interesting because it can contribute to our understanding of our evolutionary history. The configured data, in its enriched form as a recognised campsite, contributes to our understanding of human history generally.

At this point, the question shifts. Is the documentation of a campsite or a village, no matter how secure, enough to tell us what we want to know? Is it good enough to explain the past, or does it require more interpretation if it is to fulfil our explanatory needs.

There appears to be a two step process here. From the remnants of human material culture, we wish to be able to identify sites, habitations and activities. From these configurations of data, we wish to be able to infer broader statements about the past. Can we talk confidently about the change from nomadic hunter-gatherer groups to 
settled agriculturists? What changes in cognitive capacities does the increasing diversity of pre-human tool types indicate? Does the sudden shift in artefact types in Europe of thirty thousand years ago, the middle to upper Palaeolithic transition, represent a cognitive shift, or a cultural invasion? It is determining how we can secure the answers to such questions that we will examine over this thesis. The explanatory goals that we are interested in here are explanations that are compatible with the explanatory goals of biology. We want to be able to talk meaningfully about human beings in their biological and evolutionary context.

\subsubsection{An overview.}

In order to make the endeavours of archaeological theorists clear, the first chapter will provide some historical background to archaeological theories. There are three reasons for this. The first is that the first attempts to formulate a specifically scientific Archaeology were in many ways a reaction against what had gone before.

Archaeology was a descendent of antiquarianism, and the collection of artefacts for their own sake was still a component of Archaeology. As Archaeology became more professional, and as new methods became available to it, Archaeology began to reconsider what its role was as a discipline

This leads to the second motivation for this historical overview. As Archaeology began to shake of its amateurism and its antiquarianism it began to try to make sense of artefacts that confronted it. This chapter also incorporates a criticism of the first attempts at archaeological theory, notably an attempt to explain artefact change via the mechanism of diffusion. It also briefly covers some alternative explanatory strategies that were beginning to be used as the discipline of Archaeology gained better tools such as carbon dating and aerial surveys, providing new information and hence new possibilities for understanding.

Third and most importantly this chapter deals with the first changes in the explanatory goals of Archaeology. At this point in Archaeology's history (the 1950s) Christopher Hawkes outlined what he saw as the difficulties that Archaeology would 
face in attempting to explain archaeological data. Hawkes' Hierarchy, as it is known, will be used as a rough yardstick for explanatory adequacy for the rest of the thesis. Hawkes Hierarchy has its problems, but it should provide a useful measure.

Chapters 3 and 4 look at the work of Lewis Binford. Binford and his followers were the first to attempt to put together an explicitly scientific Archaeology with well-defined explanatory goals. Chapter 3 looks specifically at the theoretical component of that work and its attendant problems. Chapter 4 looks at some practical consequences of this movement and its application. In many important respects the practical results of what was called the "New Archaeology" laid the ground work for the means of testing and evaluating the claims of archaeologists, and despite its limitations and problems, I hope to show that processual Archaeology and its attendant "Middle Range Theory" continues to make an important contribution to archaeological practice.

Chapter 5 lays out the requirements for a specifically biological and Darwinian Archaeology. It does this after looking at the criticism of the work of Lewis Binford and the processual archaeologists by Robert Dunnell. Dunnell is important due to his criticisms of the processual Archaeology of Binford but also for the fact that those criticisms in part stemmed from an avowedly Darwinian perspective. His alternative proposal is explicitly different in how he believed that Archaeology should define itself as a science. To set the stage for such an explicitly biological Archaeology we need to clarify just what such Archaeology requires.

Chapter 6 looks at Robert Dunnell and the Selectionist archaeologists in detail. Dunnell's concerns are twofold. One, he is worried about the ontological status of many of the enriched data sets that archaeologists use. Despite the efforts of Binford in trying to make explicit and testable the interpretation of Archaeology's raw data, Dunnell is concerned to show that outmoded and untestable theoretical ideas drive interpretations of Archaeology's raw data. The second concern is to show that Darwinian evolution, with subtle amendments, was capable of making inroads into explanations of the temporal data of Archaeology. 
Chapter 7 is an introduction to the work of the behavioural ecologists and their conception of how Archaeology should be done. However it is also an opportunity to contrast two archaeological theories that both claim to have their origins in biology, the behavioural ecological archaeologists and the selectionist Archaeology of Dunnell. This chapter demonstrates that while both approaches have their strengths and weaknesses, they are in important ways incomplete, particularly in how they account for the cognitive capacities of Homo sapiens. In essence, this chapter begins to clarify the difficulties that a scientific Archaeology of human evolution and ecology faces. It does this by introducing the ideas of Steven Mithen. Mithen argues that one of the difficulties faced by archaeologists has been the problem of human intent. I support Mithen's viewpoint, although with qualifications.

Chapter 8 is the summary chapter. What I want to argue in this chapter that in order to explain some features of human life, more attention will need to be paid to the cognitive abilities of the human organism than has traditionally been shown in Archaeology. Within those areas of Archaeology that have struggled with a biological and evolutionary account of Homo sapiens, typically human cognitive capacities are ignored by archaeologists, or seen as general-purpose problem solving skills. That picture is wrong, and without a better understanding of the cognitive capabilities of Homo sapiens, the explanatory capabilities of a scientific Archaeology will remain limited. As such, I argue that one of the requirements of any Archaeology will be to be able to integrate the cognitive abilities of Homo sapiens into its explanations of the past. The limits of our understanding of the past will be in direct proportion to the limits of our understanding of the capacities and limits of Homo sapiens. 


\section{Chapter 2: Hawkes' Hierarchy And \\ Its Context}

\subsubsection{Introduction}

Archaeology as a discipline grew out of antiquarianism, the collection of historical objects of interest or value. This kind of collection has a long history. Renaissance artists, like Michaelangelo, were influenced by the collections of Roman and Greek sculptures of the Medici family and others. The collection of artefacts historical and anthropological has been a reasonably respectable hobby for those that could afford it for some time. ${ }^{1}$

However, Archaeology began in the early decades of the twentieth century to become a recognised field of study, with academic posts at Universities and the regular teaching of the subject. With this increase in professionalism came a broadening of what was collected. In the past it had been primarily precious objects and art works that were the focus of collectors. With regular workers in the field Archaeology began to document everyday objects as well. The treasure hunting aspects of antiquarianism was augmented and replaced by the collection of a wider range of objects; ones with anthropological value rather than fiscal value. Moreover, documentation of prehistoric landmarks and monuments became important.

\footnotetext{
${ }^{1}$ Admittedly some of the practices of the people engaged in supplying antiquarians with "the goods" were less respectable, particularly in areas such as Egypt. Much of what counted as Archaeology was organised grave robbing. (Glyn E. Daniel, 1967) The controversies over the Elgin Marbles, with Greece claiming they were "stolen" is a legacy of early Archaeology's cavalier and
} 
Despite this broadening and professionalisation, the theoretical discussion of Archaeology and its practices didn't really emerge until the 1940s-1950s. Before this, Archaeologists were primarily concerned with typologies for artefacts. These typologies were based on geographical and temporal origin and archaeologists were not usually concerned with much more than that. This was not much more than the collection of the raw, uninterpreted data of Archaeology.

This type of Archaeology was Culture History, and it was just concerned with the documentation of chronologies for artefacts and cultures. In fact, the term "culture" was not used in the sense that we would use it today. As we shall see, to say that an artefact belonged to such and such a 'culture' was only to provide a typological marker for an artefact. The configurational aspects of finds, their location in time and place only served as labels for the artefacts. So to say that an artefact was "Etruscan" was to allow the artefact to be catalogued correctly.

Despite the fact that early professional Archaeology was somewhat lacking in theory, it is necessary to review it briefly for a couple of reasons. Firstly, it provides some historical background to the work of Lewis Binford and others who began to explicitly suggest a theoretical position for Archaeology. Although Binford and the "New Archaeologists" made a distinctive positive contribution to archaeological theory and archaeological method, their approach was coloured by, and a reaction against, what had gone before. As a consequence the "old Archaeology" that the "New Archaeology" was supposed to supplant is worth outlining.

Secondly, looking at the beginnings of professional Archaeology is to see the discipline in its theoretical innocence. The early professionals were not particularly concerned with the appropriate way to do Archaeology, nor were they engaged in the theoretical fights with which modern Archaeology seems beset. Therefore, it is

accquistional nature. 
worthwhile showing why the theorising of later archaeologists is required by showing the less rigorous Archaeology as the base condition. Just how much Archaeology can you do without theory? And just what does a non-scientific Archaeology look like?

The first section of this chapter looks at the cultural historical archaeologists. These early archaeologists saw their role as documenting cultures and their history, and they left little room for the interpretation of their finds. Why a culture adopted a new technology or explanations of how new technologies fitted into the activities of peoples daily lives was not important. The key was that the new technology or feature of the archaeological record was put into a chronological and geographic context.

When the cultural historians did more than documentation, and started trying to explain the presence of technologies and artefacts, they relied on the notion of diffusionism, a problematic form of explanation that we will briefly review. Cultural Historical Archaeology lost favour as on the one hand new technologies and attitudes made new means of Archaeology possible, and on the other hand from a growing awareness of the explanatory limits of Archaeology as practised.

The second section of this chapter covers the early attempts at new ways of doing Archaeology, what Bruce Trigger describes as "functionalist" Archaeology (Trigger, 1990), concentrating on the work of Childe and Clark as examples of the new approaches. These archaeological approaches were as yet without a conception of Archaeology as a science, but they set up the conditions for an awareness that Archaeology could do more than document the history of a culture through its artefacts. Functionalists are the freewheeling spermatozoa that would give rise to more "scientific" Archaeologies; half right and wriggling in the general direction.

This chapter intends to show the shift from the cataloguing of artefacts and the construction of typologies, to the beginnings of attempts to extract more information from, and importantly to explain artefacts. Archaeology began to do more than catalogue objects and cultures, it began to try and explain them within their historical context. In doing this however, problems emerge, notably in how to tell a good explanation from a bad one. 
This chapter broadly sets up the problem that requires solving; what are the explanatory goals - and crucially - what are the explanatory limits, of Archaeology? As Archaeology changed, as this new thinking about Archaeology and its task emerged in the 1950s, Christopher Hawkes outlined what he saw as the difficulties that this new archaeological approach would face. We end this chapter with these thoughts.

\subsection{Culture History}

From the early 1800s archaeologists, such as they were, had seen past cultures as stages in the progression to civilisation. Societies passed through a sequence of technologies and diagnosing the stage that a culture was at was the name of the game. The "three age system" of Christian Thomsen, Stone Age, Bronze Age and Iron Age, is a legacy of this type of Archaeology. The assumption of progress underlying these general schemes never had serious theoretical justification, and they withered in the late 1800s as Archaeology became more professional and more like history.

"In all of the social sciences grand evolutionary schemes were being criticised as unsound and abandoned in favour of particularistic, inductive approaches. Historians emphasised the importance of the dispassionate collection of facts, and regarded interpretation as little more than irrelevant personal opinion." (Trigger, 1980:p24)

Archaeology took a similar track, documenting the "facts" of pre-historic cultures. Archaeology of the time was primarily concerned with the history of human material culture, in particular nationalistic histories. Piltdown man wasn't just an early hominid, he was the first "Briton" and along with the builders of Stonehenge and the later pre-Roman Celtic people was one of the ancestors of the British people. Again, like the classificatory schemas for technological progression, this legacy is still with 
us in some form. Archaeological evidence bolsters claims of nationalism and ethnic identity to this day. We should not write off Cultural Historical Archaeology as something done in the past. $^{2}$

For Cultural-Historical archaeologists of the 1930s and 40s the diagnostics for a culture revolved almost exclusively around its artefacts. It was the typology and the chronology of a geographical region whose artefacts were under study. While there were variations, the general idea was to document the range, types and styles of recovered artefacts and define a culture and its historical place on this basis. Clearly, there are parallels here with both natural history and geology. Just as biologists were classifying species, and geologists were naming geological strata as epochs, there was a tendency for archaeologists to look for phenomenological patterns in their "data" (i.e. artefacts) and group according these features. This was a systematising of data according to geographical and temporal relations. The essential point to extract here is that that systematisation aimed at providing chronologies of cultures. The aim was to provide Sequences of data with extant or known classical cultures as an end point in a historical chronology.

It is important for us to realise that the word 'culture' as we understand it, with all its connotations of language and behavioural differences was not what was meant by culture as used by the Culture-historians. "Culture" was a term used to mean a group of artefacts, of archaeological finds, with certain features in common. Frequently certain features would be diagnostic of a culture. Some of the names for various cultures used by archaeologists, "The Bell Beaker" people, and "The corded ware"

\footnotetext{
${ }^{2}$ I will not be covering the modern versions of cultural history in this thesis as they are well outside its scope. See (Ucko, 1995) for a survey of some of the recent work in this area. Reclaiming a cultures past has been an important component of reclaiming identity for some groups. Archaeologists, like other social sciences, have on occasion donned sackcloth and berated their lack of sensitivity to minorities.
} 
culture is a reflection of this practice. A range of artefacts having broadly stylistic features in common defined a culture.

This technique was used not only for human cultures, but for tools and collections of tools associated (temporally at least) with pre-sapien hominid cultures as well. So the Acheulean handaxes, generally associated with Homo erectus and named after early finds in St. Acheul in France, was a culture that extended throughout Africa, temperate Europe as far as southern Britain and into Asia. The typical Acheulean handaxe was one of the features diagnostic of this culture. The Acheulean also lasted over 1 million years.

The early work of the Australian archaeologist V. Gordon Childe is a good example of the type of work admired from the twenties to the forties. Childe's books "The Dawn of European Civilisation" and "The Danube in Prehistory" were muchlauded pieces of archaeological scholarship in the 1930's and his charts were to be much imitated. (Trigger, 1990) It's worth looking at one of Childe's charts in order to get a good insight into cultural-historical thinking. (Figure 1) 


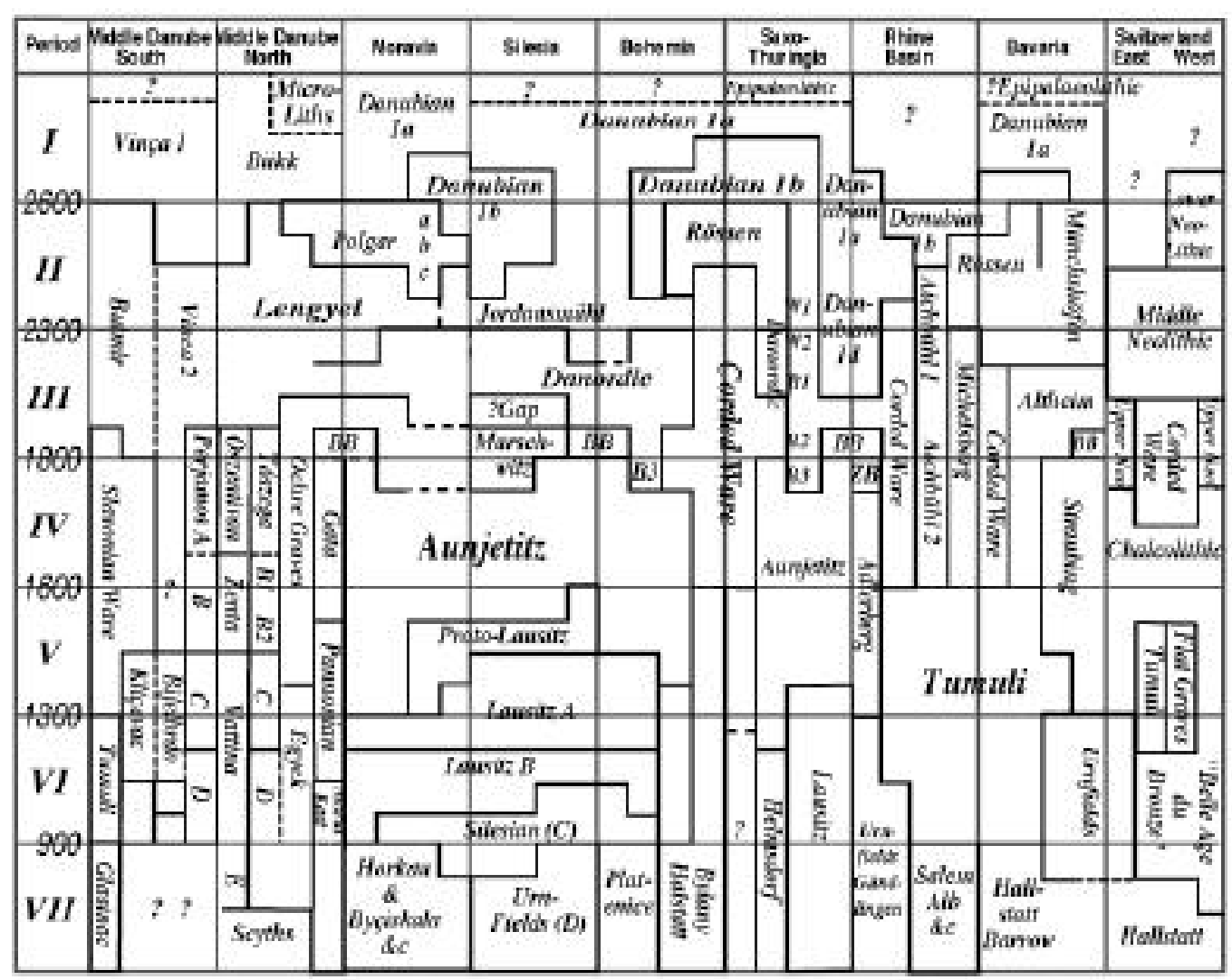

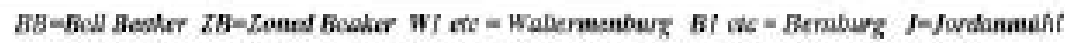

Table Giving Correlations of Several Cultures in Time and Space

Figure 1 (Trigger, 1990)

Childe's chart is a result of the meticulous observation and cataloguing of thousands of artefacts and their stratigraphic and geographical relation to each other. The horizontal provides a spatial dimension and the vertical a temporal dimension, allowing contiguity in space and time to be determined. The diagnostic for these cultures is archaeological finds and their presence or absence in various geographical locations. So the chart has within it the proto-Lausitz, Lausitz A and Lausitz B culture, all generally in the same region with minor perturbations. This sequence of Lausitz "cultures" reflects the changes in the assemblage of artefacts. There is no historical source naming or isolating these peoples. There are no recovered clay tablets from a contemporary culture giving these peoples a name, no contemporary literate group with mercantile records saying "sold some cheap grog to Jack from 
Lausitz B". For pre-historic cultures, such labels won't be available ${ }^{3}$. Shared language, shared beliefs etc is not, in this picture, the diagnostic for a culture. There is an assumption that shared artefacts types will parallel a cultural group, but this is an assumption only. Given the tendency for early archaeologists to rely for their diagnostics on imperishable ceramics, I have a sneaking suspicion that if a similar methodology was applied to late 20th century New Zealand remains, we would quite possibly be the "acoroc cup" people.

A similar approach to archaeological classification was found in North America, with pre-contact American cultures being similarly cut up into geographically and temporally defined groups based on artefact types. An extreme version of this was the Midwestern Taxonomic method, a system of classifying archaeological finds based on artefacts that compared different levels of similarity of found objects.

"Artefact assemblages representing a single period of an occupational site were called a component; components sharing an almost identical set of artefact types were assigned to the same focus; foci with 'a preponderating majority of traits' to the same aspect; aspects sharing only more 'general characteristics' to the same phase; and phases sharing a few broad traits to the same pattern." (Trigger, 1990:p190)

This system of classification paid little attention to anything but the found

${ }^{3}$ Archaeologists of the period divided up the past into historic, proto-historic and pre-historic fields of study, the distinguishing feature being written sources. So "history" had written sources available, pre-historic didn't. Proto-historic was a fuzzy in between bit. For proto-historic and historical Archaeology there may well be some kind of label available for a culture. Cultures with writing may refer to cultures without and in the process name them and say something about them, providing at least some kind of insight. The excavations of a sequence of archaeological remains at a site in Hissarlik, Turkey got the designations Troy I through to Troy VII simply because one of the cities rebuilt on the same site was named in the Homeric epic (probably Troy VIIa) (Glyn Edmund Daniel, 1981 p158). Whether the inhabitants of the initial small village at Troy, Troy I, knew themselves as Trojans of course is unclear. 
remnants of earlier peoples.

"No inferences about human behaviour were included in these definitions nor was any attention paid, as Childe had done, to the functional significance of different classes of artefacts or to the ecological significance of what was being found. Quantitative comparison of different classes of artefacts was neglected in favour of simply noting the presence or absence of artefact types." (Trigger, 1990:p190-191)

What's interesting here is that this seems to be Archaeology without explanation. The mid-western taxonomic method was an extreme version of a trend in cultural history. That trend was to classify cultures and document the history of a 'culture' through the existence of "traits" as represented by artefacts, without saying anything much about the culture as a group of individuals or as a society. Certainly there was no placing of a culture in its ecological setting. The Midwestern taxonomic method, it would seem, was Archaeology with a rigorous methodology of typology, but with no explanatory agenda. Without the idea that there was a natural progression that cultures went through on the path to civilisation, the classificatory schemas of the Midwest taxonomic method and the detailed schemas of Childe looked explanatorily sterile; they said nothing, explained nothing.

This really was the base condition of Archaeology, no explanations given. On a simplistic reading of cultural historical Archaeology, all the debates within Archaeology were concerned only with the dating of chronologies, or regional boundaries between cultures. What's more, merely working with remains and classifying them could be misleading. Donald Thompson had done ethnographic work with Australian Aborigines that highlighted the fact that one cultural group could use different tools in different areas as part of a seasonal foraging cycle. (Trigger, 1990:p297) Cultural history classifications as rigid as the Midwest Taxonomic method - a catalogue of artefact assemblages - would miss such information. The different material remains would be different "Cultures". Quite simply, it was clear that more needed saying. 


\subsubsection{Diffusionism and Its Problems.}

Faced with large amounts of data regarding technologies and material cultures of both a temporal and geographical nature, there were clearly patterns; shared technologies, spreading ideas, sudden changes in artefact types in areas that had remained stable for long periods. In documenting the history of cultural groups, it was clear that cultures changed, and there seemed to be a need to explain that change. Archaeologists had abandoned the notion of some innate technological sequence through which all cultures passed. However, the detail as provided by a chart such as Childe's cried out for some unified explanation. The changes in a nationalistic history of the British Isles required more than a polite display of artefacts from the past. It shared artefacts with contiguous nations, it made sudden leaps of technology and it had a record that hinted at invasion and conquest and trade.

The primary means of explaining these chronologies through the 30s and 40s was diffusionism. Diffusionism steadily replaced the earlier hypothesis that there was a select, innate series of stages that cultures went through on the path to "civilisation". Rather than a predetermined path of change, diffusionism instead claimed the mechanism of cultural changes to be primarily via the spread of ideas either through direct colonisation or via influences. Metallurgy emerged only once and was "diffused" to other areas, potentially by trade, or by other means such as conquest. Generally, certain cultures, further down the technological track than others, developed new technologies or ideas that then diffused to other areas.

An example would be something like the megalithic tombs of the Atlantic coast of Europe and the British Isles.

"The skill reflected in their construction, and the impetus to invest so much effort in stone monuments, was seen to have come form the east, from more civilised lands. The comparative poverty of the material culture of their builders was thus made to seem less extraordinary when contrasted with the monuments themselves." (Renfrew, 1973:p120)

British megalithic tombs were seen as a product of a long chain of diffusion from 
the Mediterranean and could be seen as part of a "megalithic religion" for Atlantic Europe that had spread. (Renfrew, 1973:p123) So you could include in your story of the British Isles the idea that the notion of building stone tombs was the result of some kind of cultural irradiation that swept through Western Europe from the Aegean. ${ }^{4}$

Diffusion as a theory however faced a number of problems. For a start, dating was relativistic rather than absolute, especially for North American pre-history. Rather than an independent date for any chronology, archaeologists had to rely on complex systems of cross dating to test hypotheses about diffusion. The problem was simply that a claim about diffusion came with an assumption that a certain cultural feature "diffused" over time through a succession of cultures. The originating culture would possess some feature that over time transmits to recipient cultures. This transmission would have directionality, and the only means of confirmation is by some form of dating technique. Without a reliable date, the diffusion could just as easily go in a different direction.

European pre-history did have the written historical record for Egypt that could be used to provide at least some clues as to dates for other cultures as far back as 3100BC, although reliable dates only extended to 2000BC. (Renfrew, 1973:p28) With the written history of Egypt and other literate cultures providing an anchor, any Mediterranean cultural remains that included trade goods from Egypt could be dated with some confidence. These cultures can by extension cross date other cultures but with an increasingly greater margin for error.

Once this cross-referencing was in place relativistic dating through typological methods is available. Artefacts of a similar type would be put together into an

\footnotetext{
${ }^{4}$ Later C14 dating by Renfrew and others revealed that the British monuments were earlier than the Mediterranean ones and that the hypothesised sequence of diffusion across numerous cultures was in fact, dead wrong. (Renfrew, 1973)
} 
evolutionary sequence providing, again, a series of relative dates showing earlier or later developments within a culture. Typology showed a culture and its sequential changes and so long as one part of the sequence can be reliably cross dated, the sequence can be fixed. (Stiebing, 1993)

However, anything before the third millennium BC was almost entirely relativistic in its dating. You could tell that one culture came after another in the same area through typological means or simply because its remains were laid down one after another. Earlier cultures were underneath more recent. Nevertheless, there was no real method for comparing time scales between regions or sites and certainly no reliable way of getting absolute dates. Some pre-human cultures could be associated with the faunal remains of extinct species, clearly dating the artefacts earlier, or perhaps interleaved with geological events. Eruptions, which deposited ash layers, can aid dating. However, with no generally accepted absolute dating all chronologies could be concertinered up, with shorter or longer periods between cultures or areas. Again, it is worthwhile looking at Childe's chart in this regard. The temporal dimension, in the vertical, can be compressed or expanded at will and still make sense of the raw data. The fact that this expansion and contraction of time frames was a feature of Archaeology was well recognised by at least some workers. Gordon Childe, a highly respected and professional archaeologist, could joke to his students while stirring his tea "I think I'll have a long chronology this week" (Green, 1981:p114)

The problem was that with no absolute dating method available, diffusionist speculations could not be tested. One of the extreme cases of diffusionism was published in a 1923 book called "Children of the Sun", written by W. J. Perry. This "hyper-diffusionist" thesis credited all significant cultural innovations to the Egyptians. Metallurgy, numeracy, stone working and all innovations in human material culture originated from the Nile delta and spread though Europe by traders and explorers. Perry's hypothesis became extremely popular with mass audiences. So popular in fact that the American archaeologist Roland Dixon felt obliged to write a 
rebuttal to Perry's thesis before a book could be published claiming Meso-American civilisations as the products of Egyptian seekers of the "Givers of Life". (Glyn Edmund Daniel, 1981:p150)

The trick with extremist diffusion was to document the cultural innovations of a group and then, to put it crudely, adjust the chronologies in other geographical regions so that the same innovations came after the favoured group. Without absolute dating, the facts could be shuffled to suit the theory. Then all that was required was some mechanism for diffusion to occur. The spreading could either be by influence to adjacent regions, immigration, exploration, trade or whatever.

The defining of cultures by diagnostic features of artefacts leant itself easily to this way of thinking even if not all workers took diffusion to the extremes of Perry. A cultural "trait" that appeared sequentially in first one culture and then another could look like a diffusionist process. Innovations need only be explained once and then tracked through time and space. Childe, while recognising the inherent problems with this approach, did precisely this with the spread of metallurgy from the Near East to the Danube. Indeed Childe regarded the Danube as important because he saw it as part of a conduit for cultural innovations from the civilisations of the Near East through to Europe. (Green, 1981:p91)

But as long as dating was relativistic and capable of being adjusted to suit whichever source of cultural irradiation an archaeologist fancied, there seemed no real way of testing competing diffusionist explanations.

However, there was a second and even more important problem for diffusionism. The problem is that it didn't really have anything to say about why things diffused. Clearly, a functional technology like metallurgy could justly claim to be an obvious candidate for diffusion. So too something like agriculture, with Cavalli-Sforza and Feldman giving a precise tracking of the spread of agriculture that, although confirmed by carbon dating in their case. (Cavalli-Sforza \& Feldman, 1981) However, something stylistic and less obviously functional like stone tombs or even pyramids, required a motivation for transmission. Why would an architectural style 
diffuse? Diffusion of itself is incomplete as an explanation. Why would the peoples of Western Europe construct crude imitations of Mediterranean architecture? If traders constructed them, what were they trading and why were they travelling so far? The truth is that many claims for diffusionist hypotheses were implicitly making claims about the peoples under study. The diffusion of a megalithic tomb building comes with an assumption of a megalithic religion, with all the collateral assumptions of proselytising and conversion. These are claims about more than the artefacts of peoples. These are claims about their beliefs and behaviours, with no means of testing such claims.

The sensitivity of diffusionist hypotheses to inexplicit and untestable ideas about the source and recipient cultures becomes obvious once we make diffusionist models explicit through an ideal model. In an idealised model, an innovation generating culture $(\mathrm{S})$ is surrounded by recipient cultures, $\mathrm{r} 1$ to $\mathrm{r} 6$.

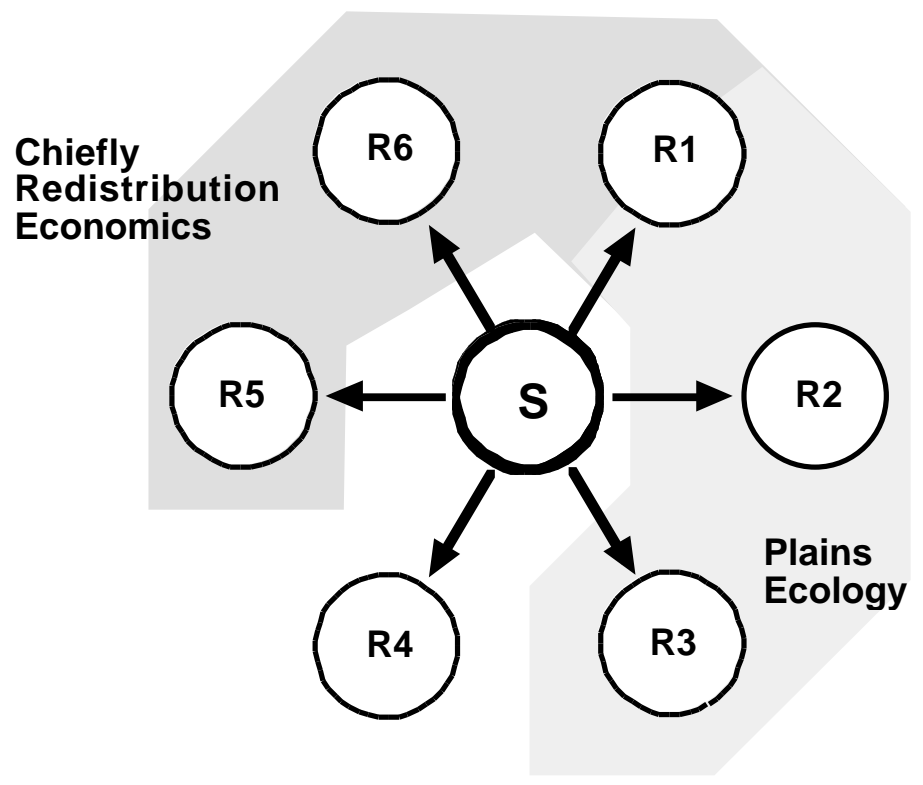

\section{Figure 2}

In such a model situation as this, any innovations are imitated or diffused to all recipient cultures equally. R1 to R6 should be more or less identical in their receptiveness to whatever it is that is being diffused. The only point where they may be different is how far away from the source culture they are, so that a chronological 
delay may be evident.

However, the problem is that they never will be identical. R1, R2 and R3 may be plain dwelling cultures and R4 to R6 may live in environments that are more mountainous. Geographical differences may make some potentially diffused traits more or less attractive to the recipient cultures. Some innovations generated by the source culture may be of no use to the cultures in the mountainous areas. Therefore, it seems plausible that geographical and ecological differences are going to play a role in what cultural traits are accepted by the receiving cultures.

As well, socio-political factors are going to play a role in the cultures receptiveness to some innovation. The writing and numeracy systems developed in response to the needs of a highly centralised, mercantile monarchy may not find any place in a society of scattered villages with customs of chiefly redistribution. Wellestablished traditional hierarchies may suppress innovations that threaten their power base. Established religions can counteract innovations. Socio-political differences mean different receptiveness to different aspects of an external culture.

So broadly, two distinct factors will shape any cultural groups receptivity to diffused ideas, environmental factors and social factors. An understanding of these factors is required gain a better understanding of the technological particularities of a culture.

Between the wars, there was within professional Archaeology a growing awareness that cultural history did not so much explain pre-history as document it. True, the cultural historical documentation of Childe and others provided a context and framework for artefacts as seen in museums. Nevertheless, what was the explanation of the variation that was apparent? How could regional differences be explained? The cultural chronologies of artefacts risk being a sterile filing system unless they have further interpretation. Perhaps one of the best examples of how this cultural-historical view manifested itself is in the title of a book by Flinders Petrie. The book, published in 1920, sums up the achievement of the cultural-historians in my view. The title of the book was "Pre-historic Egypt Illustrated by over 1,000 
objects in University College, London." (Glyn Edmund Daniel, 1981:p151)

\subsection{The Beginnings Of Change}

Archaeology was changing due to three distinct pressures. The first was the emergence of professional Archaeology as an academic discipline. Archaeology was becoming less about the collection of artefacts for a collection, be it public or private. The treasure hunting aspects of earlier Archaeology was disappearing and site excavation was becoming more professional and organised. ${ }^{5}$

Secondly, there were an increasing number of technical innovations. Since World War 1 geologists, geographers and archaeologists had become aware of the unique insights of aerial photography. Views form the air revealed prehistoric sites as of interest in themselves rather than sources of artefacts. In some cases, flight revealed features of the landscape that were previously unrecognised as historical sites. Ancient roads, disturbed soils from long gone foundations, irrigation works and the like were detected from the air, though virtually invisible to observers on the ground. Such aerial reconnaissance and the mapping that accompanied it also raised questions about geography and prehistoric people's relationships with the landscape. The mapping of sites also began to raise ecological questions as distribution patterns started emerging.

Pollen analysis and similar techniques also started to become important in this regard. The Swedish archaeologist E. J. Lennart Von Post started using preserved pollen in stratigraphic analysis to determine the extent and nature of prehistoric vegetation. The biologist Harry Godwin started using similar techniques in England

\footnotetext{
${ }^{5}$ Although treasure hunting and the pillaging of sites remains a problem to this day. However, governments of the past did grant licences to effectively pillage archaeological sites. The history of late nineteenth and early twentieth century Archaeology looks occasionally like an Indiana Jones movie with daring raids and competitive theft.
} 
for archaeological research in the early 1930's and worked with Grahame Clark. (Trigger, 1990:p248)

The crucial technological breakthrough however was not to come until after WW2 with the emergence of carbon 14 dating. Although not in widespread use and not completely accepted, by the early 1950's C14 dating had started to make serious impacts upon Archaeology and to unravel previously accepted chronologies. The new chronologies began to suggest that some innovations appeared more than once. In other cases innovations appeared outside of accepted "civilised" cultural regions and so "diffused" in the wrong direction, from "periphery" to urbanised "centres". The 20 years following C14 dating's introduction would see the revision or wholesale abandonment of many diffusionist theses. These technical innovations meant that the amount of evidence, and the types of evidence, were becoming more extensive and suggesting new possibilities. The raw data of Archaeology came to include more than artefacts.

Third, and perhaps more important than the technical developments was the changing attitudes of archaeologists themselves. Unrestrained speculation like that of Perry's hyper-diffusionist thesis made it clear that there had to be principled empirical constraints on archaeological hypotheses. But more importantly, diffusion as an explanation couldn't by itself provide all the explanation for the data that was increasingly available. Diffusionism couldn't explain cultural variation.

\subsubsection{Functionalism: Childe And Clarke}

As we saw in our model of diffusionism, there were at least two possibilities as to how the nature of a group could impede or enhance the diffusion of a technology; social factors and ecological factors. The import of social factors on diffusion became the particular interest of Childe. Already in the "Danube in Prehistory", published in 1929, Childe had recognised that straight diffusionism wouldn't explain all the cultural idiosyncrasies of the Danube cultures. For instance, metallurgy didn't emerge in the Near East, traverse the Aegean cultures and diffuse through the Danube to the 
rest of Europe unaltered. The various peoples of the Danube adapted the technology, in a some cases improving it, and it was this altered and changed technology that was available for adoption in western Europe, not the original metallurgy of Asia minor. The recipients of these cultural innovations in turn adapted and changed the technology.

Childe had a background in left wing politics, He had worked for the New South Wales Labour government in his home country of Australia in the early 1920s, and as such he had something of a Marxist outlook. The result was that Childe started to look at Archaeology in the light of political economics. Never dogmatically Marxist, Childe's approach began to provide insights into potential mechanisms for internal change within cultural groups, and how socio-economic factors could shape a culture's reaction to external cultural stimuli.

The result was works such as "Man makes himself", published in 1936, where Childe attempted to examine the social and economic forces that shaped cultural remains. Childe was still working within the ideas of diffusionism, but became, during this later phase of his work, more concerned with the overall matrix of a culture rather than individual traits.

Childe's impact and popularity was such that archaeologists generally became more receptive to ideas regarding the internal social and economic dynamics of the cultures they studied. Rather than just see artefacts, people began to see the cultures, the people that produced the artefacts, as being worthy of study.

The second movement within Archaeology is best characterised by the work of Grahame Clark. Clark's particular interests were in the ecological factors that shaped cultures. Clark was interested in studying how human beings had lived in the past. For Clark this meant taking environmental factors and their impact on cultures very seriously. Clark attempted to match ecological factors with economic and subsistence patterns, an approach that was to be increasingly influential.

The result of his approach was that Clark could write articles such as "Bees in 
Antiquity", relating the rise of farming in Europe to increased bee populations, and the increasing use of bees wax in bronze casting. (Trigger, 1990:p267) Perhaps even more importantly, in 1952 Clark could begin to apply the idea of an eco-system to his archaeological analysis. (Trigger, 1990:p269) Human beings became, for perhaps the first time in Archaeology, located within an explicit ecological setting.

Clark emphasis on economics and interrelationships of groups with their ecological setting meant that he could supply explanations of settlement patterns and begin the process of explaining the ways of life of past groups. Perhaps most importantly of all, Clark began the process of working with other scientific disciplines. The beginnings of zooArchaeology, palaeoethnobotany and bioArchaeology, where specialists from other areas would bring their understandings to material remains are to be found in the collaborations of Clark. Such collaborations allowed Clark to extract even more information from sites than previously, giving insights into diet, foraging patterns and the relations with organisms within the environment.

These two distinctive approaches of Childe and Clark both marked the beginnings of attempts to move beyond the typology of artefact collections. In part this was an attempt to move beyond documenting artefacts and the temporal and geographical location that produced them, and a beginning of seeing artefacts as the products of cultures. "Culture" as a term became to be seen as less of a label designating temporal spatial location, and more the object of study in its own right. Artefacts became less the things that needed explaining, and became part of what did the explaining about cultures. In order to do this artefacts needed to be documented much more closely and their relations to each other documented with equal precision. Information about spatial relationships between artefacts becomes as critical as information about temporal location. A collection of artefacts at a given stratigraphic level might suggest a similar location in time and hence a single culture. However, a collection of artefacts associated with tool manufacture within the remains of a single dwelling may suggest the rise of specialists within a historical community, leading to questions 
about economic surplus in a society capable of supporting specialised craft workers.

With the emergence of this more anthropological Archaeology comes new problems. For this kind of Archaeology is attempting to reconstruct a society long dead from its material remains. To say that a society was resistant to the ideas of its neighbour due to its tribal hierarchies is to make a claim that the material remains that have been uncovered are somehow evidence of the group being tribal. But just how those inferences to be done? The process of enriching the raw data of Archaeology with interpretations and statements about an artefact's context was beginning to emerge in a coherent way. But with this process comes problems

\subsection{Hawkes Hierarchy}

The approaches exemplified by Childe and Clark had become part of the intellectual milieu of European Archaeology. Archaeology had become a recognised discipline within academia leading to a genuine professionalism on the one hand, on the other hand, Archaeology had begun to redefine what it was it studied, and that was more than just culture history. It was the cultures themselves - their economics, ecological relationships and social structures - which were increasingly being examined. This Archaeology was something we would recognise as an anthropological Archaeology in its nascent form.

In 1953, Christopher Hawkes of Oxford University gave a talk for a Werner-Gren supper conference at Harvard University. The revised paper was later published in American Anthropologist under the title "Archaeological Theory and Method: Some suggestions from the Old World". (Hawkes, 1954) In 1953, Hawkes was in a position to look back over almost 20 years of change within Archaeology. The older culturalhistorical approach had given way to the idea of Archaeology as something akin to a historical anthropology. Typology and the classification of artefacts was seen as a 
first step, a means to an end, rather than the end in itself. ${ }^{6}$

In his paper, Hawkes makes a number of points. However the most crucial insight he shared was that explaining cultures rather than talking about artefacts required much inference and a certain amount of educated guess work. In doing this, Hawkes suggested that there was an ascending level of difficulty in inferring different aspects of the culture under examination. The interpretation of some aspects of artefacts was more secure than the interpretation of other aspects. He talked about these as an ascending hierarchy of difficulty.

The lowest level of Hawkes Hierarchy is the techniques of manufacture for objects. Inferences regarding techniques of manufacture should be relatively easy. How something is made can be learnt from the object itself.

The next level of difficulty was the "subsistence-economics of the human groups concerned." (Hawkes, 1954:p161) To discover this requires information about the economic (or subsistence) use of the artefacts discovered and information about the physical environment of the group concerned. Because of the growing awareness of ecological factors that had come to the fore prior to the $1950 \mathrm{~s}$, particularly through the work of Clark, Hawkes was very clear about the role of the physical environment in determining the nature of a group's material remains.

The next level was the socio-political institutions of a group. This is always going to be difficult. While various contexts within which things are found may provide some clues, the inferences from artefact to the behaviour that produced it will always be difficult. No one object is going to provide the information required. Relationships

\footnotetext{
${ }^{6}$ American, or New World Archaeology had taken similar turns. Walter Taylor had recently criticised the American cultural history approach in his book "A Study of Archaeology".(Taylor, 1948) Nevertheless the changes from cultural historical approaches and typological approaches had been slower in the Americas and was certainly less established. The Midwest Taxonomic was still being taught.
} 
between objects might in that a 'site' rather than a single artefact may provide some ideas, but this will always be open to multiple interpretations.

The final level of difficulty is the religious and spiritual life of a group. Inferring religious ideals from a group's artefacts without any external reference will be very difficult indeed.

What's interesting about Hawkes claims is his reasoning behind this hierarchy. ${ }^{7}$ Hawkes saw the lower levels of his hierarchy as comparable to animal adaptations. In this, he was influenced by the increasing awareness of environmental factors that was apparent in the work of people like Grahame Clark. Although he doesn't explicitly talk in adaptive terms, the techniques of humans "differ from animal only in the use of extra-corporeal limbs, namely tools, instead of corporeal ones only". (Hawkes, 1954:p162) Hence tools could be interpreted functionally in the same way that an organism's adaptations can. For the next level, there were again parallels with animals. Human subsistence-economics are comparable to animal subsistence needs. ${ }^{8}$ The only noticeable difference being, according to Hawkes, the "degree of forethought which they involve" (Hawkes, 1954:p162).

However, the higher up the hierarchy the less like animals humans become. What separates the easily explicable from the difficult to explain is just how obvious something is as an adaptation.

\footnotetext{
${ }^{7}$ Hawkes does not explicitly talk in adaptive terms. I am taking Hawkes' ideas to their logical conclusion based on the fact that he does draw a parallel with animals regarding inferring what a artefact is for.

${ }^{8}$ Here Hawkes seems to be foreshadowing later work on foraging theory.
} 
"The critical factor, standing between fair intelligibility and stark unintelligibility, is surely ecology, the study of the physical environment. So long as you can depend on that, as you can for the material aspect of man's life, his technological and his economic existence, your exercise of this sort of Archaeology ${ }^{9}$ is rewarding." (Hawkes, 1954:p162-3)

So the physical existence of humans, the way they made tools and their subsistence activities, are within the realms of explanation. Hawkes notes that this may be difficult, but it is not impossible. It's the mental life of humans, their belief systems and the way they see the world that provide the difficulty. It's worth while quoting Hawkes in order to gain the full flavour of his claims.

"...human communal institutions next transcend the animal level very considerably; and human spiritual life transcends it altogether. So the result appears to be that the more specifically human are men's activities, the harder they are to infer by this method of Archaeology. What it seems to offer us is positively an anticlimax: the more human, the less intelligible." (Hawkes, 1954:p162)

The key point to extract out of Hawkes' Hierarchy is that Hawkes believes that important features of human life transcend animal features. If we want to base interpretation of human artefacts solely based on ecological and economic factors then we are going to have difficulty with coming to any kind of understanding of the mental life of those who artefacts are under study. In trying to reconstruct human behaviour then the more closely related to the subsistence needs of a group an artefact or collection of artefacts are, then the more easily explainable they are. Once archaeologists attempt to identify or explain socio-political structures or religious beliefs, they are bereft of interpretative tools, and such hypotheses cannot be confirmed.

The fundamental problem is this: As long as archaeologists concentrated on

\footnotetext{
${ }^{9}$ By "this sort of Archaeology" Hawkes was primarily referring to the ecologically based Archaeology of Clark.
} 
objects, they could only ever explain those objects. An artefact of itself could provide clues to its function and its method of manufacture. But its symbolism, its meaning to an individual or a group, its relation to a group's political or social systems, is not obvious. Consequently, any claims about such relations are open to question. The inferences from a shard of ceramic to 'container of dimensions $x$ ' and 'pottery made with technologies $y$ and $z$ is a secure inference that can be confirmed by the nature of the artefact itself. The inference that such a pot was used by a social group in a certain way, and was understood by the group as having a certain meaning was, well, less obviously secure.

Hawkes hierarchy highlights the need for and the problems of making inferences about the cultural and mental lives of extinct peoples from the raw data of Archaeology. Even finds that unambiguously pointed to the existence of social activities and the social life of people such as ruins of villages or multiple dwellings, could not with equal clarity point to the specific kind of social life that created them.

\subsubsection{The End Of The Beginning}

We can see from this historical appraisal that early Archaeology was in many ways a product of antiquarianism. We could almost consider early archaeologists as enthusiastic collectors, fanatically organising their precious objects into elaborate classifications. However, that is perhaps a little unfair. The early professionals of Archaeology were not immune to the desire to say something about the peoples that produced the precious objects now resting in their glass cases. But though they generated theories that would account for their evidence there was no way of checking their theories nor constraining them.

Theories generally should have two characteristics, on the one hand they should generate explanations of the phenomena, but on the other hand they should be testable. Given two differing accounts of a phenomena, say Perry's hyper-diffusionist account of the pyramid like structures of meso-american temples, and an ecological account, how can we choose between them? How can we test them in such a way that 
we can discard one and accept the other?

While some of the new techniques that were becoming available to archaeologists in the 1950s, most notably carbon dating, allowed the explanations of archaeologists to be tested, it was only where there was physical phenomena which could corroborate the theories. In cases where the objects themselves were of no help, where the objects stood in need of interpretation, there didn't seem to be any reliable methodology for generating or testing explanations. And as we will see in the next two chapters, even physical information could be misleading.

Hawkes, almost as a side point in the context of his article, highlights this with his Hierarchy. Once we want more information from an artefact than when or where it is made, it becomes increasingly difficult to determine the truth of statements about its past. Whether Hawkes is right in thinking that this difficulty depends at least in part of what kind of information you want, be it social, political, economic etc, is part of what is at issue here. Archaeologists increasingly wanted to say something about the cultures that produced the artefacts that they had uncovered. So they need to be able to infer things about the past from the raw data of the archaeological record. In order to do that requires some kind of understanding of the relationship between the lives and behaviour of homo sapiens and the material culture that they leave behind.

The next chapter deals with the first explicit attempt to formulate that relationship in a way that can be explanatory and testable. It begins the process of looking at archaeological thought that was explicitly attempting to be scientific in its approach to the human past by giving itself ways and means to check its assumptions, and to make transparent its means of providing explanations. Archaeology became selfconscious. 


\section{Chapter 3: Binford and the "New Archaeology"}

\subsubsection{Introduction}

As we have seen, the Archaeology of the Cultural Historians, practised from the 1920s through to 1940s, was without any kind of restraint in so far as interpretation went. Although a more serious attitude was emerging, it lacked any real structure. There were not as yet any claims that Archaeology should "do this" in "this way". Clearly, Archaeology was changing, but the change was as yet directionless. This chapter begins the process at looking at an Archaeology that really did try to formulate some form of constraints on speculation and consciously began the move to become a science. Although flawed, the "New Archaeology", or processual Archaeology as it came to be known, was the first thought through move to put Archaeology on a sound empirical footing. It was the first high profile attempt to provide Archaeology with an explanatory agenda, and a methodology to fulfil that agenda.

The most obvious mover in all this was the American archaeologist Lewis Binford. Binford's contribution to archaeological thought comes in three parts. Firstly, that Archaeology should be anthropological in nature. It should do more than document and provide chronicles for past cultures. This was an acknowledgement of the possibilities that a richer interpretation of the data could bring. Binford and the New Archaeologists were keen to go beyond the collection and ordering of data.

The second contribution was that Archaeology should be a science. What Binford took that to mean was to shape much of the debate over archaeological theory for the next 50 years and is covered here in the latter part of this chapter. This particular 
contribution is, as we shall see, problematic. For Binford looked to the philosophy of science for insights into what made a science a "science". The result was the adoption of a model of doing science that was inappropriate for Archaeology. The reasons why it was inappropriate are interesting. Perhaps most ironically, the model of science adopted contributed to Binford's third contribution to Archaeology. This was his realisation that in order to achieve the twin goals of anthropology and science, that both a methodology, and some bridging theories would be needed. As we have seen, there is a process of inference from the found artefacts and other raw data of Archaeology to statements about the past. Claims are made that configurations of artefacts represented a campsite, a community; the result of some human activity. Binford recognised and highlighted the fact that such inferences needed to be explicit. If archaeologists wish to use the reconstructed behaviours of past people to contribute to anthropology, then that reconstruction process needs to be well ordered and reliable. The resulting awareness of this problem manifested itself in what became known as Middle Range Theory, a set of ideas that was as much an attitude towards archaeological practice as a theory.

This chapter will deal with the Binford's conception of Archaeology's role, and the conception of science that influenced the "New Archaeologists". The following chapter will deal with the practical implications of these conceptions in relation to methodology and bridging theories.

\subsubsection{Binford}

As the older culture historical approach began to fray around the edges there were various attempts to re-orientate Archaeology. Lewis R. Binford spearheaded the attempt that grabbed the most attention, particularly in the United States, though others, notably Leslie White and Walter Taylor in the United States and Grahame Clark in Britain, were also important.

Binford trained initially in the Mid-West taxonomic method. Long lists of traits were learned and individual potsherds identified within a highly ordered taxonomy. 
The cultural history as taught to Binford was in many ways a tracking of traits and trait frequencies through time and space. Binford clearly found this deeply unsatisfactory. (L. R. Binford, 1972) Luckily for him, later in his student days he came under the influence of other academics that were actively exploring more interpretative methods. Once he graduated, he began, in a series of articles, to articulate this new approach.

As we saw with Childe and Clark in the previous chapter, the revolution in Archaeology had already begun. In particular with reference to Clark, new sources of information were emerging that forced a reappraisal of Archaeology and this was affecting the US based archaeologists as well. However Binford has been unusually influential, and particularly so in the United States. I suspect that this is partly to do with the character of Binford as an individual and his longevity as a worker in the field $^{10}$, but I also think that Binford genuinely attempted to codify this new approach to Archaeology. Binford's contribution, besides a rebellious attack on the older approach, was an explicit stating of his theoretical position. The fact that Binford described himself as "...Archaeology's Huxley" (L. R. Binford, 1972:p9) is an admission of his self appointed evangelising role but an underestimate on his part of his own contribution to theory building. Archaeology didn't really have a Darwin, just the bulldog.

Binford, and many that followed him, was convinced that Archaeology should become more science-like. Binford was against the "uncontrolled community governed speculation" (Gibbon, 1989:p68) of traditional Archaeology. Given some of the speculations that had emerged, this was a fair complaint. The question here is, just how to govern it? For an answer to this, Binford looked to the sciences as a model of explanatory rigor. Consequently, archaeologists of the 1950s began to think that

\footnotetext{
${ }^{10}$ Binford's first article was published in 1959 and he started publishing regularly in 1962 . He is still publishing and active in early 2001
} 
Archaeology had to become a science.

Archaeologists were keen to complete the professionalism of their discipline.

Binford inspired an enthusiasm among a generation of archaeologists to become more science-like in their approach to Archaeology. Colin Renfrew, writing in the early eighties, summed up the attitude that infected this "New Archaeology" at the theoretical level.

"Archaeology today is an ambitious discipline, seeking to apply the rigor of the sciences to the surviving material evidence of the human past. This aim of employing scientific explanation within the broad field of human history; and thus of exploring systematically the organisation of culture and the dynamics of its change, requires for its fulfilment a firm basis in theory." (Renfrew, Rowlands, \& Segraves, 1982:pxvii)

So how was a previously historic discipline, and a discipline that was concerned with chronicle and classification, to become scientific? Colin Renfrew, an English 'convert' to processual Archaeology, made the claim that Archaeology is a "distinct analytic unit." (Renfrew et al., 1982:pxvii) Archaeology isn't just a branch of anthropology or history. It has its own problems and can't just borrow tools from other areas. So what were these problems and what was the basis upon which this move to a science could be built? How was the archaeological project to be conceived?

\subsection{3. "Archaeology as Anthropology"}

In complaining about the state of Archaeology in 1962, Binford said " it has been noted that Archaeology has made essentially no contribution in the realm of explanation." (L. R. Binford, 1962) While Archaeology had done much to highlight the diversity of historical cultures, and to document the range of human material existence, it had done little to explain it.

A list of traits and the changes in trait frequencies really did nothing more that document artefacts. Importantly the hard core of cultural historians did nothing to explain the variations within a series of traits. The form of the taxonomy of the 
artefacts remained unexplained. For instance the trait lists produced by the Mid west taxonomic method could have been used as a data source regarding regional variation and climate. Differences within a taxonomic level ${ }^{11}$ could have been matched to differing resource availability, building up a good picture of cultural plasticity over geographical variation. But, such data was never really used this way or indeed in any other way. Artefact taxonomies and a history of the changes within the taxonomy were all that was required. Many archaeological workers considered taxonomies complete in and of themselves. There was no theoretical motivation to explain the form that such a data source would take. Nor was such data routinely matched to other variables such as resource distribution. "Why?" questions were never asked about the archaeological record.

Some, such as Childe and Clark, had begun to explore possibilities of looking at the data in relation to other variables such as population levels and environment. Childe's pragmatic Marxism is a clear attempt to provide some kind of theoretical grounding for explaining cultural change, and Clark was obviously exploring the ecological context of cultures. On the whole there had been little attempt at this kind of thing and what had been done was not systematic, and their presuppositions were not explicit.

Binford and others wanted to explain variation, not just document it. What's more Binford wanted this done in a way that could contribute to a broader anthropological project. Binford wanted Archaeology to be a constructive partner to anthropology. The role of anthropology as Binford saw it was to...

"... explicate and explain the total range of physical and cultural similarities and differences characteristic of the entire spatialtemporal span of man's existence." (L. R. Binford, 1962:p217)

\footnotetext{
${ }^{11}$ As noted earlier, the Mid West Taxonomic Method grouped artefacts in a series of hierarchies. A component was the lowest and smallest, then focus, aspect, phase and finally pattern.
} 
Binford was not fooling around here. Anthropology, and Archaeology as anthropology, was going to do it all.

Binford wanted anthropological-like data, data of human behaviour and behavioural change that would contribute not only to an understanding of the past but to an understanding of the present. "Archaeology as Anthropology", historical anthropology, but Anthropology none the less.

This was a shift in emphasis for Archaeology. Past lifeways were to be the object of study for Archaeology, not the archaeological record. Human behaviour, and behavioural differences, was Archaeology's subject matter. Until Binford, the subject matter of Archaeology had been primarily the material culture of past societies, not the behaviour that generated that material culture. Under this new regime, the material culture of past societies that archaeologists dealt with would contribute to an understanding of past cultures. It would need interpretation that would allow past behaviours to be reconstructed.

To be in a position to make this claim Binford had to believe that it was possible to reconstruct the ways of life of a group from the remains it left behind in the archaeological record. This reconstruction of past lifeways was crucial if Archaeology was to contribute to, to be, anthropology.

So this reconfiguration of the archaeological project came with an assumption that the archaeological record, the material remains of past cultures and the concomitant ecological and environmental data that was increasingly being gathered, could provide enough information to make claims about the human activity that was taking place at the particular time that the data was laid down. Binford not only wanted different 'why?' questions asked, he believed that those questions were capable of being answered by the archaeological record.

According to Binford in later years (L. R. Binford, 1972:p17) the assumptions about Archaeology that the early processual archaeologists had that gave them confidence to ask new questions were of the following nature. Firstly, that the 
archaeological record was not just the random result of past activities. There was an organisation to the archaeological record. Secondly, that organisation in the record reflected in important ways the nature of the group of individuals that created that record. Explanation of the relationships within the archaeological record "will refer to the character of the organised properties of living cultural systems as it existed in the past." (L. R. Binford, 1972:p17) The archaeological record was such that it could be used as a database for an understanding of past life ways. It was a record of past behaviours, not just a record of changing material culture. If Archaeology was to be a historical anthropology, it had to make that claim.

So the basis that Archaeology's move to an anthropological science was to built upon was a belief that Archaeology was in a position to re-construct past behaviours, that Archaeology could contribute to anthropology. This was an important claim that was being made by processual Archaeology. Archaeology was to be more than just story telling or collecting and cataloguing. It was a two-fold claim. First it is the claim that Archaeology could detect and determine past behaviours from the found remains of extinct cultures. Second, it is the claim that process of detection could be systematic, reliable and science-like in its precision. In sum, processual Archaeology claimed that Archaeology can generate explanations, understandings, about past behaviours with the rigor of a science.

However, once this claim is made, it leads to a question for those engaged in thinking about Archaeology;

"What is the appropriate form for the explanation of the human past? How shall the validity of explanations be evaluated by bringing them into effective contact with the data?" (Renfrew et al., 1982:pxvii)

In other words, how can the urge to be science-like and the belief that the past can be explained be effectively married? There was an explanatory task, to explain past human behaviour, and there was a belief that this should be done in a manner resembling the sciences. 


\subsubsection{Logical Empiricist Explanations}

If Binford wanted Archaeology to be scientific, he needed some conception of science. Leslie White, one of Binford's most influential lecturers, had suggested to Binford that he read some philosophy of science to understand just how scientists really worked and for better or worse, he did. (L. R. Binford, 1972:p8) For a variety of reasons, ${ }^{12}$ Binford and his followers adopted logical positivism as the model to which archaeological practice should aspire:

"... a few archaeologists in the 1960's adopted a logical empiricist conception of science in order to reform their discipline by making it 'explicitly scientific' " (Gibbon, 1989:p2)

This 'explicitly scientific' Archaeology would work in a new way. Archaeology would need to come up with theories that were general in scope and fairly abstract.

"Perhaps the single most defining feature of the positive heuristic was the assumption that the explanatory social science goals of the New Archaeology could only be reached through the identification, confirmation and use of universal laws as defined in the logical empiricist (specifically Hempelian) research program." (Gibbon, 1989:p68)

How this played out in Archaeology was to have various repercussions.

Hempel's vision of science, the vision that was embraced by Binford and others in the early 50s, was that its confirmation and strength lay in the fact that it adhered to a

${ }^{12}$ I haven't found a good account of why New Archaeology adopted positivism. Bruce Trigger believes that it really just suited the needs of the time. The increasing emphasis on science and science funding by the USA during the 50's created a climate whereby claiming to be a science was an important way to secure funding, and socially the mood of America was one of optimism that science could explain all aspects of human life and that progress was an inherent feature of human history. (Trigger, 1990 p289) Binford himself simply states that from "a practical science point of view , the arguments of Karl Hempel were the most useful" (L. R. Binford, 1972 p18) Whatever the causes, logical empiricism has maintained a fairly strong grip on archaeological theory until 
certain pattern. So long as a hypothesis, in conjunction with some data or starting conditions, logically implies the phenomenon, and the phenomenon is present, then the hypothesis is confirmed. The covering laws, the hypotheses, should not ideally be limited to any time or place but should rather be universal. ${ }^{13}$ This was the Hypothetico-Deductive model of science that was first outlined by Hempel and Oppenheim in the late 1940s.(W. C. Salmon, 1989:p3)

For explanations of phenomena, the ideal form was that of the deductivenomological model (D-N explanations). The idea here is that universal covering laws explain phenomenon in conjunction with some starting conditions. The explanation should be deductively valid. The hypothesis should, when included with information regarding the particular circumstances, deductively entail the conclusion, a description of the phenomena to be explained.

"... a statement of particular or general facts is explained if and only if it is deduced from other statements which include at least one general scientific law." (Honderich, 1995:p17)

So to explain something according to the D-N model would look something like this;

1) All metals conduct electricity (General Law)

2) Copper is a metal (Starting condition)

2b) This wire is made of copper (Starting condition)

fairly recently.

${ }^{13}$ It's worthwhile noting here that within the realm of Archaeology it only had to be universal with regards to human behaviour. A truly universal hypothesis of the kind generated by physics that could apply to all times and places in the universe were not really required. As Merrilee Salmon points out many of the covering laws of Archaeology were in fact empirical generalisations, but such generalisations effectively and reliably serve the role of laws in fields such as Archaeology or biology despite the fact that they only hold on earth as such. See (M. H. Salmon, 1982:p18-26) for discussion of the archaeological case. 
$\therefore 3$ ) This wire has conducted electricity

Because archaeologists in the 1950s and early 60s characterised scientific explanations using this explanatory form, they felt that Archaeology needed to do something similar. An archaeological explanation according to this schema would look something like the following:

1) Technologies diffuse from advanced cultures to peripheral ones given some form of contact. (General Law of Archaeology)

2a) Egypt was an advanced culture contemporaneous with Greece. (Starting condition)

2b) There was contact between Egypt and Greece. (Starting condition)

2c) Stone-working technique $X$ is found in both Egypt and Greece (Starting condition)

$\therefore$ Technique $\mathrm{X}$ arose in Egypt and diffused to Greece

This admittedly simple argument is supposed to explain the presence of certain archaeological data in Greece. ${ }^{14}$

The move to the logical empirical style explanation of Archaeology was supposed to make explanations explicit. By outlining the evidence or starting conditions clearly, and by outlining any assumptions that resembled a general law or theory, archaeologists should be making much that had previously been implicit more obvious, and allow much more in the way of coherent criticism. So there were good professional reasons for the shift to explicit explanatory schemas. Making the reasons for a conclusion transparent should allow for the benefits of peer review and debate. Speculation would be overt and open to question. If this was the way that the sciences

\footnotetext{
${ }^{14}$ Note here that the premise 1 potentially needs to have an auxiliary hypotheses along the lines of "this is the only method of getting cultural innovations." i.e. That diffusion is the only source of change. There is here an in-built assumption here. Clearly such an explanatory form is less than straightforward in the case of archaeological explanation, but further discussion of this problem will left to the next chapter, and pretty much the rest of the thesis.
} 
did it, then this was the way that a discipline aspiring to be a science should do it as well.

However, there are problems here. The Hypothetico-deductive conception of science seemed to imply the need for something resembling archaeological theory, and it wasn't entirely clear that Archaeology had anything resembling theory. Indeed, on the D-N model, Archaeology seems to need two types of theory. There is a two stage process in Binford's conception of Archaeology. The first stage is the reconstruction of past behaviours. From the raw data of potshards and soil samples, an inference is made to the activity that generates such traces. That inference requires some laws or theories about the relation between behaviours and the material traces such activities leave behind. The next inferential stage is to place such reconstructed behaviours into their anthropological context. Under the Hypothetical- Deductive model of science some kind of theory is required that can be used to derive an anthropological understanding of the reconstructed behaviour.

With the need for theory comes the need for some precision about other aspects of the archaeological project. Certain conceptions need re-configuration. If Archaeology is to study cultures, and contribute to the formulation of laws of anthropology, it needs to set out clearly what was under study. So there are two stages to the process for Archaeology. The first stage is to reconstruct past behaviours. The second is to explain these in relation to anthropological theory. The two stages will interact with each other. As we shall see, the anthropological theory that is "under test" will shape the more mundane reconstructions of behaviours. We will deal with both these processes separately. It's to the conception of Archaeology as anthropology that we will now turn.

\section{2 "The New Archaeology."}

What we've seen so far is this. Binford's made two core claims, that Archaeology should be more science-like and rigorous, and that Archaeology should contribute to, and be a part of, anthropology. He has made these claims on the basis of believing 
that the archaeological record was organised, there are enough regularities to fuel a scientific Archaeology and that the archaeological record was capable of delivering anthropological and behavioural information about the group that was responsible for the site under study. Once these claims were made Archaeology needed some conception of how a science behaved, it needed a model of scientific rigor. For good or bad, the model proposed was the Hypothetico-deductive model of science. This was to be the goal for archaeologists. Find general laws for the regularities of the archaeological record, and test claims about the behaviours and lifeways of these extinct peoples against the physical evidence.

This double-edged move came with important conceptual consequences.

\subsubsection{Reconfiguring culture.}

Because of adopting the Hypothetico-deductive model of science as the goal for Archaeology, there is a rejection of certain forms of explanation. It ruled out explanations that were reason giving or that were merely chronicle. A historical explanation of the kind that Archaeology was to provide, could not be in the form whereby the explanation of an event was in terms of the decision of an actor. There had to a generally applicable law given. There was to be no "explanation by reference to a persons reasons or motives for doing something." (Gibbon, 1989 p25) So diffusionist theses along the lines of Perry, with Egyptian seekers for the "givers of life", were ruled out. They attributed intentions to agents, the "seekers", to explain the spread of various technological and stylistic influences the hyper-diffusionist claimed to detect in non-Egyptian cultures. Such explanations were not reliant on laws. They were reliant on individual and particular features of a culture and its intentions. Given that there was no written record of a group's intentions, there was no test for such explanations. General laws are testable. We can make a claim that sugar dissolves in water and test it any number of times. A claim that an individual will behave in a certain fashion due to certain beliefs that they have is not testable in the same way.

To the extent that they treated Cultures at all, culture historians had tended to see 
cultures as normative: "a specific aggregation of internalised ideas or norms".

(Trigger, 1990 p302) Culture was the collective beliefs of any group of people under study. In Binford's words a

"normative theorist is one who sees his field of study as the ideational basis for varying ways of life... the archaeologists task then lies in abstracting from cultural products the normative concepts extant in the minds of men now dead." (L. R. Binford, 1972:p196)

According to this picture, the material remains of a culture were the causal results of a set of beliefs. It was the beliefs that were to be recovered by the archaeologists if anything other than artefacts were to be recovered at all. So the as explanatory mechanisms for the form the culture took was the beliefs of people. In the case of a diffusion hypothesis like the spread of a megalithic religion, the 'whys' of the diffusion were assumptions about potentially unverifiable cultural motivations. The motivation for temple building would be a cultural belief that was "extant in the mind of men now dead", unverifiable in pre-literate cultures where such things couldn't be determined through the examination of texts, but yet posited by Culture-historians as an explanatory mechanism. The understanding of culture, such as it was, had allowed such an explanation, and the historical turn of the cultural historians had allowed prehistory to conducted in the manner of history.

This way of viewing culture couldn't provide the covering laws necessary for a fledgling science such as the "New Archaeology". Collective beliefs, individual motivations, the will of a people, were just the sort of psychological causes that the new archaeologists wanted to get out of their explanations. The adoption of the Hypothetico-deductive conception of science as the guiding heuristic for Archaeology demanded that this be the case. Explaining a historical event in terms of the psychological factors of the people involved was an unacceptable form of explanation. It couldn't be tested, it wasn't verifiable in pre-historic cultures and in some cases it looked as if it was ascribing mysterious psychological motivations to the people of the past. The Hypothetico-deductive conception of science suited a 
generation of archaeologists that was rightly suspicious of some of the explanations and story telling that had gone on in Archaeology. So the D-N model played a positive role in validating the rejection of a certain explanatory strategy that was indeed probably inherently untestable. We will examine the negative consequences of the D-N model in the following chapter.

The older view of culture as a set of internalised norms made no sense within the H-D conception. To overcome this processual archaeologists had to redefine what they meant by culture:

"Called the systemic view of culture, it proposed that a culture is a complex, systemic, integrated, adaptive, extra somatic and material-based organisation of behaviour and not a mental phenomenon."(Emphasis added) (Gibbon, 1989:p70)

The processual archaeologists saw culture as an adaptation to the physical environment.

"The notion of adaptation lay at the heart of this approach and was conceived as relating to the behaviour of groups, with specific reference to the balance between people and their resources." (Maschner \& Mithen, 1996)

Binford explicitly stated that culture was the "extra-somatic means of adaptation for the human organism" (L. R. Binford, 1962:p218). Culture was an integrated group phenomenon that responded to environmental constraints. The ultimate cause for cultural features was located in the physical environment within which the culture was found, rather than in the actions or beliefs of the individuals who made up that culture.

To generate theories about cultural adaptation required an approach over and above that of merely artefact collection. The physical environment, entire sites of human habitation, and the relationships between objects became an important source of information. Soils that showed a history of disturbance related to agriculture become as important as the antiquarian treasures found within its grasp. The damage to an object may be a source of interest rather than of regret. The remains of burnt 
corncobs became a source of information rather than rubbish. The presence or absence of resources within the physical environment became of fundamental importance.

As mentioned earlier, such a shift in attitude had already begun. Clark and the later works of Childe had already begun to examine past societies and their dynamics rather than catalogue artefacts. This reappraisal of what culture meant was an accessible and acceptable, perhaps even necessary conception given the moves that Archaeology had already made. Binford and the processual archaeologists were attempting to provide some kind of method that would allow them to get at the mechanisms for change, and understand material culture, that was consistent and possessed some kind of scientific validity.

\subsubsection{The forces of Change}

Another part of the explanatory project was to explain change over time. This was an area of explanation that was the particular province of Archaeology as opposed to anthropology. Only Archaeology had access to the historical data required to explain how changes occurred within cultures or societies.

The explanation of change needed to be, like cultures, in terms that eschewed the psychological. Individual or group motivation was a disallowed form of explanation. Equally documenting chronologies for cultures, the primary focus of much of the cultural historian's work, was unacceptable. There needed to be reasons for the chronicled differences in material culture. Processual Archaeology adopted primarily two causal mechanisms for change. Population pressures and ecological pressures, both clearly entwined.

"The New Archaeology embraced various forms of ecological and demographic determinism which located the major factors bringing about change outside the cultural system and treated human beings as the passive victims of forces that mostly lie beyond their understanding or control." (Trigger, 1990)

For processual Archaeology "... change was conceived in terms of the environment 
impressing itself on human populations..." (Shennan, 1996:px) That external environment could be the physical environment or the social environment when demographic pressures forced changes or rival societies emerged. If the Egyptians were the source of cultural irradiation for the Mediterranean and Europe, it couldn't be because they had some peculiar motivating force that fired their creativity. Whatever allowed them to innovate and spread ideas needed to be some particular physical property of the world; demographic pressures, an environment that allowed a food surplus that could support specialised labour or a combination of the two.

Bruce Trigger goes so far as to claim that processual Archaeology ruled out any internal changes in cultures - All stimuli would be external. Either environmental conditions or competing cultures were the stimulus for change. Demographic changes were envisaged to be dependent on changing technology and environment as well, so the causal arrow for demographic change was from the environment onto the culture as well.

"New Archaeologists have continued to condemn explanations of change that invoke either conscious or unconscious psychological factors. Instead they have identified relations between technology and the environment as the key factors determining cultural systems and, through them, human behaviour." (Trigger, 1990:p302)

Given this, explanations of change provided by Childe were ruled out as well. Unless seen in strictly materialist terms as the result of a cultural interaction with environmental factors, Childe's pragmatic Marxist interpretations of change were not acceptable forms of explanation ${ }^{15}$. Childe's mechanisms of change were frequently internal social factors.

${ }^{15}$ Running Marxist interpretations in the United States of the 1950's and 60's probably wasn't a career option anyway. 


\subsubsection{Artefacts and Hawkes' Hierarchy}

Because of his redefinition of culture, Binford classed objects from the archaeological record depending upon what kind of information they could provide. Firstly there were technomic artefacts, artefacts that were directly concerned with "coping with the physical environment" (L. R. Binford, 1972:p23). The next class of artefacts would be sociotechnic, articles with their primary function in "the social subsystems of the total cultural system" (L. R. Binford, 1972:p24). Objects relating to identity status (perhaps as grave goods) would be good examples of this kind of object. The final major class of objects will be ideotechnic artefacts, ". . items which signify and symbolise the ideological rationalisations for the social system..." (L. R. Binford, 1972:p24) This would be various symbolic and potentially abstract aspects of a culture. Binford suggests things such as symbols of deities, clan symbols and such like. All of these different classes of objects would share stylistic features in common that would unify the culture as a whole.

In later years ${ }^{16}$ Binford would admit to this being "a bit naive" (L. R. Binford, 1972:p17) Some articles are clearly going to cut across multiple spheres. For instance in discussing the design of ceramics in a later article, Binford suggests that there are two variables that might change. The primary function, relating to the specific use of a ceramic artefact, and secondary function, a by-product of the "social context of the manufacturers of the vessel or of the social context of the intended use of the vessel." (L. R. Binford, 1972:p200) So changes over time in uses to which ceramics were put would indicate changes in subsistence strategies (changes in the technomic aspect of

${ }^{16}$ It should be noted here that (L. R. Binford, 1972) is a collection of earlier articles. The ones quoted here being reprints of (L. R. Binford, 1962) and (L. R. Binford, 1965), so at least some of Binford's modifications are with ten years hindsight. Binford's "Archaeology as Anthropology" written in 1962 was, Binford admits, written late at night in "a state of frustration" (L. R. Binford, 1972 p17), so revisions of ideas are to be expected. 
the artefact). Changes in size of vessels may indicate that food sharing at a group level was taking place if the vessel was larger, and smaller vessels would indicate smaller family orientated provisioning, potentially indicating sociotechnic differences. (L. R. Binford, 1972:p201) However, the important aspect to take from this is that Binford saw a change in one aspect, be it technomic or otherwise, affecting other aspects. Changes in subsistence strategies would affect social aspects of a group, which in turn would affect political relations and potentially ideologies. The reflection of these changes will be within the relationships between the various artefacts, not individual artefacts of themselves.

Now it's worthwhile highlighting Binford's claims against Hawkes' Hierarchy at this point. Remember that Hawkes' claim was that some facets of past cultures were always going to be more difficult to reconstruct than others. At the lowest level there was techniques of manufacture, the next in difficulty was subsistence economics, followed by socio-political institutions and finally religious and spiritual aspects which would be the most difficult to infer form the archaeological record. (Hawkes, 1954:p162-63)

There are two ways to take Binford regarding Hawkes' hierarchy. On the one hand Binford could be taken as saying that the higher levels of the hierarchy, religious and political institutions, were of no explanatory import to anthropologists. It is certainly true that by adopting a materialist stance, rejecting ideational explanations and talking in terms of culture being an adaptive complex processual Archaeology can be interpreted this way. Even the ecological functionalism of the British archaeologist Graham Clark highlighted the role of different subsistence strategies in different resource settings. However, I don't believe that that is the case with Binford's theory. Rather Binford believed that all aspects of cultural groups can be explained.

"He [Binford] maintained that the archaeologists primary duty is to explain the relations that are extant in the archaeological record. In particular he repudiated the idea that it was inherently more difficult to re-construct social organisation or religious beliefs than it was to infer economic behaviour." (Trigger, 1990:p298) 
All objects found within the archaeological record, and their relations to other objects, should be informative regarding the culture that produced them. Binford's real response to Hawkes' Hierarchy lies in his archaeological holism. He believes that all components of an extinct culture can be explained by appeal to ecological factors. Cultures as a whole are adaptations to the environment.

Because Processual Archaeology had the assumption that components of a cultural system are not independently variable of one another, any change in one variable should be indicative of change elsewhere. Cuvier maintained that the components of living organisms are so tightly interconnected that the whole organism could be reconstructed from any part. (Rudwick, 1972:p130-104) Likewise, Binford maintained that the inter-relationships between the various components of the archaeological record were such that the entire system is reproducible from its parts. Systems can be re-constructed in their entirety once some broad laws are in place about the relationships between parts. The idea here is that any change in a particular variable would result in changes elsewhere in the cultural system in a way that was regular and predictable. The overall environmental adaptation of the culture had to remain systemically viable.

"'Non-material' aspects of culture are accessible in direct measure with the testability of propositions being advanced about them." (S. R. Binford \& Binford, 1968)

So long as there was some means of testing it, a hypothesis about the ideological beliefs of a people was acceptable. Given the implied dependence on all aspects of culture on environmental or demographic factors, there was no real reason not to suppose that religious or political systems are beyond explanation. Given the right theories, and enough information, and tight enough connections between the components of a culture, Hawkes' Hierarchy was collapsible.

It is clear that Binford believed that whatever shaped a society and changed it through time was measurable, and the causes were regular and predictable. Whether this causal regularity was extensive enough to collapse Hawkes' Hierarchy was 
unclear. The important take home message is simply this: The relation between the archaeological record and the behaviour that produced it could be determined. It was this re-constructed behaviour and an understanding of it that was to be Archaeology's contribution to anthropology. Processual Archaeology took behavioural reconstruction to be achievable in a controlled manner without positing unverifiable causes, and it took the primary causes to be external physical conditions to which a culture was an adaptation, rather than the internal dynamics of cultures.

\subsubsection{Conclusion}

The two core claims of Binford, that Archaeology should be a science and that Archaeology should be anthropology, are conceptually distinct. There is no reason to suppose that the one implies the other. The claim that Archaeology should be anthropology could just as well be a claim that Archaeology be an interpretative anthropology closer to the humanities. Equally, the claim that Archaeology should be a science is a claim for rigour in archaeological practice rather than a claim about Archaeology's project.

The consequence of the two claims combined was the re-configuration of culture that Binford needed. He had to make the claim that archaeological data was capable of generating the information required to do anthropology. The cultural forces that produced the archaeological record needed to be systematic enough, be causally regular enough, to collapse Hawkes' Hierarchy.

However, there is a major problem here. The Hypothetico-Deductive conception of science, and the Deductive Nomonological explanations that came with it, required laws. For Archaeology, the project of finding laws was deeply problematic. For the anthropological project to which Archaeology was to contribute did not have any laws. If we re-examine the two stages of processual Archaeology, this may become clearer.

The first step was to reconstruct the events that contributed to the creation of the archaeological record. So when faced with an assortment of artefacts and remains, 
some kind of statement needed to be made about the relationship between the data points, the individuals artefacts and other pieces of information. Perhaps a site is identified as a campsite where carcasses were dismembered. We need ways of testing such identifications. The 'enrichment' of the data - its initial interpretation - needed to proceed with the rigour of a science.

Binford and the processual archaeologists did deal with this first stage of the archaeological project. What became known as Middle Range Theory was an explicit attempt to secure the initial interpretations of sites. It was somewhat confused in its theoretical discussion, but it clarified the problems of interpreting archaeological data in such a way that Archaeology could make progress. It put site interpretation on a much sounder footing.

The next stage was an explanation of that enriched data. This explanation process was to be an anthropological explanation. To explain a feature of a past culture using a D-N style explanation required a broad law-like statement about all cultures. It is worthwhile re-quoting Binford on the role of anthropology at this point to underline the problem. The role of anthropology as Binford saw it was to...

"... explicate and explain the total range of physical and cultural similarities and differences characteristic of the entire spatialtemporal span of man's existence." (L. R. Binford, 1962:p217)

Any broad law-like statement that could be used to explicate and explain the past had to be theoretical statements at quite a high level of abstraction. They would need to be applicable across cultures and across time. Anthropology didn't have laws of that type. At least, none that were useful for historical explanations. The processual archaeologists never really came to grips with the lack of these broader explanations of the past that they wanted. In fact, much of the work of processual Archaeology has concentrated upon the reconstruction process, with little work on its broader theories of history that explanations of the past would require.

It should be clear that Binford overreached himself here. The adoption of the D-N style of explanation required laws that were not there. There is little reason to suppose 
that D-N explanatory models tied to general laws could deal with the variety and peculiarities of human cultures. So our question is, what were archaeologists doing? Binford had set the twin goals of scientific rigour and Archaeology as anthropology. How did archaeologists respond? 


\section{Chapter 4: Processual in Practice}

As we've seen, Binford made two inter-related claims; that Archaeology should be anthropology rather than history, and that Archaeology needed the rigour of science. But anthropology is about the behaviour of Homo, not its material culture as such (although it's clearly a part of the lifeways of a group). Studying just an artefact doesn't get us very far up Hawkes Hierarchy. Understanding its role in the patterns of human behaviour does.

Binford realised that an artefact isn't fossilised behaviour, it is a by-product of that behaviour. What's more, the selective nature of the preservation process and the potential traps for the unwary in making sense of what was preserved, all contributed to a need for Archaeology to build a bridge from the artefacts found, to the anthropology done. Because Archaeology wanted to do anthropology, they needed that enrichment of the data that would allow them to make claims about the behaviours of the past. This should have been a claim that was independent of the applicability of the Hypothetico-deductive model of science. In fact, the two things became somewhat confused. As we shall see, the process of reliably reconstructing the behaviours that were causally related to an archaeological site, became confused with other features of the H-D model of science. In particular the Hypotheticodeductive model includes notions of bridging laws and auxiliary hypotheses which clouded the discussion.

The first part of this chapter deals with these discussions of what became known as Middle Range Theory (MRT) and the confusion that surrounded the concept.

Once this is discussed, I will look at just how archaeologists were working in practice and the problems that emerged as a means of disentangling the theoretical 
claims of the "New Archaeology" from the actual work of archaeologists.

\subsection{Ground work.}

\subsubsection{Middle Range Theory}

Archaeological sites are created by a combination of factors, only one of them being human behaviour. In order to bridge the gap between the information in the archaeological record and behaviours, in order to be able to extract behavioural information from the detritus of past lives, an empirical theory was required; a theory about the relationship between behaviours and the found remains.

"What we are seeking through middle-range research are accurate means of identification, and good instruments for measuring specified properties of past cultural systems. We are seeking "Rosetta Stones" that permit the reliable accurate conversion from observation in statics to statement about dynamics." (L. R. Binford, 1981:p25)

Binford recognised that the move from unearthed artefact to behaviour wasn't a simple one. There would be auxiliary hypotheses involved, empirical evidence generated by other sciences. More importantly there were bridging theories required. These are distinctively archaeological theories about the relationship between sites and human action. These came to be known as Middle Range Theory, " ... a set of theories or propositions that bridge the gap between the empirical observation and broad, often abstract and un-testable, general or high-level theories." (Maschener in (Fagan, 1996)) Middle Range Theory - and in particular the realisation that is was required - is probably Binford's most important contribution to Archaeology. It made explicit the process of interpreting raw data, and it demanded that that process was rigorous and coherent.

Middle range theory was supposed to be a collection of theories about how the statics of the archaeological record relate to the dynamics of the systems that created them. The reason for this is that Binford recognised something important; 
"The archaeologist investigates phenomena that he has reason to believe remain from the past. These investigations are conducted in the present, resulting in all the observational statements generated by archaeologists being contemporary facts. How does an archaeologist convert these contemporary observations or facts into meaningful statements about the past?" (L. R. Binford, 1981:p22)

Archaeological data was something in the here and now, but archaeologists wanted to give an explanation of past behaviours of which artefacts are a by-product. Not only are the artefacts and other data a by-product of past behaviours, for the contemporary observer they are also the by-product of various post-depositional factors.

"We seek to know the past through the investigation of contemporary phenomena, and we seek to describe the past in dynamic terms, having only "statics" to provide the clues." (L. R. Binford, 1982:p132)

The realisation that this was the case, that they were engaged in a reconstruction of the past based on fragmentary clues, is arguably the most crucial insight of the New Archaeologists. It is obvious when it's pointed out, but it had never been explicitly stated. The fact is that archaeologists deal with pieces of evidence in a way similar to a investigator determining what happened at the scene of a crime. They attempt to reconstruct past events based upon the interpretation of evidence that exists now.

Archaeologists who were attempting to reconstruct past events need some kind of guiding theory in how this should be done. In this regard there should be, according to Binford, the ability to generate a genuine 'science-like' theory or observation language that was ideologically neutral.

"Archaeology is perhaps in a fortunate position in that while there is much contemporary "culture" or paradigmatic bias regarding the nature of man or concerning the causes of history, there is very little folk "knowledge" regarding the formation of the archaeological record..." (L. R. Binford, 1982:p129)

Binford hoped that middle range theory, the bridging laws between archaeological data and higher level theories, would be reasonably free of political contention. There had always been arguments over basic data, but the hope was that those arguments 
could be about facts, rather than differing ideologies. Where as anthropology can be fraught with ideological splits based on different conceptions of what it is to be human, middle range theory would be science that was free of such politics. Regardless of whether an individual worker was a Marxist archaeologist like Childe, an Ecological determinist like Clark, or of any other persuasion, the interpretation of the raw data should be free of bias and independently testable.

The initial conception of MRT was as bridging laws, the previously quoted Rosetta stones, allowing a relation to be built between archaeological data and the higher level theories of anthropological Archaeology. Bridging laws are not unusual in science. For instance different stain preparations differentially colouring a cell that allow for analysis of how a cell is constructed act as 'bridging laws', relating observed phenomenon to the higher level of theory. Part of the explanation of cell structure in such a case includes theories about why the cell's structure differentially take up the colour of the stain. A bridging law in such an example serves as a bridge between the observable phenomena (the stained cell) and the thing to be explained (the cell construction). In order to connect the two things another theory is used. In this case, a theory of the differential staining of cells.

Such bridging theories can be related to the general theory that is under test in an experimental set up. They are also frequently tied to the observational language of a discipline, for their role is to specify how the raw data relates to the higher general theory. The relationship between bridging laws and higher level theories is sometimes more obvious in the social sciences. The claim that an anthropologist is looking at the Ache culture is a claim that such a thing as a culture exists, and that it is one of the objects of study for an anthropologist. An alternative theoretical position may see a culture as a group of individuals with regular interactions, and the object of study may well be the individuals. What counts as a good explanation in the two cases may well be different.

The problem in Archaeology's case is that bridging laws were effectively bridges 
to nowhere. Without the higher level theories that were to explain the past, the original notion of a middle range theory is not really applicable. In fact, MRT came to be more closely tied to the problems associated with the initial interpretation of data. It became a set of methods for enriching data, rather than a bridge between the data and high level theory.

\subsubsection{MRT and Archaeological Practice.}

Initially Middle Range Theory (MRT) was conceived as the bridging laws between data and theory. Over time however, MRT became the shorthand for the initial interpretation of data as the results of human behaviours. It also came to include ideas regarding other sciences and their role in this process.

As we saw in the previous chapter, Binford early on made the claim that Archaeology should adopt Hypothetico-deductive model as its ideal for doing science. It should frame laws, and then test those laws against the archaeological record in its entirety. The laws would be very broad and at a high level.

However the laws of a science, and the derivation of explanations, is never straightforward. Besides bridging laws, other sciences are frequently involved within a field and play a role in any explanation or confirmation. For instance, work on cell structure in organisms comes with assumptions about how microscopes work. How microscopes work is within the scope of the sciences of optics and physics. If optics has it wrong, and what a researcher sees down a microscope isn't a reliable source of information about cell structure, then part of the argument falls down.

Archaeologists are well aware of other sciences and their promise and problems. Carbon 14 dating had made huge impacts upon Archaeology. As absolute dating methods become more precise, increasing amounts of precise data about the past become available. Such novel techniques are never without their teething problems, and it is only with time that they become acceptable components of explanations.

Such 'auxiliary hypotheses' have long been recognised as a part of the scientific process. (Boyd, Gasper, \& Trout, 1991; W. C. Salmon, 1989) During an experiment, 
some things are not actively being tested within the experimental set-up, even if they may be passively tested. A biologist is not actively testing the general laws of optics every time she looks down a microscope. Such auxiliary hypotheses are conceived of as being logically independent of the specific theory under test. Nevertheless, under a Hypothetico-Deductive model of science, the theory of optics is being passively tested during any work with microscopes.

A number of sciences contribute auxiliary hypotheses to Archaeology. Perhaps the most notable examples are carbon dating and its successor techniques. These techniques were developed and tested by physicists. Yet, the dates that carbon dating provide are crucial pieces of information as part of explanations and the data gathering process. Yet, they are importantly independent of any anthropological theory, or indeed archaeological theory. They can play a role in testing any archaeological explanation while remaining independent from it. Other areas of contribution to Archaeology would be biology, geology and chemistry.

So auxiliary hypotheses, the contribution of other sciences, fits fairly neatly into the pattern of archaeological confirmation and explanation. Other sciences are going to play a role in Archaeology, and the Hypothetico-Deductive model of science captures that well.

The distinction between Archaeology's bridge laws - laws developed by archaeologists and for Archaeology - and auxiliary hypotheses has not been kept clearly in mind in many of the discussions of middle range theory. Clearly, many disciplines are needed for the reliable reconstruction of past behaviours. Other sciences are involved in disentangling the data that the archaeological record can provide. Geology is important for older sites in relation to dating and sediment formation. The integration of biology and ecology is needed for ecological settings to be reconstructed. Studies of animal behaviour are needed to distinguish animal site construction from human agency. Nevertheless, these contributions are not about extracting human behaviour per se, they are about the archaeological site and what forces acted upon in over time. These are the contributions of other sciences to the 
project of understanding site formation and the provision of data. The auxiliary hypotheses contribute data to the archaeological project.

For some, the study of all these processes of site formation processes was Middle Range Theory;

"Principles of site formation processes have become virtually synonymous with "middle range theory." " (Raab \& Goodyear, 1984:p258)

However auxiliary hypotheses were not the only things that were included within MRT, and so some level of confusion within Archaeology arose around the concept. It is hard to deal with large number of processes that contribute to site formation and it is difficult to disentangle the behavioural component from other factors. But that behavioural component to site formation was the special concern of Archaeology, and was MRT as others saw it. And it was legitimate to worry about the security of inferences to behaviours. Binford's promotion of MRT was connected to these specific concerns. To see their legitimacy, it is worth considering a few examples where the project of extracting behaviour from archaeological remains did not rest on well-established MRT.

The Leakeys had made claims for prehistoric living floors starting just after World War Two based upon the presence of tools in close proximity in a temporal layer of the strata. J. Desmond Clark was to take up these claims later and they entered the interpretative repertoire of paleo-anthropologists of the 1960s. The evidence for these living floors were a group of tools all found at a similar layer in the sediment. (L. R. Binford, 1981:p13-14) It was assumed that the configuration of the tools represented the way that they had been discarded by early hominids; i. e. That they were relatively undisturbed since deposition and that the inter-relationships between the artefacts reflected behaviour. This idea of living floors helped bolster the man the hunter hypothesis of the mid-twentieth century. The problem was that the assumption that the artefacts were undisturbed was probably false. The configuration of the site was probably the result of geological processes. Site formation processes had 
obscured the behavioural data. Binford claims that the assumption that the site was entirely the result of hominid behaviour should never have been made at all.

"We need to abandon the logic of treating alleged habitations, living floors, and living sites as if they were monuments. The logic is one of identifying an envelope or container, and then uncritically accepting everything within it as referable to the behaviour of ancient man. A complete re-evaluation of basic archaeological concepts and the logic associated with their use is in order." (L. R. Binford, 1981:p18)

Binford believes that the over-interpretation of the site was due to the fact that there was no independence of the interpretative framework from the archaeological data; there was no way of describing the data that did not presuppose the dubious interpretation

"There are no methods for giving meaning to the archaeological observations that are independent of interpretative arguments offered by the investigators." (L. R. Binford, 1981:p252)

There was no independent means of verification for the theory of living floors. MRT was supposed to provide the independent means of verification required by providing a set of tools for separating site formation processes from the original behaviour. Middle range theory was also about the study and understanding of site formation processes.

What we have here is really that the first stage of the archaeological interpretation, the process of interpreting data included three elements. It would include auxiliary hypotheses from other sciences. These would be partly to provide precise dates and other "data points" such as pollen analysis for the ecological information from the period. They would generate, in other words, much of the raw data about the site. However, other sciences would also contribute to the second element of MRT, the understanding and testing of site formation processes. This part if MRT was directed towards ensuring that the data used by archaeologists was relevant to human behaviour. It was a sifting process, ridding the data of any configurations not caused by human actions; showing, for example, that old bones were broken by animal jaws 
not human teeth. . The third component is perhaps the most problematic, MRT as a set of bridging theories connecting human debris to the human actions that generate them. We will deal with those problems more closely in the next section.

The thing to underline at this point is that MRT was primarily concerned with the logic of how to approach an archaeological site in such a way as to minimise errors of interpretation. Part of that logic included the use of other sciences to help with disentangling the information. This clarification of concepts, measurement techniques and so forth were as much part of the practical side of Archaeology as it was explanation and theory. To reconstruct a plausible story that explained the archaeological data, to get a "crime" to fit the evidence, required some refinement of the data and a degree of credibility in its own right. In this regard, MRT contributed to the testing and confirmation process of Archaeology. It was sufficiently independent of higher level theories to be a source of confirmation, a test. The auxiliary hypotheses of other sciences would be especially relevant in this regard. The logic of site formation processes would also enable security for behavioural inferences.

\subsubsection{MRT as Explanation}

MRT was not just bridging laws. In was about securing the inference from the raw data of an archaeological site to a claim that the site represented the result of a particular activity on the part of some bipedal apes, Homo sapiens included. In order for archaeologists to be able to make reliable inferences from raw data, Binford urged the study of contemporary extant cultures as a way of building up information regarding the relationships between artefacts. If archaeologists were going to extract behavioural information from the archaeological record, they needed to be able see just what information was relevant. The relationship is similar to studying the tracks of animals. In order to determine just what information the marks on the ground provide, some understanding of the relation between the tracks and behaviour of the track maker is required. In Archaeology's case, the only option available for building such an understanding was to examine extant cultures and use them as sources of 
analogy for interpreting data.

"We clearly recognised that most of ideas about the kinds of organisation which might have existed in the past came from our knowledge of the range of variability in organised human life as documented ethnographically." (L. R. Binford, 1972:p18)

Binford felt that "archaeologists must be trained comparative ethnographers." (L. R. Binford, 1972:p18) Modern cultures and the study of how they interacted with their material culture, particularly material culture that was likely to be preserved, was a key part of the process of building statements about material remains.

The logic here is simply this. One of the reasons a site may be recognised as the remains of a village is that we have knowledge of extant villages. So too with something more opaque like the remains of a campfire. Having made a temporary hearth out of found stones, seen the discoloration of the stones and the remains of the fire the next morning, most of us would recognise a campfire made by someone else. It is possible that most of us would recognise a campfire long after use. The logic of Binford's plea to study extant cultures is simply the same logic extended to other activities.

So perhaps most ironically of all, Binford claims we need to examine human behaviours in order to make sense of archaeological sites. After all, if non-human agents need to be distinguished from human agents, then unsurprisingly human behaviour needs documenting as being different.

Regardless of the tenuous nature of analogies between pre-historic cultures and existing ones, such analogies make the reconstruction of the archaeological data potentially more reliable.

This kind of comparison is familiar within biological explanations. Closely related species can be used as a way of determining the relevant differences in parameters that affect those species. If an extinct culture can be seen as a variant or a close relative of an existing one then the comparative study of cultures is going to be a useful tool. So Ethnology is clearly going to play a role in determining site formation 
processes. Binford actively engaged both in the ethnographic study of activities that would lead to site formation, and the study of other non-human formation processes. For instance, Binford studied various assemblages that were known to be animal structured, such as the remains of wolf kills. He then compared them with closely documented human structured assemblages. Modern ethnographic groups were studied in their methods of butchery etc. (L. R. Binford, 1981) By comparing the two sets of remains, Binford could collect data regarding what kind of assemblages we should expect from ancient sites. Clearly, there are other forces at work as well. Binford was very aware of the need to account for factors such as preservation, erosion and the post-depositional disturbance of sites. There needed to be the documentation of all these contributions to the formation of the archaeological record.

Middle range theory was a productive research programme in its own right. Not only did it document non-human forces that acted on the archaeological record, but it developed an account of the behaviour that produced the record. This is where things become complex again. Middle range research that included the study of human behaviour can and did end up saying things about the past. This is in part why Binford referred to it as middle range theory. It was not only concerned with the construction of an impartial set of bridging laws between artefacts and the behaviour that produced them, it also made at least some inroads into the general theories of behaviour that Binford wanted as well. Although Archaeology did not have the broad laws for Archaeology that would cover all cultures at all times, the reconstruction of an archaeological site that used ethnographic analogy could end up saying a great deal about at least that site. Archaeologists, if they engaged in closely reasoned analogies with contemporary groups, could give quite sophisticated and reliable accounts of particular sets of archaeological data. Although not the broad contribution to archaeological theory that Binford envisaged, it is, as we shall see in the following section, a seductively productive research program.

We have seen in the preceding sections a shift in what middle range theory meant 
to archaeologists. Initially conceived as a bridge from raw data to very general theory, it developed into a way of testing and confirming the original reconstruction of archaeological sites. Middle Range Theory was a set of ideas designed to ensure that there was no error in extracting information from archaeological data. However, the inclusion of ethnographic information within MRT meant that it had the potential to develop an explanatory character as well. It gradually developed into something like a substitute for the permanently missing general theory of Archaeology. How this played out in Archaeology is what we now turn to.

\subsection{Archaeological Explanation - Particular And General}

An archaeologist carefully recovers a pot from some sediment. On its own, as a single artefact, any covering laws of the kind required by the deductivenomonological form of explanation that can be used in explaining a single pot, risk being trivial. A covering law might well be functional for instance, along the lines of "pots are containers for things". However, an explanation that includes such a covering law would be a little silly. Such explanations are not going to get individuals very far up the academic ladder. Saying that it has been discarded or lost is not going to be much use either. Who discarded it? Why was it discarded?

So how then to explain these groups of items and any changes in groups of items over time? Its at this point that some kind of higher level laws seem to need to come into the picture. Quite how was never quite clear. The reason being that it wasn't quite clear what archaeological laws would look like. Obvious laws that played a role in Archaeology tended to come from other sciences and act as auxiliary hypotheses. $\mathrm{C}^{14}$ dating and the idea that deeper layers of sediment were older than layers closer to the surface were important contributions from other sciences, physics and geology respectively. What about archaeological covering laws? What laws were going to explain the relationships between individual artefacts and groups of artefacts? What laws would explain identifiable groups of artefacts?

On a day to day basis, as archaeologists published and tried to work to the 
Hypothetico deductive model of science, what counted as archaeological laws was a great deal indeed.

"The central problem for Archaeology is that of understanding the past through material remains, and any laws that are primarily concerned with this problem are at the centre of archaeological theory." (M. H. Salmon, 1982:p20)

So according to Merrilee Salmon's picture, in early processual practice, any relationship between objects or data, regardless of what it was, could count as an archaeological law.

"It was argued that any laws that relate archaeological objects to one another, or state relations between material culture and human behaviour, deserve the name "archaeological law." " (M. H.

Salmon, 1982:p30)

It looks like almost any statement about the relationships between archaeological features counts. A whole group of pots, roughly equivalent in age and within a recognisably distinct region could have some kind of hypotheses put forward acting like a law as part of the explanation of them. A statement about a group of artefacts that correlate with certain environmental features also looks like a law. So long as there was some kind of regular correlation between data, be it environmental, some feature of artefacts, geological information or so on, some kind of statement would play the role of a law in archaeological explanations.

However, it's clear that there is a problem here, particularly when it comes to confirming any hypothesis. Any hypothesis for groups of artefacts risks being highly localised.

"It is difficult to see how a general "law" formulated in relation to the pueblos of the American Southwest, for instance, and applied solely in that region, can make any serious claim as a hypotheticodeductive explanation." (Renfrew, 1982:p21)

So what can happen, and in many ways did happen, is that a lot of the explanations given can look general, they can appear as law-like, without ever really being applied out of a narrow context. Hence, they are incapable of test as the broad abstract laws 
that they were supposed to be. Rather than questioning the hypothesis, what should be a counterexample merely demonstrates the highly localised nature of the original hypothesis. It became clear that casting explanations in Archaeology into a D-N model, even if possible, served no purpose.

An example might help. Yuki Kimura re-evaluated some of the work of Nicholas Toth on Olduvai hominids and their stone tools.(Kimura, 1999) Kimura's work suggests that some of Toth's conclusions may not be generally applicable. The work of Toth on some of the Olduvai hominid sites didn't really cover how tools were being used elsewhere. They were too localised. When Kimura looked at evidence from other hominid sites of a similar age, the explanatory scenarios, the hypotheses, didn't work, they couldn't adequately account for the evidence. The generalisations that Toth inferred about hominid behaviour were incorrect. They only really referred to the Olduvai hominid behaviour, not to hominids generally.

Toth's conclusions are unusable as a general model of behaviour. Given the Hypothetico deductive schema for scientific confirmation, the hypothesis put forward by Toth has been shown to be inadequate as a general law. The problem is that as an explanation, albeit a localised explanation of just the Olduvai hominids, it seemed, and still seems, satisfactory to all concerned, including Kimura.

So what's happening here? If archaeological explanations have a D-N form, as Binford argued, then we seem to have had a major theory failure in the case of Toth and early hominid behaviour. Unfortunately, this example can be generalised to other archaeological explanations. Many of the law-like statements that archaeologists are using seem to be overly localised. They seem to be good explanations for archaeological data, but do not seem to be testable as general law-like statements. Outside of the localised situation that they used in, the hypotheses seem to be insecure.

The reason for this according to Colin Renfrew, was that many explanations in Archaeology ended up taking what he described as a scenario form, "where processes of some generality are described, with linkages that are partly temporal and partly of 
feedback type, so that a general plausibility is generated for a sequence of related processes and events." (Renfrew, 1982:p21) In this kind of explanation, the archaeological data, in conjunction with the reconstruction processes of MRT, act like the evidence of a crime scene. A plausible tale would then told that explained the data.

For much of the work of archaeologists, scenario building, the understanding and explanation of local events, was more than adequate. Genuine high level covering laws specific to Archaeology weren't necessary to explain a local particular phenomenon. Kimura wasn't questioning Toth's explanation of archaeological finds at Olduvai, his scenario explanation. Kimura was only questioning the applicability to other sites, it was only the generality that was failing in Kimura's view, not Toth's particular explanation. So it seems possible that scenario type explanations do provide plausible and reasonable explanations. MRT made scenarios testable. There are problems that still remain about just how much such scenario explanations could actually explain.

\subsubsection{Research Projects and Unity}

Much of the talk of covering laws and so forth engaged in by archaeologists and philosophers has obscured what was actually going on within Archaeology. The theoretical discussions within processual Archaeology have focused on explanation and the search for 'laws' of Archaeology. Equally, much of the dissatisfaction that emerged with processualism in the 1980s seems concerned with the search for laws and the attempt to find better 'theories'. But, in looking at the concept of scenario building, and in particular looking at Middle Range Theory, it seems plausible that such talk was missing the point. Archaeology was behaving in a very scientific fashion, it just wasn't behaving like physics.

Scenario building and middle range theory did not provide the broad historical explanations that Binford was looking for. Explaining all cultures at all times was not going to be done by the reconstruction of individual campsites. The Hypothetico- 
Deductive model of science that Binford suggested as an ideal to which Archaeology should aspire wasn't anywhere close to what archaeologists do.

We have two options at this point. We can either reject scenario explanations because they fail to conform to the deductive-nomonological model of good scientific explanations. Alternatively, we can reject deductive-nomonological explanations as inappropriate for Archaeology. Given that scenario explanations are testable using MRT, and accepting that scenarios could be very coherent accounts of specific archaeological data, it seems that the D-N model of explanation should be the one to go.

Phillip Kitcher (1991) suggests that some sciences do not provide explanations that adhere to the D-N form of explanation, but are, nevertheless, good accounts of the data. Generally in such sciences - and biology is notable for this feature - the requirement for explanatory adequacy is through a general appeal to some guiding principle. Within biology for instance, a good explanation of a feature of an organism will make an appeal to the adaptive advantages of that feature. What makes such an explanation acceptable is the appeal to Darwinian evolution. The theory of evolution by natural selection helps provide a coherency to biological explanations across diverse situations.

Binford has a theoretical model capable of doing just this kind of work in Archaeology. He has at least one broad theoretical claim, a claim that seems to have been missed in the discussions regarding explanation that dominates the archaeological literature. That claim was this, that culture is a systemic extra-somatic adaptation. (L. R. Binford, 1962) It is the claim that restructured how processual Archaeology viewed culture, and its close resemblance to the theory that unifies biological explanations is not accidental. Binford's assumption that culture is a systemic adaptation is of itself a theoretical claim about what a culture is and what Archaeology's explanatory task is. This heuristic can guide research to look for environmental causes for cultural structures. What it suggests is that if you want to explain an archaeological find, you need to provide some kind of role for it within the 
context of an adaptive system. How does this object help the culture as a whole adapt to the physical environment?

\subsubsection{Culture as Adaptive Systems}

There was good reasons why treating entire cultures as adaptive systems made sense for Archaeology. For a start, the individual was always opaque. Stratigraphic layers in archaeological digs represent generations rather than a snapshot of a group of people and generally a single individual actor is invisible. Part of the reason the ruins of Pompeii are fascinating is that they do provide something incredibly rare, a genuine slice of life from a particular time. The Tollund man with his preserved clothing, the iceman Ötzi, found in the Swiss Alps with his bow and his copper axe (Roberts, 1993) are exceptions to a general rule that individuals will be invisible to archaeologists. Only samples of group behaviour over extended periods will be available to work with.

But it is one thing to focus on cultures as the unit of analysis. It is another to claim that they are, as interdependent wholes, adaptations. This was a strong claim, and it was probably too strong. Should any cultural factors not be the result of physical environmental factors it is potentially outside the sphere of explanation. For processual Archaeology, this is a major problem. If Hawkes Hierarchy is not collapsible, so that all the features of a culture can be reconstructed based on environmental features, then much of what archaeologists want to talk about is not explicable. Without Binford's strong holist position, the appeal to the notion of culture as an adaptive system was inherently limited. Only those things that could be viewed as adaptations to the environment could be explained with reference to unifying principle of adaptive systemic cultures.

The general criticism from within Archaeology of processualism was essentially that it failed to generate any useful insights at the upper levels of Hawkes hierarchy. It could do the subsistence and technological level well. However, when it came to art, religion etc, the appeal to cultural adaptations was less productive. Hawkes' 
Hierarchy was not collapsible in quite the way that Binford claimed. The idea that religion etc would co-vary consistently with the style of subsistence was in itself a theoretical claim bound up with the systemic view of culture.

There are two problems. First, there may be features of cultures that are not adaptations. Second, some adaptations may be individual, not collective. A good part of the dissatisfaction with processualist Archaeology was with the lack of explanation regarding cultural features that were at best only indirectly the result of adaptations to the physical environment. The upper levels of Hawkes Hierarchy caused the problems. This view is especially prevalent with those investigating human cultures where the barriers between the disciplines of Archaeology, history and art history become permeable. Other theoretical guides could potentially explain some artefacts better. In lots of ways Marxist analyses of civilisations work. They produce good economic explanations about the distributions of resources and the cultural superstructure that distribution supports.

Even in prehistoric non-human cultures, it is not clear that the systemic-adaptation view of culture is appropriate. In recent years, developments in behavioural ecology and socio-biology have suggested other adaptations that need to be taken seriously. An important area of adaptation is adaptation to social environments. Individuals may be invisible, but they still may be the entities that are adapted to their environment. Whether it be artefact decoration, the possibility that tool making is a showing off strategy (Kohn, 2000) or other features of archaeological data, some cultural features may just be by-product of individual adaptations. They may not be features of an integrated group adaptation to the environment.

If it is the case that such individual adaptations are components of physical cultural remains, then such features are potentially going to be inexplicable on the systemic-adaptation view of culture where the primary adaptation is to the environment. Worse, erroneous interpretations may ensue. For instance, social hierarchies could potentially be seen as organisational adaptations for resource exploitation rather than as the results of social competition for mate access. Social 
adaptations, those features of a society designed to make people get along with one another and compete with one another, can be overlooked.

The upshot is that Processual Archaeology could provide reliable, and indeed testable, explanations for Archaeology at the lower levels of Hawkes Hierarchy. While archaeologists were talking about culture as adaptations to the environment, they had a broad, high level theory that has utility as a guide for explanations. The belief that culture was an adaptation to the environment provided an explanatory form that enabled explanations to be judged against a standardised pattern. The problem is that at the higher levels of the hierarchy there was little sign of improvement unless Binford could convince archaeologists that Hawkes Hierarchy was collapsible in the way he believed it was. Unless Hawkes Hierarchy was genuinely collapsible, with all aspects of the material culture of mankind being dependent on environmental features, then it is not clear what model of explanation to use for social organisation and the ideological features of past societies.

Binford and the new archaeologists in general did have important achievements to their credit. That achievement lies in making both their methods and their explanations explicit. Middle range theory enabled scenario building to be testable, and explicit. As a consequence, alternatives (or variations) could be considered. Scenarios became reliable explanations for localised phenomenon at the lower levels of Hawkes hierarchy. When Explanations of material remains relate to the subsistence strategies of a group, they can be assessed against the idea of an adaptation to the environment. Moreover, the limits of Binford's idea are visible only because of his insistence on explicit hypothesis formation. 


\section{Chapter 5: Evolutionary Archaeology}

We have looked over the past two chapters at Processual Archaeology as defined by Lewis Binford. Now there are a couple of things to note at this point. For a start, Processual Archaeology took on something of a life of its own. It developed a range of approaches within the framework that I have set out. It was a broad church of acceptable archaeological practice. Generally, it accepted the idea that culture was a group adaptation to the environment. It adhered to that conception of human culture. It accepted a broadly biological conception of Homo sapien behaviour. Humans were animals with a very peculiar adaptation: Culture.

Now, I need to make an important point before we proceed. A number of new approaches to Archaeology emerged in the 1980s. These new "theories" of Archaeology fall into two broad camps; those that look to the social and interpretative disciplines and see Archaeology firmly within that sphere, and those that look to the natural sciences for their explanatory models.

The concerns felt by those that looked to the interpretative sciences are not within the scope of this thesis. The archaeological theories that I will be looking at are those that look to biology for their explanatory models. It is the archaeological theories that take the notion of culture as an adaptation seriously that will be of relevance here. In particular I shall consider the work of Robert Dunnell and the Evolutionary Archaeology he proposed, and the Evolutionary Ecological Archaeologists, who used the tools of behavioural ecology. Both these theories claim to be "Darwinian", to derive their methods from biology.

With this caveat in place, we can move on. This chapter introduces the ideas of the Evolutionary Archaeologists, in particular the work of Robert Dunnell. Evolutionary 
Archaeology, or Selectionist Archaeology is interesting because it takes Darwinian evolution very seriously indeed, but it also has an interesting take on the archaeological project. Dunnell genuinely seems to want a new way of going about Archaeology, and has some interesting things to say about processual Archaeology and Archaeology in general.

The work of Dunnell does have some difficulties though. For a start, his stance has shifted somewhat over time. His original ideas were concerned not only with the use of biological ideas, he was also concerned with the systematics of Archaeology. This was outlined in his 1971 book "Systematics in Prehistory"(Dunnell, 1971). In this, he looked at the ways in which the classificatory units of Archaeology had been defined in the past and the ways that the "New Archaeologists" has been influenced by those classifications. These concerns about the "units" of archaeological analysis have fed into his attempts to provide evolutionary explanations for Archaeology. Dunnell argues that inappropriate categories have driven the enrichment process of Archaeology, the initial interpretation of Archaeology's raw data. Dunnell wants the enrichment process to be the construction of artefact lineages.

The other complicating factor is that in attempting to show that biological ideas are appropriate in Archaeology, Dunnell tried to show that the properties of cultural systems are amenable to biological explanations. The result is that Dunnell's work is an extended argument not only addressing how to apply evolutionary theory to Archaeology, but why this should be done and the changes required in Archaeology to facilitate the application. So mixed up with the biology is a critique of Archaeology generally, and some broad claims about historical sciences and the nature of what they study.

Luckily for us, archaeological practitioners have interpreted his original ideas. The work Lyman and O'Brien and other archaeologists have extended and changed the original conception of "Selectionist Archaeology", attempting to integrate it into archaeological practice rather that the outright replacement that Dunnell has at times advocated. I will not go into the detail of the modifications and changes in 
Evolutionary Archaeology. Nor will I go into the detail of Dunnell's justification for the application of evolutionary theory. Rather, I will concentrate on analysing the attempt to use Darwinian Evolution as an explanatory mechanism in Archaeology. That does require some analysis of Dunnell's critique of Archaeology. But this analysis will only be a means of clarifying his position, rather than a full exploration of his critique.

In what follows, I will outline Dunnell's criticisms of processual Archaeology. To put his project into context, I will also outline some of the necessary conditions to which a biological Archaeology must conform. This should help make sense of Dunnell's positive project and its weaknesses. I will leave a more detailed discussion of Evolutionary Archaeology's claims to the following chapter.

\subsection{Dunnell's critique of Processual Archaeology}

To understand the approach taken by the evolutionary archaeologists, and the selectionist archaeologists in particular, it is important to make sense of the problem they saw with processual Archaeology. I have argued in previous chapters that the processual position was internally inconsistent. It could understand and make sense of adaptations to the physical environment, but because it primarily worked at the level of the group, it could not make sense of individual adaptations to group living. This was an internal criticism of processual Archaeology. The criticism of Robert Dunnell is much more external. It criticises the entire project of the processual archaeologists and traditional culture history. Dunnell thinks they have their approach wrong.

Dunnell takes the idea that Archaeology should be looking to biology - and in particular Darwinian evolution - very seriously indeed. It is worthwhile working through his criticisms for two reasons. On the one hand, they are serious charges in their own right. On the other, they highlight general problems with a naturalised Archaeology. Whether Dunnell can overcome those difficulties, we will see in the next chapter.

Dunnell believes that the explanatory task of Archaeology is to explain change 
over time. Archaeology is a historical science and its task is to explain history. Equally, Dunnell felt that Archaeology shouldn't be in the business of reconstructing the lifeways of past individuals or cultures. It should be trying to explain the archaeological record and changes within it, not attempting to reconstruct past behaviours. Its task is to explain the history that is revealed in the archaeological record. So much of the target of his criticisms is how archaeologists have explained changes in human material culture.

This is an important shift in emphasis. For Lewis Binford, the archaeological project was to contribute a historical perspective to anthropology. The task for the processual archaeologists was to reconstruct extinct cultures for anthropological analysis. Dunnell sees Archaeology as a historical science. His criticism has to be seen on that basis. Dunnell is interested in explaining the history of material culture by using evolution as a guiding heuristic. The result is that Dunnell's explanations are particularly focused on the temporal dimension of archaeological finds. Crucially, there is a shift in emphasis to the explanation of change in artefacts through time. The explanatory target for Dunnell is not past cultures, but the history of human material culture.

Dunnell's approach is a shift in emphasis from the reconstruction of past cultures to a historical picture that includes longer stretches of time, and consequently changes for which aspects of biology were important. For Processual Archaeology, the essential idea was that of adaptation. That's what cultures were for. For Dunnell, the important idea is evolution. There are changes in Human material culture over time. The archaeological record documents those changes and evolution, according to Dunnell, can provide insights into those changes.

\subsubsection{The Mechanisms of Change}

Archaeology had always seemed to require an explanation of change. For instance, there may be a sequence of artefacts over a series of stratigraphic layers. To explain differences in the types of finds at different layers, there needs to be the identification 
of some kind of mechanism of change. Now for archaeologists who looked to the sciences of their explanatory forms, the notion of evolution is clearly a potentially productive one. Dunnell thinks that biology should indeed provide the mechanisms and models for explaining the archaeological record. More specifically, he wants Archaeology to be Darwinian. According to Dunnell, the problem with traditional Archaeology was that it adopted a skewed version of evolution to explain change. Dunnell claims that evolutionary ideas within Archaeology came not from biology;

"...rather, cultural evolution is founded in the work of the social philosophers such as Spencer and the early anthropologists who followed them..." (Dunnell, 1996b)

According to Dunnell archaeologists were using the term evolution, but were not really talking about natural selection or descent with modification. In short, they were not talking about Darwinian Evolution. Archaeologists had been using 'evolution' as a phrase to cover any notion of change. The processual archaeologists, although they made gestures in the right direction, nevertheless inherited this conception from earlier workers in Archaeology. They had inherited a view of evolution as a progression, and saw it as a transformational process. Cultures "evolved" from less adapted to better-adapted forms by default. The problem lay in the fact that processual Archaeology did not completely break from its cultural historical past. The title of V. Gordon Childe's book sums up something of the atmosphere that prevailed in the later stages of cultural history; "Man Makes Himself". (Childe, 1979) Human nature was such that it would solve adaptive problems. Dunnell believed that Processual Archaeology's break with culture history was never complete, and consequently it inherited this way of thinking.

More importantly, Dunnell believed that many of the statements about change used by processual archaeologists were just-so stories, mere story telling. When faced with changes in the archaeological record of a particular culture, archaeologists would first look for environmental or demographic factors. Once these had been identified, the change in the material culture of the group would be explained as an adaptation to these factors. It was assumed that cultures had an in-built capacity to 
adapt to such changes.

This story telling flowed from the background theory that was driving the Archaeology of Binford and the processualists. The processual archaeologists took adaptation to be the "reason" for culture. Culture was a group of people "adapting" to the physical environment. Changes in material culture were people "adapting" to changes in conditions. Cultural traits were therefore given functional explanations. Cultural feature $x$ served adaptive function $a$.

"In a transformational framework, one would expect to see "adaptation" take precedence over "selection" as the mechanism that shapes cultural change. This is, of course, precisely what has happened. The modern archaeological literature is full of "adaptation," "adaptive processes," and so forth, but is exceedingly short on selection." (Dunnell, 1996a:p59) ${ }^{17}$

In itself, this is may not be problematic. Providing functional accounts of change is not necessarily a bad thing. According to Dunnell, they are not evolutionary accounts though, despite the claims that some processualists made for them:

"Functional explanations and proximate causation are legitimate explanatory goals in other disciplines, and there is no reason to reject them for Archaeology. They are not, however, evolutionary explanations, and they cannot be substituted for them, contrary to the implications of some modern literature." (Dunnell, 1996a:p61)

The difficulty with such explanations is their combination with explanations of change or stasis in cultures. It is not clear what maintains such functions over time. There needs to be a stabilising selective regime that punishes slight variations in function, such as a constant environment. Nor does a functional conception easily account for change. There is no obvious mechanism that insured that a culture came up with the right solution. It just did. The processual archaeologists functional

${ }^{17}$ It is important to note here that by "adaptation", Dunnell is talking in the psychological sense of the word. Hence his use of "scare quotes". The processual archaeologists were not talking about the biological sense of an adaptation being the result of natural selection and a selective regime. 
account of cultures leant itself to ascribing change to human intent. The result for processual explanation was that "...need as perceived by the innovators has become a viable explanatory alternative." (Lyman \& O'Brien, 1998) Archaeologists could "explain" changes in the archaeological record by attributing a perception of need to the culture under study. Without a well-confirmed theory of the scope and limits of human capacities to notice and respond to change (see chapter 8), such explanations face the same problems of testability as the cultural history explanations of diffusion that processual Archaeology rightly rejected.

Moreover, It is not clear that the function of a cultural trait can always be attributed to such a human intent as the perception of need. The ecological function of an eating taboo may well be to prevent a social group from undermining its breeding stock. However, the intent of the individuals within a society may well range from a genuine respect for cultural restrictions to not wanting to get offside with the rest of the community. None of the individuals within the culture may be aware of the functional nature of their behaviour. Explaining the eating taboo through time by attributing a functional role for it may not be a good explanation. The cause of its continuing existence or its change is not explained by its adaptive function.

This is a problem with functional explanations generally.(Martin \& McIntyre, 1994) In Archaeology, it becomes particularly acute, because there is no access to the intent of the makers of artefacts. Anthropologists can at least ask the cultural participants why they engage in an activity, or why they continue to manufacture goods in a certain way. Archaeologists do not have access to the intent of the makers of the object. In finding a communal feasting bowl, tests conducted by the archaeologist may be able to reveal its day to day function, as a container for stews for instance. Reconstructions of the cultural system may be able to point to a potential function for the pot within a cultural milieu, as a means of sharing jointly acquired food. This is turn may be a component of the group's adaptation to their environment. However, the beliefs of the individuals concerned, their understanding of its functional role and the reasons why they continued to engage in the activity will be 
necessarily opaque in Archaeology. The people are dead and gone.

In Archaeology then, the intentional dimension of cultural behaviours appears to be completely off limits. Even if a way to include the beliefs and intentions of the actors in a culture is available so that it made functional explanations workable, Archaeology has no access to the intentions and beliefs of the actors. Dunnell sees this as a fundamental weakness of processual Archaeology. While processual archaeologists might be able to identify the function of a cultural trait with fair reliability, they were in no position to explain why that trait came into existence, why it persisted over time, and why it disappeared or changed. The explanation of chronology, of the time dimension of cultures, was reliant upon an un-stated assumption of the ability of cultures to adapt, with no account of the implementation of that adaptation or its maintenance. In Dunnell's view processual Archaeology was incomplete. Functionalist explanations can explain cultures, but not changes.

Dunnell's critique has two strands. Firstly, he argues that processual archaeologists inherited a conception of cultural change that was progressive and reliant on human intention. Secondly, he claims that this reinforced their functional account of past cultures. Functionalism cannot explain past cultural changes nor why changes did not occur.

Dunnell believes that he can provide the causes for changes in cultures, as well as explain the maintenance of cultural traits. He believes that archaeologists can explain change, and give a good accounting for functional explanations of phenomena, the same way that biologists do for functional traits in animals, by appealing to natural selection.

\subsection{Biological Archaeology and its requirements}

The processual Archaeology of Lewis Binford was in a sense "biological". For Binford culture was, as we saw, an extra-somatic adaptation. So Binford had made an appeal to a biological notion, adaptation, as an explanatory mechanism. This mechanism was the measure by which good explanations within processual 
Archaeology could be judged. Nevertheless, Dunnell is right to make the claim that the processual archaeologists had no mechanism for the generation of the right adaptation. Cultures simply came up with the right solution. The implication was that cultures had an innate ability to generate the right solution to the adaptive problems that they faced. The processual account did not include biological mechanisms or explanations of how cultures responded to changes in circumstances.

Now Dunnell wants to give explanations for why the right mechanisms, the right adaptations, emerged. So what does he need to say? He wants Archaeology to give evolutionary explanations for the adaptations that processual Archaeology made claims for. What would such explanations look like? Clearly, the idea of natural selection is of appeal for Archaeology looking to biology for its explanations. However, there needs to be a demonstration that human material culture can respond to natural selection. Before natural selection can be used as an explanatory tool in the archaeological context, it has to be shown to be an appropriate tool.

\subsubsection{Establishing Lineages}

For a start there needs to be an identification of some kind of lineage. Evolution implies some means of inheritance, something that continues over time from generation to generation. That something has to be some identifiable property or object that can be transmitted from generation to generation. So there has to be ancestor-descendant relationships, and descendants must resemble their ancestors in the right ways. However, Natural selection is a theory about what happens to lineages, not a means to identify them. There needs to be some independent criteria for identifying an ancestor-descendent relationship. With no independent means of identifying a lineage, we may 'see' natural selection without one of the necessary conditions for it - inheritance from ancestor to descendant - being there.

However, in the case of Archaeology there is an additional problem. We also need to make some kind of claim that such a inherited property can be identified in the archaeological record. When we look at a set of photos of a family pet over its life 
span, we have reference point that identifies the photos as belonging to a sequence. The image of the pet in question appears in all of the photos. Similarly, we need an identifiable object or quality in the archaeological record that can identify an evolutionary sequence, a phylogeny. Therefore, the relation between the archaeological record and the inherited property also needs to be clear. We cannot afford to mistake the archaeological record as a lineage. Pieces of pottery do not inherit properties from one another. The pieces of pottery are indicators of inheritance. The same goes for skeletal finds of organisms. We take the finds to indicate a process of inheritance, and have to justify that inference.

There are two entwined problems here. Identifying the correlates of a lineage in the archaeological record, and identifying a lineage. So we can come to an immediate conclusion that something like Middle Range Theory is going to have to be in place to help securing the relation between a lineage, and the material remains with which an archaeologist is confronted. But just how that plays out is going to be highly dependent upon identifying lineages in the first place.

Lets assume for a moment that we accept Binford's idea of culture being a systemic integrated adaptation. In this context, an entire culture is the unit of a lineage. Now the idea that culture is inheritable and persists over generations is intuitively accepted. It is a component of our definition of culture that it is something passed on from generation to generation. Whether the archaeological record can demonstrate that is an open question. When faced with a sequence of artefacts through time with minor variations, are the similarities the result of inheritance or are they the result of other factors? What identifies a cultural lineage? Many of the essential things that distinguish extant cultures are non-preserving traits such as language and ideologies. What in the archaeological record can we identify that can make us confident we are looking at an uninterrupted sequence of artefacts?

This problem is serious in virtue of human behavioural flexibility. It is possible that human cultures could come up with similar solutions to similar environmental problems. It is possible that a sequence of artefacts in the archaeological record is not 
the result of natural selection. Rather, it is the result of different cultural groups occupying the same physical environment. As we saw with Binford, processual Archaeology claimed that the physical environment shaped cultures in regular ways. If something like this is true, then similarities through time are not necessarily indicative of an inherited culture. They are indicative of a common response to similar problems. This is an instance of convergence. Different cultures converging on some optimal solution to a common problem. The important components of a culture that allow us to distinguish one from another may be the non-preserving components. The culture's hardware, the stuff archaeologists find, may not be indicative of a particular culture.

There is extra complexity in contacts between cultures. Groups can get technologies from one another. So there is the possibility of horizontal transfer of cultural traits as well. Whether we class this as inheritance at all is an open question. It does mean that an entire systemic adaptation can gain new components while retaining its overall character. So a culture that really is in place and being transmitted from one generation to the next might appear in the record as a replacement of one people by a different one using different stuff.

The problem of establishing a lineage or phylogeny is magnified when we start to think of the components of a culture. Although this might solve some problems of horizontal transfer and convergence, there are many possible ways that we can see objects as possessing the features of predecessors. For instance, we can see the artefact as being part of a functional lineage. Early Greek temples were made of wood. As wood became scarce and stone increasingly used, many of the architectural forms were stone imitations of wooden structures. We know this partly from remains but partly from the presence of "skiamorphs" in Greek architecture; where one material is shaped to resemble another. In this case, marble shaped to the textures of wood. (Gordon, 1978) So such architectural features show inheritance across manufacturing mediums and that shapes the lineage of Greek architecture. We can, it seems, detect a pattern of inheritance here. The same functional object can manifest 
itself in different mediums. But, is this appropriate? Is identifying similar functions across time indicative of inheritance? And just what is inherited here? The presence of skiamorphs does seem to indicate some kind of inheritance, but it is unclear whether they are under selection or not.

Take a different case. Eastern Asia at the time of Homo erectus shows a lack of bifaces. ${ }^{18}$ This is in spite of bifaces finds being congruent with $H$. erectus finds in virtually all other areas. This may be due to the use of bamboo to serve the same function. (Schick, 1994) The tool lineage of Homo erectus runs out at the Movius line $^{19}$ and provides us with no clues to eastern populations behaviour regarding tool use. Gaps left by differential preservation of materials means the lineage is harder to assess. More crucially, it is a long way from being clear that a bamboo cutting implement is the direct descendent of the Acheulean handaxe. The mode of manufacture is vastly different. Nor can we be sure that the functional need was there in the first place. What could be a source of error here is confusing inherited needs with inherited solutions. The case for bamboo tools depends on an assumption that a continuing need exists, it is not based upon actual finds. Discontinuities in material culture may indicate breaks in a cultural lineage, but they may also indicate differences in local ecology instead.

Other criteria for establishing lineages are problematic as well, albeit for different reasons. The material a tool is made of does cover some cases of inheritance, but not others. The emergence of microlith technology - finer worked stone implements -

${ }^{18}$ Bifaces, or Handaxes are stone tools with flakes removed from two cutting edges. The type referred to here and elsewhere in the thesis are also known as Acheulean Handaxes.

${ }^{19}$ The "Movius line" was proposed as a cultural boundary by the Harvard archaeologist Hallam Movius in 1944. It represents a break in the spatial continuity of the Acheulean handaxe culture. East of the line, through South East Asia and China, there is an absence of Acheulean Mode II handaxes, despite finds of Homo Erectus, the hominid associated with this technology. See (Schick, 1994) for more detail. 
with early Homo sapien culture could be seen as a descendent of earlier stone tools. However, many microliths show signs of mounting on shafts. They were probably arrowheads or spearheads. While in some sense the later technologies were improvements on earlier technologies, in other ways it is important to recognise these developments as something new. This raises the issue of identifying splits in lineages. Is a microlith mounted on a shaft the same branch of a lineage as one un-mounted? If not, we cannot claim that improvements in microliths share an ancestor-descendent relationship. Perhaps the mounting of microlith is a new technology, while the construction of the microlith remains a descendent of earlier stone technologies. Again, we face problems identifying lineages at the scale of artefacts or cultural components. Lineages are difficult to identify, whether we think of them as lineages of artefacts, or as of lineages of the groups of makers of those artefacts.

There is an alternative route to the two we have examined. We could identify a lineage of artefacts via its users; a genetic lineage. On this view artefacts and cultural components are contributors to the fitness of the individual users of the artefacts, and are not 'fit' in their own right. After all, stones do not make more stones. Nor do stone tools make more stone tools. Changes in cultures are thereby the result of changes in fitness enhancing behaviours. Individuals within a culture make improvements on the cultural products of their ancestors, thereby boosting their individual fitness. But this view doesn't make much sense of horizontal transfer of cultural information. Human beings don't always get their cultural products from their parents. Genes do not track cultures with precision.

This is at least an indication of our problems of identifying a lineage. We seem to need some plausible way of determining what is inherited, and what in the archaeological record is indicative of inheritance taking place. Part of the solution lies in the next step that we need to take; identifying just what it is that evolution is acting on. 
We cannot assume that all of a culture's dimensions will be subject to selection pressures. The creation myths of a group and the various forms that they take do not seem, at least on casual reflection, to be a source of differential fitness. The efficiency of the foraging strategies of a hunter gatherer group do seem to contribute to differential fitness. Moreover, it is the variations in fitness that we need to identify, for natural selection works upon differing fitness. Those organisms that are better adapted to their environment do better than others. So one of the things that we need to determine is the contribution to increased overall fitness by individual features. What is under selection, and what that tells us, will be important. For we cannot assume that natural selection will leave its signature on the world in unambiguous terms. A long sequence of changes does not automatically indicate natural selection.

When we look at the archaeological record, we cannot be sure that any patterns we can see are the result of natural selection. If the tool types change, and a particular tool kit comes to dominate an area, we cannot point to this fact and assume natural selection is operative on the tool kit. It may well be the case that a hunting strategy a group uses allows it to be successful. The tools that that group uses come along for the ride. While the tool kit predominates due to natural selection, the tool kit is not selected for. Elliot Sober provides us with the distinction that we need to make:

" "Selection of" pertains to the effects of a selection process, whereas "selection for" describes its causes" (Sober, 1984:p100)

The predominance of a tool kit may be the result of selection of the users of the tools, the selection is for their hunting strategies, not their tools.

The distinction is important in biology, but potentially vital in making evolutionary claims about culture. The reason for this is simply that Homo sapiens are capable of behaviour not directly tied to survival. Many modern human cultures are the product of economic surplus. Much material culture bears no direct relation to our immediate needs. Our efficiency in harvesting energy and materials allows us to spend some of the excess production on things not directly related to our immediate 
survival. Large parts of human cultures seem to be the result of such surpluses. The decoration of hunting implements, cave paintings, personal adornment, large-scale group constructions may be side-effects of this surplus rather than direct contributors to fitness. Indirect contributions to survival or reproduction are of course possible. However, to demonstrate such indirect contributions a precise documentation is required.

So when faced with a diversification or change of the material culture of a group, what we may be seeing is increased economic surplus. Should a cultural group develop new means of subsistence that is less time consuming, but equally productive as previous methods, the time surplus could well find its expression in the archaeological record. The resulting change in the record would be the result not of selection but a side-effect of invisible changes.

It may well be that in many, indeed most, cases changes in cultural products are the result of the entire culture benefiting from a few changes in a few essential areas. The spread of some cultures may be the result of one superior technology related to food acquisition. The rest of that groups culture, it's language, adornment, and religion, come along for the ride. Having said that, although such things as personal adornment and cave paintings may not be obvious adaptations, they may serve some adaptive purpose. But in order to determine whether they are we need some means of distinguishing them from other factors.

Generally in order to tell whether something is adaptive or not we have to integrate it into some measure of the organisms overall fitness. Fitness is the ability of the unit of selection to reproduce. It is a relative measure, in that what counts as "fit" is in relation to other units of selection that are part of a population. What makes one organism fitter than another is a greater ability to reproduce in relation to competitors.

For Archaeology, we may have to ask questions about whether or not we are talking about the fitness of the organism or the fitness of the artefact. The problem is here that artefacts have two potential sources of fitness: Fitness of the tool and fitness of the behaviour that the tool facilitates. These are distinct, as defenders of meme- 
based theories of cultural evolution have shown. I may possess a very good tool that has "evolved", via natural selection, to be very "fit" functionally. Nevertheless, the behaviour or strategy that the tool facilitates may be less fit in relation to other behaviours or strategies. Archaeologists who try to apply selection models to archaeological data need to explain the origins of fitness differences in order to determine what selection is operating upon.

5.2.3. Source Laws and claims of differential fitness.

In biology we need not only theories that we can use to generate explanations about evolution. We also need laws or theories that generate explanations for differing fitness. Elliot Sober calls these laws 'Source Laws' to differentiate them from consequence laws. (Sober, 1984:p47-59) Consequence laws in biology are the results of fitness differences. In the case of animals, source laws are generally derivations from ecology. For it is the environmental context of the organism that determines differential fitness. But is this necessarily the case for Homo sapiens? $\mathrm{H}$. Sapiens are niche constructors par excellence. Their cultures and technologies ameliorate much of their environment. Clothing reduces selection on the ability to stay warm. Cooking reduces the requirement to have robust jaws and teeth for mastication. One of the hallmarks of Homo as a genus is the ability to use technologies of various kinds to provide flexible buffers between their physical characteristics and their environment.

These kinds of relationships aren't unusual in biology, but their extent in Homo sapiens is. It follows that in order determine selection on features of material culture, we may need to know a great deal about the ecology of the particular material culture under investigation. Some selective effects are obvious: Clothing in cold climates is a good example. But often the fitness of cultural products will require a deep understanding of the culture and its environment. As we saw above, it looks like Greek temples form some kind of lineage. If natural selection is operative on Greek temples, what is the selection for? Was the shift to stone the result of resource changes or was it a move to materials with increased durability, or prestige? 
In human cultures, the fitness consequences, if any, for the users of artefacts found at sites will often be the result of long and cryptic causal chains. Hawkes Hierarchy bites. Inferences about the fitness of an object's function will be harder to sustain the higher up Hawkes Hierarchy an object sits. If an object is ceremonial in its role, then any claim that is made about natural selection being operative is going to have to provide detailed information about the "ecology" of the object. In the case of ceremonial artefacts, the ecology of the artefact can appear to be the culture of the group.

Thus a selectional Archaeology needs source laws for behaviours generated from sciences other than ecology. Ideally, selectionist Archaeology will have source laws to explain the origin of the fitness differences, and how these forces interact. For Homo sapiens, their proclivity for niche construction may make those source laws necessary in order to determine the selection forces at work on their material culture.

In summary, an Archaeology looking to biology for its explanatory forms needs to do four quite closely connected things.

Firstly, it needs to establish the existence of lineages. The criteria for identifying lineages should not rely on stories about natural selection. They must be claims about how the archaeological record are indicative of some kind of inheritance taking place.

Secondly, we need to determine which factors of the archaeological record are selected, and which components come along for the ride, hitchhiking on the increased fitness bestowed by one particular feature of a cultural complex. This has important links with our first task. We may be able to detect inheritance via a hitchhiker, while the actual feature under selective pressure, the bestower of fitness, is archaeologically invisible.

And that of course leads us to our third task. In an ideal situation, we would have a good understanding of how various features of material culture interact and contribute to fitness. For this we need the source laws, and that will require borrowing from the other sciences and disciplines that can contribute to our understanding of a cultures 
adaptedness to the environment.

But ticking away under all this is the other task that is peculiar to Archaeology. Just what are we talking about? The fitness of the tool to achieve its task, or the fitness of the task? The fitness of the culture, or the components of a culture? The fitness of a group, or of the individuals in that group? If we fail to identify the bearers of fitness, we risk not accounting for the possibilities of conflict, and risk not explaining the full gamut of human material culture. Just how far up Hawkes Hierarchy can a biological Archaeology get? 


\section{Chapter 6: Selectionist Archaeology.}

Dunnell sees selectionist Archaeology as an alternative approach to explaining a specific dimension of archaeological phenomena. As we saw at the beginning of the last chapter, the functional explanations of processual Archaeology gave an account of cultures but lacked means of adequately explaining cultural change. Processual Archaeology could explain time slices, but it had difficulty with cultural chronologies. It had no mechanisms to call upon to explain change.

Cultural History had left a legacy of chronicles. There was data concerning changing occupation patterns and changing technologies for large numbers of cultures. There were phenomena of change to be explained. These sequence of archaeological finds are the explanatory target of the Selectionist Archaeologists. What shapes them, what maintains them and why have they changed the way they have?

Dunnell's first move in his positive project is to appeal to evolution to explain archaeological data. Now it is crucial at this point to say what Dunnell means by evolution. For Dunnell evolution is descent with modification and in particular the "...differential persistence of variability" (Dunnell, 1996a:p32) Dunnell believes that evolution can provide explanations for changes in the archaeological data so long as certain criteria are met. The primary criteria are inheritability and differential fitness.

"If culture patterns are in any degree heritable, and there seems to be little disagreement on this, at least at some scale, then natural selection and the other evolutionary mechanisms are operative on cultural phenomena so long as those patterns affect the fitness of human populations." (Dunnell, 1996a:p65)

So far, so good. Given an archaeological sequence of some type, evolution should explain changes in artefact type and artefact frequency. It is important to note at this 
point that Dunnell is not only talking about natural selection. Drift and founder effects are recognised as important mechanisms underpinning changes in trait frequencies. This is why history, and historical contingency, is an important component of a selectionist Archaeology. Determining when something is selected and when it isn't is going to partly rely on an understanding of the specific circumstances surrounding changes in artefacts. "History Matters." (Lyman \& O'Brien, 1998:p622)

What we have so far is this: Dunnell and the selectionist archaeologists see the explanandum, the thing that needs explanation, as the lineages of cultures. The explananda, what does the explaining, is evolution by natural selection or other means. A good explanation should point to some kind of adaptive advantage for any changes in the record, or alternatively be able to pinpoint forces such as drift or founder effects. Dunnell needs clarify a few points to get natural selection to provide explanations. He has to say just what it is that is evolving. He has to say what is fit. Is a lineage of a particular type of artefact, or is it a lineage of people, or of groups of people, with their cultural products all being an extension of their phenotype? This is the problem we saw earlier; tool fitness or behaviour fitness; individual fitness or group fitness. Moreover, we need criteria to identify lineages.

\subsubsection{The Units of selection and transmission}

If Dunnell is going to engage in selectionist Archaeology, he's saying something about material culture. He's saying that it is adaptive. That's fine. Very few would take issue with that per se. The idea that culture is an adaptation, isn't really in dispute. Nevertheless, to explain differences in the archaeological record by appeal to selection is to make the further claim that some artefacts, artefact types or groups of artefacts differ in enhancing something's fitness.

Here we come to the first problem. We have to get some definitions straight. We have to distinguish between replicators, the thing that transmits from generation to generation, and vehicles. Vehicles or interactors are the things that replicators build. 
Selection operates in a direct way on vehicles and this affects the frequency of the replicators in the subsequent generations. In the case of biology, groups of genes build organisms. Genes are the replicators. The complete organism is the vehicle or interactor. Because groups of genes are involved in the building process, they are at least partly dependent for their success on the other genes an organism possesses. No matter how much an individual gene can contribute to an organisms fitness, if the rest of the genes detract from the interactors' ability to reproduce then its effects will be lost.

For an Evolutionary Archaeology, we need to do two things. Ideally, we need to determine the replicator, the units that replicate across generations. Crucially, we have to determine the vehicle. What it is that selection operates on. So we come to the first hurdle for selectionist Archaeology; what does Dunnell think the replicator for human cultures is? Dunnell actually doesn't say. What's perhaps more surprising is Dunnell's stance on the issue. He claims that we do not need to know the unit of transmission, the replicator;

"It is well worth remembering that biology made use of evolution for many decades before it was able to identify the units of transmission." (Dunnell, 1996a:p66)

Dunnell's argument is the following. Selection acts on something, perhaps groups, perhaps individuals, perhaps even memes or some other unit of cultural replication, and the artefacts are the phenotype of whatever it is that is replicated. Artefacts are the 'interactors' for whatever replicates, though if the replicator is the meme, perhaps artefacts are both interactor and replicator.

For selectionist accounts to get off the ground Dunnell believes that this crude conception is really all that is required. Regardless of what the replicator is, it is the phenotype, in the case of Archaeology the artefact, that faces the pressures of selection, that interacts with the world.

"What is critical is inheritance, however effected, and variability, however caused." (Dunnell, 1996a:p49-51) 
So long as there is some kind of variation in material culture, and so long as that variation is inherited, then natural selection can account for the changes in artefact types and frequencies. The Selectionist Archaeologists do not want to commit themselves to any particular replicator, they just want to say that culture is the interactor for whatever replicates.

"Paleobiologists do not worry about the reproduction of particular replicators - genes - when they study the evolution of forms of fossil organisms. A bone or tooth is not a replicator; it is part of an organism's phenotype. Whether a tooth represents one or multiple genes is as yet unknown, but this does not keep paleobiologists from trying to determine and explain the evolutionary histories of the organisms whose phenotypic hard parts they study. Similarly, artefacts are not replicators; they are what is replicated. Cultural traits conceived as ideas in the minds of individuals are the replicators that are transmitted; social learning is both the transmission mechanism and the source of variation resulting from transmission errors and recombination." (Lyman \& O'Brien, 1998:p619)

Dunnell admits that we will need to know at some point in the future the unit of transmission, the replicators for culture.(Dunnell, 1996a:p66) But he does think that an evolutionary Archaeology can be viable without knowing the atomistic unit that gets passed from generation to generation. From the quote above, it looks like the unit of replication is ideas in individuals. But none of the Selectionist Archaeologists want to commit to a particular conception of the replicating unit. Nor do they think they need to in the short term.

The question that Dunnell cannot dodge is the issue of interactors. What are the 'vehicles' that interact with the environment? The answer to this is that the vehicles for the unknown units are the subject matter of archaeologists; the material culture of Homo sapiens. Dunnell and the Selectionist Archaeologists really want to explain all changes in cultures. So they wish to explain Changes in tool types, and changes to individual tools. Changes in the subsistence strategies of individuals and changes in group strategies. This is why it is so important for this program to be able to identify traits that are directly selected, and distinguish them from those that come along for 
the ride. Remember that the target for Dunnell's explanations is the material culture of human beings over time. And in particular it is the chronology of artefacts - the sequence of past cultures - that the selectionist archaeologists are looking to get the theory of natural selection to explain.

"Evolution is change in the composition of a population over time. In evolutionary Archaeology, the population is artefacts, which are viewed as phenotypic features, and "it is the differential representation of variation at all scales among artefacts for which it seeks explanations" "(Lyman \& O'Brien, 1998:p616)

Selection operates on artefacts. The material culture of human beings is the extended phenotype of Homo sapiens. Evolutionary forces act on this, shape it, and change the population of artefacts over time. It does this by natural selection acting on variation within the population of artefact types. So long as those variants contribute differentially to fitness, natural selection is operative.

To what is this contribution to fitness? Generally, Dunnell sees the contribution to fitness being a contribution to the fitness of individuals. However, Dunnell does not rule out inclusive fitness, where related individuals aid the reproductive success of one individual. Nor does he rule out the possibility that the contribution may be to the fitness of a broader, unrelated group of individuals.

In fact, Dunnell does explicitly suggest that in complex societies group selection could be operating. Dunnell recognises that inclusive fitness, fitness as the result on selection on kin, could potentially scale upwards to a group that was less related. However, certain criteria have to be met for this to happen. Firstly, the rate of change has to be sufficiently speedy. More importantly though, the group needs to be functionally interdependent, with a high level of specialisation. This interdependence and specialisation leads to the third factor, that individuals cannot reproduce the entire culture, "...individuals no longer carry the full "code" for reproducing the human phenotype, including its behavioural component." (Dunnell, 1996a:p51)

Clearly, Dunnell still has a lot to tell us. To measure changes in trait frequencies in material culture is not enough. Such a process would be analogous to population 
genetics in biology, providing data on changes in trait frequencies in populations.

This wouldn't get us near Hawkes Hierarchy, let alone get us up its ascending scale. If selectionist Archaeology is to do more than the archaeological equivalent of population genetics, the selectionist archaeologist needs to tell us how to identify the contribution to differential fitness. Which aspects of material culture contribute to fitness, and which aspects come along for the ride? He also needs to identify lineages of artefacts or cultural traits independently from the claim that they are selected.

Unfortunately, this is where things start to go awry for Dunnell. For as we shall see, he ends up entangling the two issues. Determining which aspects of material culture are selected, and identifying ancestor descendent relationships, should be separate issues. As noted earlier, the means of identifying a lineage must be independent of the claim that natural selection is operative. ${ }^{20}$ Dunnell confuses the two issues, and consequently fails to provide an important component of his theory.

Before we discuss this however, we must take something of detour back into Dunnell's critique of Archaeology generally. The reason for this is that Dunnell identifies "cultural traits" in a way that is distinct from other theories. And to see why he does this, we need to understand his concerns about traditional archaeological categories.

\subsubsection{Objects and Traits}

Before we look further at Dunnell's attempt to apply evolutionary theory, we need to briefly talk about what Dunnell sees as cultural traits. It is important to understand where Dunnell is coming from in this area, because it influences his theory heavily. As we saw in the earlier section, there are problems in Archaeology about just what is selected. The behaviour, the artefact, perhaps cultures. So where does Dunnell stand on this?

\footnotetext{
${ }^{20}$ Chapter 5:5.2.1
} 
Dunnell has been concerned about the ontological status of archaeological categories longer than he has been interested in natural selection and evolution. "Systematics in prehistory", written in 1971, was an early attempt by Dunnell to create a system of classification that was independent of the theory that explained those categories. (Dunnell, 1971) It is worth keeping in mind that Dunnell's scepticism about the units of Archaeology, the stuff that is talked about and measured, runs deep. It colours his approach to Archaeology in important ways. Particularly what constitutes Archaeology's subject matter.

The problem for Archaeology (of any kind) is the nature of the empirical units. Just what should an archaeologist measure? Refer back to the table of V. Gordon Childe for a minute and his different cultural groupings for the Danube. As noted earlier, the reality of the various cultures is unclear. Just what is the analytical unit of Archaeology? For much of Archaeology of the last century the essential units of analysis has been the culture on one-hand, and artefact types on the other, with cultural groupings generally taking precedence. The analytic unit was a culture. This was the object of study and analysis. How a culture $x$ adapted to environment $A$ was the appropriate form of an archaeological analysis. The observational language of Archaeology is enriched, not raw, data. Archaeologists talk about cultures, campsites, bifaces and villages. But how do we choose an appropriate observation language?

Dunnell questions the usefulness of classification into cultures for evolutionary Archaeology. Cultural evolution for Dunnell is an abstraction "...without a subject matter." (Dunnell, 1996a:p39) Cultures and other analytic units used by archaeologists were arbitrary units. There are analogies here with the problem of species identification in evolutionary biology. A fossil represents a time slice in a continuously changing lineage, just as much as it is representative of a particular historical population or species. Some evolutionary biologists have as a result retained a certain scepticism about species as a meaningful category. In Archaeology's case, the boundaries potentially blur through space as well as time. Isolating the geographic boundaries of a culture is difficult with trade goods, 
migration and similar adaptive needs making cultures look like variations on a shared theme.

Sciences have observation languages; a set of terms that are used by practitioners to denote quite specific features of the world. Within Archaeology the most obvious attempt at developing a neutral observation language was the Mid West taxonomic method, whereby artefact groupings were given names based upon different levels of geographic and temporal spread. Broadly, cultures, artefact types, classificatory schemes such as that used for stone tools (Mode I through to Mode V), eras such as Palaeolithic, Neolithic, and cultural phases such as bronze age and iron age, are all attempts to put together some an observation language for Archaeology. They are supposed to be indicative of some particular feature of the world that all workers within the field recognise. The observation language also helps to define problems that require explanation. The middle to upper Palaeolithic transition is supposed to pick out a distinctive boundary, a genuine feature of the world that requires understanding. It is not merely an arbitrary label.

Dunnell doubts that this is really the case with archaeological terms. Many of the labels used by archaeologists are potentially arbitrary and may be misleading. The term 'chopper' for instance is supposed to pick out a particular tool type within the Stone Age tool repertoire. Yet, the term may be a misnomer. Choppers may in fact not be tools in their own right; rather they may be a constantly reused source of flakes, the genuinely functional tools. In fact, the history of Archaeology is littered with artefacts given names and descriptions that turn out to be misleading. ${ }^{21}$

${ }^{21}$ See (Toth, 1985) for an example. Toth's reappraisal of Oldowan artefacts demonstrated that the objects previously much debated in regards to function were probably hammerstones used in the construction of other tools. Equally, many tool 'types' were stages in a developmental sequence. This can flow on into how the Oldowan 'culture' and the capacities of the hominids associated with the Oldowan is understood. 
The problem as Dunnell sees it is that the processual archaeologists and archaeologists in general were using their reconstruction of behaviour to provide them with their classificatory schemes. To give a set of artefacts the term "chopper" is to group the object by supposed function. There is a covert reliance for many classifications on a reconstructed supposed function. These tools are scrapers. Those tools are choppers. Artefacts were being grouped by appeal to some behaviour that the archaeologist presumed was facilitated by that artefact. A classification can be undermined if a reconstruction of behaviour is faulty or misleading in some regard. Dunnell wants archaeologists to only deal with facts.

"The units in any theory that purports to be scientific, whether evolutionary or not, must be empirically identifiable and measurable in the phenomenological record. This is the basic flaw in the "behavioural correlates" notion of the reconstructionist school."(Dunnell, 1996a:p66)

A taxonomy that depends on guesses about behaviour can be misleading. Moreover, classification by appeal to behaviour risk suppressing the variation inherent in the archaeological record. Dunnell want the features of the archaeological record to be much more independent of the reconstruction process. The identification of a trait should be an empirically testable feature of an object. So in the case of pottery, features that would be traits would not be the supposed uses of the object, but rather things such as weight, size, shape, decorative patterns and glazes. These features of objects are detectable and verifiable. There should be no argument about an objects weight or size.

Dunnell's concerns about the reconstruction process, and his concerns about being an empirical scientist, lead him to conclude that traditional ways of identifying objects, of classifying them, are of no value. Their viability rests on a reconstruction of the culture or the artefacts function that may be misleading. These are legitimate concerns. There have certainly been cases where reconstructions have been flawed. The process of identifying the behavioural correlates to archaeological data is not easy. The task of building MRT is a long one. 
His answer to this is to say that the traits that an evolutionary Archaeology should deal with, and need to account for, should only be features that are identifiable in the archaeological record. A lineage should be identified using the raw data, rather than of behaviours, or reconstructed functions. So as an example all stone tools from a geographically contiguous area should be lumped together, weighed, measured, assessed for number of flakes removed etc, and placed in chronological sequences verified by geological and other dating methods. The construction of phylogenies can then proceed using the methods of cladistics. So tools sharing more features are related. (O'Brien, Darwent, \& Lyman, 2001) Natural selection is then supposed to explain variation inherent in those tools.

Dunnell has attempted to refocus Archaeology's project by first constructing lineages based on the "hard parts" of the archaeological record, rather than construct phylogenies based on the enriched data that MRT would generate. The phylogenies thus constructed are the explanatory target, rather than cultures, groups or individuals. Dunnell is suggesting a different mechanism for enriching the raw data of Archaeology. Rather than the reconstruction of static sites, Dunnell wants the reconstruction of historical lineages. The enriched data are artefact phylogenies, not site reconstructions. This, as we shall see, has consequences for the rest of his theory. By using verifiable physical properties of the objects, Dunnell hopes for the verifiable and independent construction of lineages. However, this also has other consequences. Dunnell has abandoned the idea of behaviour as being the means of structuring the interpretation of the archaeological record. That has serious repercussions, for taken seriously, it gives up on source laws, on explaining fitness differences. We will start looking at those repercussions with the identifying of lineages.

\subsection{3. $\quad$ Lineages, style, and traits.}

As we saw earlier, there is going to be problems in Archaeology in identifying lineages. Just how can you show that different time-slices in the archaeological record are linked by an ancestor descendent relationship? If two groups come to a similar solution to similar problems, their cultural products could look the same, but share no 
common ancestor or relationship.

There is a second problem. Which artefacts do you lump together? Which similarities across strata are prima facie evidence of cross-generation copying? Weighing various objects is going to be a useless way of grouping them. Dunnell is relying on common sense to distinguish things with enough in common to make variation within them worthwhile testing. There needs to be criteria to determine which things are variants under selection though differing fitness. As noted earlier, fitness is not an absolute measure. It is a measure of differences with a population of competing individuals.

In this context, lumping together the stone tools of Papua New Guinea Highlanders and the American Mid-West is clearly silly. This is not a single population of artefacts. Geographical and temporally contiguity does some work in identifying populations but not all. Many artefacts are complementary rather than in competition. There still needs to be some claims made that variants are variants of something, share ancestry, and compete in some way. Two styles of bow might be in competition, in some important sense; but they do not compete with arrows.

It's at this point that Dunnell needs to start distinguishing between different aspects of the archaeological record to identify the populations of artefacts that are the pool of variation upon which natural selection operates. He does this in an interesting but deeply problematic way. It is interesting for it does potentially offer a way of reliably tracking cultures. It's problematic because it relies on differentiating between the features of artefacts that are under selection, and the features that are not. The distinction that Dunnell uses is Style and Function.

Dunnell recognises that not all cultural traits will "...have readily apparent or measurable adaptive value..." (Dunnell, 1996a:p65) The cultural traits that do not have adaptive value Dunnell regards as style. Style is all the parts of cultures that do not contribute to fitness. Consequently, he distinguishes between style and function, describing them as dichotomies. 
So the diagnostic for determining whether a feature is functional or stylistic is whether natural selection is operative on the particular feature of the artefacts. However, Dunnell suggests that artefacts themselves may not be the correct unit of analysis. So within the archaeological record, any individual artefact may have features that are functional and features that are stylistic. It is features rather than objects themselves that are cultural traits. Style for Dunnell is those features of objects that are non-functional. It is not style, such as decoration etc, in the sense that we typically apply the term, however much of our common sense usage of the word 'style' would come under Dunnell's definition.

Style then is selectively neutral, and therefore can potentially serve as the archaeological equivalent to the molecular clock of molecular evolution. Dunnell's notion is built on an idea from cultural historical Archaeology; seriation. Seriation, the division of artefacts into "evolutionary" sequences, is a well-worn tool of archaeologists in providing relative dates for sites. Seriation was first used by the Swedish archaeologist Christian Thomsen in the 1830s in conjunction with his threeage system..$^{22}$ (Glyn Edmund Daniel, 1975, 1981; Trigger, 1990) Thomsen's system did not rely upon the presence or absence of a particular material characterising the "age". Stylistic elements were also included when assigning an object to a particular period. A bronze object could still be "iron age" should its decoration be diagnostic of an Iron Age artefact.

Style appears to be the product of groups and consequently may track cultures. They can be the source of information regarding the diffusion of technologies and the movement of people and its use as a cultural diagnostic has a long record of success.

\footnotetext{
${ }^{22}$ The three ages being Stone, Bronze and Iron age. Trigger points out that Thomsen's system was classificatory rather than "evolutionary", (Trigger, 1990 78-79) however its easy to take on board Dunnell's criticism that such classification could be perceived as evolutionary, and the three age system was certainly viewed as evolutionary by later workers.
} 
An obvious example of how this might work is the Maori carving of musket stocks in nineteenth century New Zealand. The particular technology is an import, but the stylistic elements of such weapons marked them in a more distinctly cultural way. The same type of object can have features that indicate that different cultures use it.

In this particular case, things seem remarkably obvious. The functional traits are those associated with the function of a musket. What tracks the cultural usage of the weapon is the different embellishment, the non-functional traits. Such distinctions will not always be obvious, not even in the case of the carved muskets. ${ }^{23}$ And this is a problem. How do you distinguish style from function? Dunnell needs criteria for determining when something is a style and when it is not within sequences or lineages. The beak-head pointing out from some ships is functional. It serves as a vital anchor point for the ships rigging. In other ships it is purely stylistic, a design hangover similar to our earlier example of skiamorphs in Greek temples. (Gordon, 1978) Despite the apparent usefulness of Dunnell's distinction between style and function, without some means of telling what is functional, he has made no real progress. This is Dunnell's fundamental problem. It is one thing to track traits through time, it is another to identify them and isolate their contribution to fitness. Moreover, the possibilities of using stylistic features of an object as a non-selected marker for a lineage disappear. The problem here is simply this. Dunnell has forgotten the organism.

\subsubsection{Separating Style and Function: so how do you tell?}

Dunnell has to provide some kind of principled way of identifying what features of an object are adaptive. But what makes a trait adaptive is its functional role in its context. We do not attribute functionality to a trait of an organism, without an

\footnotetext{
${ }^{23}$ One could imagine a scenario where carved muskets were highly valued among Maori, and possession of such a weapon increased the prestige of its owner.
} 
understanding of the organism. Indeed, one change in evolutionary biology over the last twnety years is its increasing realisation that the identification of function, especially in the fossil record, is very difficult. selectionist archaeologists think of themselves as the equivalent of paleobiologists. Should a paleobiologist uncover a large number of fossil carnivores over a temporal sequence, he does not identify the selection pressures that have shaped those hard parts independently of examining the rest of the organism. The engineering constraints of putting robust teeth into a gracile jaw may shape the forms of the teeth just as much as the function. Part of the "environment" for a trait is the other traits of an organism that it needs to work alongside. Likwise, Part of that environment for a cultural trait is the artefact of which a trait is a component. Claims about the beak-heads of ships do not make sense unless we understand the rest of the ship. Traits serve roles within the overall functionality of the artefact. So selective hypotheses require complete artefacts to be understood. The problem gets even broader. Traits will frequently make sense only when we discover the use that an object is put to and the behaviour that an artefact facilitates.

Evolutionary Archaeology, the selectionist approach, cannot do without behaviour and hence MRT. Without it, it cannot understand why the tools have been selected. All it can do is measure changes in tool types and claim that a frequency change in trait $x$ in the archaeological record appears to indicate selection. It cannot guarantee anything. The fact that a trait looks as if it has been under selection can be very misleading, given the risk of traits hitchhiking and the possibility that the adaptive status of a trait changes. Such data may be suggestive. But without understanding behaviour there is no means to tell whether there has been selection for an artefact feature.

Clearly, the selectionist Archaeology as outlined makes no sense in relation to Hawkes Hierarchy. If we interpret Hawkes Hierarchy as a series of explanatory goals, then it is not clear how selectionist Archaeology is going to help meet any of them. Without incorporating the resources of MRT, selectionist Archaeology cannot explain 
the role of those traits in a culture. The upshot appears to be that selectionist Archaeology is thrown back onto the resources of processual Archaeology. Processual did make some functional claims about the roles of various artefacts. Consequently, it could provide some of the distinctions necessary for distinguishing traits under selection from those that hitchhike.

So let's examine how far Dunnell has got in relation to the questions we outlined in the previous chapter. Dunnell does have some good things to say about the identification of lineages. The cultural historians did have some useful tools for identifying cultures over time. Dunnell's distinction of style and function will assist with that. The problem is though that distinguishing between style and function requires a good answer to our second question, working out the selection of traits, and the selection for traits. We need ways of distinguishing traits that hitchhike from traits that are directly under selection pressure. Finally, once we have identified lineages and populations, changes in trait frequencies do not necessarily indicate selection is operative. There are other mechanisms such a drift that can equally account for statistical changes.

Fundamentally, his problems rest on his lack of source laws to determine how features of human material culture contribute to fitness. Dunnell is right to be worried about reconstructing past cultures, but he needs those reconstructions to be able to determine the adaptive or non-adaptive role of a cultural trait. Other features of a culture, features with no "hard parts", may determine whether something is adaptive or not. Dunnell needs behaviour to make sense of hard parts. 


\section{Chapter 7: Behavioural Ecology and Archaeology}

\subsubsection{Introduction}

This chapter starts the process of looking at the Evolutionary Ecological Archaeologists. It's an unfortunate name. It becomes confusing when we talk of Evolutionary Archaeologists and the Evolutionary Ecological Archaeologists. Realistically it is an extension of behavioural ecology to archaeological data and to avoid confusion I will refer to it as behavioural ecology. Within the archaeological literature however, it is known as Evolutionary Ecological Archaeology; Behavioural Archaeology is a separate position with a different agenda, one that we won't be going into here. ${ }^{24}$

The chapter starts with an outline of the Behavioural Ecology position. The Evolutionary Ecological archaeologists have close ties with anthropology, and are primarily interested in using the insights gained from behavioural ecology in understanding the archaeological record. Clearly, we can see this as an extension of the processual archaeological project but using even more of the tools and concepts of

${ }^{24}$ Behavioural Archaeology is an extension of the Middle Range Theory of Binford. It just happens to be taken to extreme lengths. Its project is to provide laws about the relationships between the material remains of culture and the behaviour that produced it. Its mainly the work of Michael Schiffer. (Schiffer, 1976, 1996; Schiffer \& Miller, 1999) "Garbology", the study of modern garbage and its relation to modern behaviour is one of its off-shoots. But it has all sorts of problems. Many of the laws seem to be statements about relations between discarded objects and use that are causally empty. See also (L. R. Binford, 1981) for a critique. 
biology. The chapter then presides to look at how this works in Archaeology. From there, we move to look at Behavioural Ecological Archaeology's relationship with the selectionist Archaeology of Robert Dunnell. They both claim to be "Darwinian Archaeologies", nevertheless, they have argued with each other. I suggest that the reason for the dispute between the two positions is because they have differing conceptions of the role of intent in explanations of Archaeology.

\subsubsection{Behavioural Ecology}

Behavioural Ecology generally is the use of formal models to aid in the explanation of behaviour. The basic concept is that natural selection will favour behaviours that make the most efficient use of resources. Behaviours that are better at helping an organism survive and reproduce, that contribute to the fitness of the organism, will emerge through natural selection.

Behavioural ecologists model the use of any kind of biologically significant resource. For instance, time can be a resource. Should a predator continue to lie in wait for prey, or would the time be better "spent" in moving to a new location? The working assumption of the technique is that the choice that the predator makes will be the optimal solution to this problem. Predators that made better decisions would be in a better off than those that made less optimal choices. Behavioural Ecology is a cost benefit analysis of different choices or strategies and the way they contribute to an organism's fitness. These models assume no conscious planning or thought on the part of the organism. Natural selection weeds out organisms with good strategies from those with bad ones. The behaviours are seen as unconscious heuristics used "intuitively" by the organism. As we shall see later, this assumption becomes more problematic in the case of Homo sapiens.

The formal models of behavioural ecology have a number of features. For a start, Darwinian biology sets out certain goals that an individual organism should be aiming for. Reproduction is the ultimate goal but along the way, other goals may well need to be met. Food acquisition and access to mates are the most obvious of these . 
Within the process of food acquisition there may be other goals. Minimising risk in hunting prey matters. Being the dominant male in some social systems also matter in reproduction.

The goals of behaviours can be nested within other goals. There may be a set of strategies available to a male chimpanzee regarding becoming alpha male in a chimpanzee troop with the concomitant sexual access that that implies. The alternatives might be alliance building and trading off exclusive access to females, or "going it alone" with the greater aggression required. Reproduction is the ultimate goal, being alpha male is a proximate goal, and the male is faced with decisions about what is the best option. Being alpha male, and having social structures that include alpha males may in itself be the result of a strategy that is optimal given female distribution states.(Foley \& Lee, 1989) So the proximate goal of being an alpha male is itself defined by a higher level strategy, males maximising their sexual access, again concerned with the ultimate goal of reproduction.

This clearly points to the next component of an behavioural ecology model; the environmental context. These are envisaged constraints on the organism. Some will be obvious. Predators can only travel so far in a day. Potential prey may be individuals scattered across a landscape or 'clumped' in herds. Females may be groups around rich food resources, or foraging separately over a wide area. Some constraints may not be so obvious. One constraint will be the ability of the organism to respond to some feature of the world that can cue a change of strategy. Organisms need proximal cues for behaviour changes. In some cases, an organism may not receive or be able to process the information needed to change strategies. These particular difficulties will haunt us for the rest of this thesis.

We have constraints and we have goals. The next thing that is required for a formal model is some kind of currency that is empirically measurable. The currency will be some form of limiting resource. For a model of prey choice in predators, the currency might be energy expended by the hunter on a particular prey type, versus energy gained from the consumption of a captured prey. The "currency" is a useful 
and empirically testable means of assessing which strategy is the best.

The final component of a behavioural ecology model is a set of optional strategies or "decision set". A predator might have options of lying in wait, patrolling a small area or searching a range. This would be its decision set. The optimal strategy will depend upon changes in one essential variable.

"In applying the model, all constraints but one are considered to be relatively fixed. The remaining constraint becomes the independent variable that predicts choices among the decision set." (Winterhalder \& Smith, 2000)

Once these factors are all in place, a mathematical model comparing the different strategies should determine which strategy is the best. There will be one strategy that maximises gains at minimal cost. It will be "profitable" in whatever currency the model uses, and it should be able to eliminate unprofitable strategies.

Behavioural ecology can be quite good at explaining changes in strategies over varying time frames. Over a yearly cycle, the likelihood of prey encounters for a predator may change as seasonal migrations change the makeup of the local prey populations, and hence the encounter rate. So behavioural ecology models can suggest the optimal strategy at different times of the year. Over longer evolutionary time frames, the same behavioural ecological model can work to explain longer-term changes in behaviour. Archaeologists have used behavioural ecology models to look at changes in hunting over longer periods, from hundreds to thousands of years.

(Mary C. Stiner, Munro, \& Surovell, 2000)

Behavioural ecological models simplify and model behaviours in such a way that our empirical grip on them is a little more tractable. The idea is to set out a cost benefit model of differing behaviours, and use this as a guide to understanding why one option is chosen over another. Even mismatches, where an organism engages in sub-optimal behaviour, can be informative. More on that later. 


\subsubsection{Behavioural Ecology and Archaeology}

Behavioural Ecology's application to Human behaviour began in the 1970s, initially in anthropology. In particular a few anthropologists began to use optimal foraging theory to investigate hunter-gatherer lifeways. Anthropologists would use models that took into account foraging time and alternative strategies, and assess whether such strategies were optimal.

In the archaeological context, behavioural ecology suggests that the manufacture and use of artefacts and other features of the archaeological record is explicable in the light of a similar cost/benefit approach. Making a tool, an artefact, has costs in terms of time, energy, and even has risks associated with it. Kathy Schick and Nicholas Toth, while experimenting with the manufacture of stone tools wore leather gloves and eye protection. They suggest that stone tool making risked cuts, abrasion and other injuries. (Schick \& Toth, 1993) One can imagine that stone tool making in a material like obsidian is like working with broken glass. For hominids without access to antiseptics, injury and the risk of infection are potential costs. The payoffs for stone tools had better be worth the risks.

An example of the application to Archaeology of these techniques is the explanation of stone caches; collections of stones suitable for tool-making that are unmodified and away from their geological source of origin. The explanation for these caches is in terms of the energetic requirements of searching the landscape, foraging if you will, for the resources to make stone tools. The suggestion is that "manuports", stone that has been moved from its geological origin, are a means of minimising energy costs associated with transporting the raw materials for tools. By collecting together raw materials, the toolmakers can have a ready supply of the necessary stones for use when the need arises. This is modelled is through assessing the cost and benefits of working with caches. An assessment is made of the cost of transporting raw materials in relation to the cost of not having access to materials when the immediate need arises. Stone caches are supposed to be a more energy efficient way of having access to raw materials. So, the theory goes that anyone that 
uses stone caches will be better off than those that don't.

This fundamentally is the behavioural ecology approach in Archaeology. Understanding, explaining the found traces of human activities, why they are there, why they are of the form they are, or indeed explaining any aspect of material culture, is a matter of reconciling its costs and benefits on natures balance sheet. The behavioural ecologists take Binford's notion of culture as an extra-somatic means of adaptation seriously. Where they differ from earlier processual Archaeology is in their focus on individual adaptation. Early processual Archaeology could occasionally slip into thinking in terms of group adaptations to environments. Behavioural Ecology generally works at the level of the individual.

Equally, they can avoid some of the charges of functionalism that levelled at the processual archaeologists by Dunnell. Having the "right" strategy is supposed to enhance fitness, so Behavioural Ecologists can point to the mechanisms of natural selection to anchor their speculations about behaviour. They did not ascribe the choice of a particular option to the intent of the individuals. Rather, they ascribed the choice to natural selection. However, on shorter time frames, over say seasonal variations in prey availability, the behavioural ecologists must assume that some trigger is working to make an organism shift strategies. If one style of hunting is not working, then agents shift to another. The option to switch strategies is dependent upon the organism being able to recognise the changing variable. So they do make tacit assumptions about the cognitive capacities of the agents to which these models apply.

Archaeology does face a difficult problem with behavioural ecology approaches. The behaviour is itself not visible. Whatever it attempts to model must have some correlate in the archaeological record. Importantly, that correlate needs to be directly related to the independent variable in such a way that it can rebuild or predict the relevant strategy. If for example the decision set for hunting strategies, ambush versus chase, has no correlate in the archaeological record, then there can be no precise modelling of the options. If either strategy produces the same results in the 
archaeological record, then there is no way of knowing which was used.

Archaeologists using the tools of behavioural ecology can only look at behaviours with a tangible physical side effect that preserved in the archaeological record.

In the case of different hunting strategies, there may be such a correlate. Different hunting strategies result in hunters taking different cross sections of a prey populations. Ambush techniques may be indiscriminate about which prey is being taken. A wide distribution of animals of different ages and sexes may be associated with campsites and other archaeological finds. Hunting techniques that involve chasing animals would tend to have disproportionate representation of the slower members of the target species population - the old and the young - in the remains associated with the campsites. (Avery et al., 1997) So from this we can sure those different strategies were used, and engage in useful reconstructions of what it would take for one strategy to be better than another. In the case studied by Avery et al, changing resources tended to shift which strategies were better. Ironically, because of the success of the earlier indiscriminate strategy the Homo sapiens themselves were a significant part of the reason for the resource changes. An oft repeated pattern in the history of Homo sapiens. ${ }^{25}$

In situations where there are variations in the archaeological record that archaeologists are seeking to explain, behavioural ecology needs to assume that the variations are related to some sort of optimisation. So behavioural ecological Archaeology is in the business of reconstructing the dynamics of changing costs and benefits. It should be equally comfortable at explaining stability. So long as the constraints and payoffs do not change then the optimal strategy should stay the same as well.

${ }^{25}$ See (Mary C. Stiner et al., 2000; M. C. Stiner, Munro, Surovell, Tchernov, \& Bar-Yosef, 1999) for the Palaeolithic case. And of course see (Flannery, 1994) for the Australasian examples. 


\subsection{4.}

The "Currency Problem"

However behavioural ecology when applied to humans does have other problems besides that of a direct physical correlation. Sometimes humans don't do what we're supposed to; we don't behave optimally. For instance within anthropology, some have argued that in some situations large game isn't in fact the optimal solution for protein acquisition. Yet, the groups involved do hunt larger game.

Part of the difficulty may lie in a point that emerged in the discussion of processual Archaeology. There are times when social or mating needs may override other needs. Technically, it is a matter of identifying the correct variables. Which is the shifting variable that determines when one strategy is better than another one? This is the currency problem. In assessing different problems, there may be different currencies involved. Sometimes the value of an action may be worth little, or even cost, energetically, but accrue other benefits. The social standing and the potential for mate access, or the building of alliances within a group, may mean that an analysis of an action in cost benefit terms for say, protein acquisition, doesn't work out. Kohn suggested that one of the functions of the later Acheulean handaxe was social prestige, rather than a tool solely for protein acquisition. (Kohn, 2000) So in understanding the effort that went into the making of the handaxes, it may be better to use as the currency for a cost benefit analysis some kind of social standing or social credibility.

This is where mismatches between optimal behaviour as predicted by a formal model, and the actual behaviour, can be useful. The divergence from the optimal suggests that the model does not include all the relevant factors. The hunting of large game may not be just about protein acquisition, it may also play a role in a group's social structures. So modelling the hunting of large game using energy as the currency may not be appropriate. The model may have to take into account some kind 
of social standing, and use a different "currency"26 or the strategy set might be wrong. In this way, behavioural ecology can work as a test for explanations in Archaeology. Behavioural ecological modelling can test any explanations of the type given by processual archaeologists. In this respect, Behavioural Ecology when applied to Archaeology really is the natural inheritor of processual Archaeology. It still takes very seriously the notion that culture is an extra-somatic adaptation.

By taking the behavioural ecology approach, archaeologists can also potentially get around the problem that Processual had of not taking into account adaptations to group living. Other members of the species are part of the environment for an individual organism, and can act as constraints limiting available options for individuals. So rather than accounting for behaviour in strictly energetic terms, behavioural ecology may be able to account for behaviours in terms of other "currencies", mate access, social standing and the like that take into account intragroup problems. At base, this still requires that behaviour is a measurable enhancement of fitness. So social standing must translate into increased resource access and thence to increased chances of offspring survival. Here the nesting of strategies is important. Given a certain group structure - the social environment local constraints may determine available strategies for fulfilling ultimate goals of survival and reproduction.

Despite this, there is a lurking problem. Just how well does a behavioural ecological approach avoid the charge of storytelling? To restate the concern, archaeologists since Binford have tried to frame their explanations without reference to the beliefs and desires of the individuals under study. This was a large problem with cultural historical accounts. They "explained" past behaviours by attributing motives and beliefs to past groups. So what "motivated" the construction of megaliths

\footnotetext{
${ }^{26}$ The New Zealand Maori concept of "mana" may be worth investigating in this regard. Mana is generally translated as "prestige" or something similair..
} 
on the Atlantic seaboards of Europe was a system of beliefs diffused from the Mediterranean. (Renfrew, 1973) Such explanations are at the top of Hawkes Hierarchy, difficult inferences to secure and almost impossible to test.

Behavioural Ecological Archaeology, and Selectionist Archaeology for that matter, attempt to avoid such explanations by shifting the causal mechanism for the behaviour down to the more tractable regions of Hawkes' Hierarchy. The levels that Hawkes described as those which "differ from animals only in the use of extracorporeal limbs, namely tools, instead of corporeal ones only." (Hawkes, 1954:p162) In particular behavioural ecologists shifted the explanatory burden to subsistence strategies. As Hawkes notes, "...the critical factor, standing between fair intelligibility and stark unintelligibility, is surely ecology, the study of the physical environment." (Hawkes, 1954:p162-3) That goes for behavioural ecology and selectionist Archaeology. So long as something can be seen as an adaptation to the physical environment, then it can be explained in those terms without recourse to human intent. It looks like the biological archaeologies we have examined are making a similar bet to the one that Binford made; that Hawkes Hierarchy will be collapsible. In this case, a little more obviously down to ultimate Darwinian biological forces of maximising fitness. This would effectively eliminate intent as a causal role in explanations.

Or does it? After all, behaviour is the target of the explanation, even if that behaviour is directed at fulfilling a biological need. Separating human behaviour from human intent isn't so straightforward, even in the case of subsistence strategies. This is why the currency problem in the human case is a real one. Another real and complex problem is that Homo sapiens make decisions about alternative behaviours. The choice between two behaviours still requires a proximate mechanism that chooses.

So one of the things that we need to look at here is how Archaeology deals with, and explains, the role of human intent within its theoretical structure. Humans seemingly engage in activities that are counter-productive and less than "strategically 
optimal". Equally, they make choices for the good. Sometimes they do so when these choices seem very cognitively demanding. So how does Archaeology looking to biology conceive of human intentions? Can it eliminate human intentions entirely, or does it need to account for them?

\subsection{Intent in biological Archaeology.}

On the surface at least, Selectionist Archaeology and Behavioural Ecological Archaeology are complimentary. In lots of way they should be. Selectionist archaeologists liken themselves to paleobiologists, looking at changes in material culture over long time-periods. Selectionists claim that like paleobiologists they are in a position to see broad patterns through time. The behavioural ecological archaeologists on the other hand are closer in role to standard behavioural ecology, explaining adaptations and the day to day behaviour of organisms. This looks like a standard division of labour within biology. Yet, these two approaches have argued. ${ }^{27}$ They have each claimed that the other is misguided and that theirs is the better way to do Archaeology. So how do the two positions disagree?

Part of the problem may well be something of a level mismatch. Behavioural ecology typically focuses on small-scale everyday problems faced by organisms. Selectionist Archaeology seems much more interested in the broader sweep of human history.

${ }^{27}$ See (Boone \& Smith, 1998) for the behavioural ecology critique of selectionist Archaeology, and (Lyman \& O'Brien, 1998, 2001) for the response. 
"Darwinian evolutionary Archaeology is neither reductionist or extrapolationist. It is grounded in the same macroevolutionary principles as paleobiology and is geared explicitly toward reconstructing hereditary lineages and providing explanations for those lineages' having the appearance that they do." (Lyman \& O'Brien, 2001:p409) ${ }^{28}$

So perhaps we can see the characterisation of the two positions as research into macroevolution and microevolution.

Yet, as we saw with the analysis of Dunnell, there did not seem to be any means to determine a contribution of an artefact to fitness. Behavioural ecological models should provide some of those mechanisms, and seems to be in a position to do so over a range of time frames. Behavioural ecology seems to provide the tools to determine the contribution to fitness of different bits of material culture. In fact, as Bettinger and Richerson point out, some of the few studies done by selectionist archaeologists seem to recapitulate behavioural ecological modelling (Bettinger \& Richerson, 1996:p224). Cost benefit analysis and behavioural ecological models providing accounts of varying fitness should be welcomed with open arms by selectionist archaeologists. So why are they arguing?

The point at issue is how each position accounts for human intent in its explanation. We will look at the selectionist take on intent first, and then the behavioural ecological Archaeology position.

One of the things that we did not examine when we looked at selectionist Archaeology was just how to generate the variation that natural selection needs to work on. Without variation, there is nothing to 'select'. There needs to be fitness differentials for selection to work. For selectionists the human makers of artefacts generate variation. Variation is the product of human agency, though constrained

\footnotetext{
${ }^{28}$ It may be worthwhile noting that the paleobiology and macroevolution that the selectionist archaeologists are thinking of is the conception of Stephen Jay Gould.
} 
agency. Stone tool cultures don't suddenly provide the variation capable of building lap top computers. Cultural evolution, the evolution of cultural traits, will be cumulative, it will build on existing variation. It cannot 'invent' a solution to an adaptive problem. The selectionists are worried that behavioural ecologists disregard these historical constraints by assuming that the optimal behaviour is available to agents faced with cost/benefit tradeoffs.

However, once these constraints are understood, the selectionists see human intent, human minds, as generators of random variation that natural selection then works on. Human beings fool around in the world, varying their material culture and selection operates on that variation, culling out those variants that does not contribute to the success of the organisms. Human inventiveness and creativity is analogous to mutations arising in genetic material, providing the variation for selection to work on.

Selectionist thinking suggests that the material culture is itself under selection with processes analogous to natural selection. Note here that there is no 'intent'. There are no choices being made by the possessors of the material culture. By claiming that human agency generates variation, the selectionist archaeologists are essentially saying that human decision making plays an equivalent role to random mutation in the evolution of culture. So human choices and decision making plays no role in shaping the overall form of the archaeological record. Intent can be left out as an explanatory mechanism all together.

Here the two positions start coming apart. The dispute between the two accounts is about what it is to be an agent, and what role human agency plays in evolutionary accounts of archaeological data. Both selectionist archaeologists and behavioural ecological archaeologists want to eliminate intent from their explanations. Attributing intent to past societies, the desire to achieve certain ends, is not open to empirical test. Both parties want their claims to be based on clearly defined mechanisms. The difference is what role human agency plays.

The behavioural ecology position is very different from that of the selectionists. It assumes genes have built an interactor capable of highly flexible behaviour. The 
interactors can optimise on solutions, reconstructing their environment in such a way that it aids survival. The behavioural ecological picture includes within it some kind of decision-making capability. Behavioural ecologists assume that selection has acted upon humans, and other organisms, to be what we can think of as "selective agents". Selective agency is where the organism itself acts in such a way as to choose a solution to a problem. Like natural selection, selective agency doesn't have to choose the best solution. It simply has to choose a better solution than others it is in competition with.

The ability to hit upon optimal solutions given fluctuating environments is itself an adaptation. $H$. sapiens has an adaptation for the building of a flexible, variable response to changing situations in the environment. Humans have been selected for behavioural plasticity. So for behavioural ecological Archaeology explaining archaeological data is a matter of isolating what would be the best decision for a group of people to make. To explain data, archaeologists tacitly assume some quite powerful decision making process of the individuals or groups under examination.

So the selectionists and the behavioural archaeologists are seemingly arguing about how to account for the apparent intelligence of human behaviour within evolutionary accounts of material culture. Are human beings random generators of material culture, with their behaviours providing the variation needed for natural selection? So natural selection is the mechanism of change. Or does intent operate as a proximate mechanism to ultimate biological goals?

It seems that a strong selectionist line is just wrong. Selectionist Archaeology cannot be right. It risks underestimating, or ignoring, human inventiveness and ability to respond to different conditions appropriately. For selectionist Archaeology human cognitive capacities, human intent, have no role in explaining the archaeological record. Darwinian Archaeology explains material culture by Isolating selective pressures and the changes in fitness they conferred. Human agency plays no role in selectionist Archaeology. In the case of human beings constructing artefacts etc, we would expect there to be some ability of this type. Homo Sapiens, on the face of it, 
possess the ability to get from one problem solving method to another without having to go through the gradual process of change that could involve a lack of fitness. They can get from fitness peak to fitness peak without having to go through stages of lowered fitness. Selectionist Archaeology cannot account for that ability.

Behavioural ecology may not be the right way to go either. According to their picture the archaeological record is the result of humans optimising their material culture. But there is problems with this view, and again the problem is human agency. We are smart, but not that smart.

Steven Mithen, despite his sympathy with the behavioural ecological position, is concerned that despite what we have said so far about behavioural ecology avoiding functional explanations and their capacity to explain change, this is in fact false.

"These approaches explain the static state of individuals or groups (and their material culture) with their environment at one particular point in time by reference to functional relationships (e.g. energy maximising, risk minimising) but cannot address how these states are arrived at and will be maintained as the environment changes. As archaeologists we should be concerned with change and consequently our most useful evolutionary perspective is one that emphasises adaptation as a dynamic process rather than as a static state."(Mithen, 1990:p8)

The issue for Mithen is that behavioural ecology may be able to assess the changing payoffs in different environments, and hence explain the ultimate functional reason for changes. However, there is no examination or account of the immediate proximate causes of change. So where behavioural ecological models fall over, and fail to match the behaviour predicted, it may be not so much that the model is wrong, rather it may be that the capability to change is not in fact present. So the complaint from Mithen is that the decision-making capability is considered to operate in such a fashion that it is open ended, and works to ultimate goals rather then proximal ones that individuals can assess. There is no accounting for the capability to make decisions. Yet, the decision making process itself must have limits. Cultural legacies and the physical environment may place quite well defined constraints upon what 
strategies are available. However, behavioural ecology does not explicitly account for the possibility optimisation fails because the individuals concerned cannot process alternative options.

The Behavioural ecology assumption is that given a range of options in the "decision set", the right decision will be chosen. If it is not, then there are three options.

Firstly, it may be an instance of the "currency problem". All the factors affecting the costs and benefits of a tool may not of been taken into account. The model just might be wrong. Artefact $X$ doesn't just serve a role in foraging for food, it also serves a role in social signalling which changes the costs and benefits. Mismatches between models and actual behaviours point to this as a possible factor.

Secondly, the model might be wrong because there may be historical constraints that make some options unavailable. At least some of the criticism of the behavioural ecological archaeologists by the selectionists is along this line.

"The major source of the misunderstandings, however, is a failure to grasp how the tenets of Darwinism are conceived by evolutionary archaeologists to apply to Archaeology. We do not dismiss the evolutionary ecological program recommended by Boone and Smith.... Rather, we believe [it] fails to employ some of the critical and uniquely historical aspects of Darwinian theory." (Lyman \& O'Brien, 1998:p616)

The selectionist archaeologists think that behavioural ecological models do not explicitly build in historical constraints into their models. The concern seems to be that there is an assumption that extinct cultures can choose from all available strategic options, when in fact they are much more constrained by history than behavioural ecology allows for.

Over shorter time frames, behavioural ecology clearly wins on this particular point. If the archaeological record clearly shows different strategies of hunting in a temporally contiguous setting, it seems likely that the mechanism that explains that change is Homo sapiens maximising their options. So a history of multiple strategies, 
either seasonal or within a generation, that then is whittled down to one strategy seems to indicate that options have been explored and a process of optimisation has taken place. But it is important to note here that the selectionists are not wrong in saying that history matters.

Steven Mithen is concerned about the third option for explaining mismatches. Individuals may be unable to 'see' or cognise one of the modelled strategies. Organisms can only change behaviour based upon available informational inputs. This is an important sub-category of the selectionist concerns about the lack of historical constraints. The constraints are those of the organism's cognitive capacity, themselves shaped by the history of the culture, but also the history of the organism. Where identifying such constraints becomes crucial is when looking at the material culture of human evolution. There needs to be an account of the important differences between hominid species in their cognitive capacities.

The issue that is creating the problems is the role of human intent within archaeological explanations. The selectionist archaeologists see it as the generator of variation that the mechanisms of Darwinian evolution can select. The behavioural ecologists see it as an undefined capacity directed at choosing strategies that will work towards ultimate goals. Both want the elimination of intent from explanations. Mithen's concern is that by not studying and not including intent, we miss making sense of some of the changes, and failures to change, in material cultures.

One way out of this is too include intent, human decision making and human inventiveness within the Darwinian research program. Bettinger and Richerson make the point that

"individual intentions - decisions at any rate - figure as forces in most theories of cultural evolution... It is hard to see how one can build a firewall that separates intentional and nonintentional processes; they seem to interact intimately. "(Bettinger \& Richerson, 1996:p227)

In fact, according to Bettinger and Richerson Behavioural ecology works best when it does take intent into account, despite the claims that this weakens the 
arguments by making them rely too heavily on intent.

"We should be wary of substituting folk psychology for real psychology in theorising about intent, as evolutionary psychologists constantly warn. It would not seem to follow that, however, because some theories of individual intent are grossly teleological that all of them are or that intent is not a legitimate matter of study and theorising. It is quite clear, for instance, that all sorts of organisms are capable of learning, which requires intent, by which we mean an abstract goal against which outcomes of various behaviours are evaluated. It is, moreover, specifically with reference to models involving individual intent that evolutionary theory has consistently proven itself superior to traditional anthropological theory."

(Bettinger \& Richerson, 1996:p227)

We will now look at Mithen's attempt to remove the "firewall" between intentional and nonintentional processes.

\subsubsection{Mithen and the "Eco-psychology of decision making"}

Clearly, some kind of understanding of human psychological decision making is required. The human capacity to learn, take on board new information and change strategies in anticipation of future requirements is a complicating factor in any explanation of human behaviour. Selectionist Archaeology risks underestimating it. Behavioural ecology risks overestimating it without acknowledging the historical and cognitive constraints that are placed upon it. The attempt of archaeologists to get rid of intent from explanations was never going to be successful.

A better strategy is to include some consideration of human cognitive abilities within Archaeology. This is the cognitive Archaeology of people like Steven Mithen, his "Eco-psychology of decision making." (Mithen, 1990)

Mithen takes seriously behavioural ecology. However, he believes it needs tempering with an understanding of the role of intent for the purposes of Archaeology. 
"How can we gain an adequate understanding of what happened in the past, and why it happened, without making explicit reference to people taking decisions on the basis of accumulated knowledge between alternative courses of action?" (Mithen, 1990:p1)

To achieve this end of making explicit references to decision-making capacities, Mithen needs to offer a theory that takes this into account. He does this by offering a version of behavioural ecology modified in important ways, and then attempts to integrate it with some conceptions about human decision making strategies.

Perhaps the most crucial move that Mithen makes is to shift attention to the individual decision-maker. This is a tricky position to take in Archaeology. As mentioned earlier in the discussion of Binford and his view of culture, archaeological sites are frequently the accumulation of the actions of many individuals. ${ }^{29}$ The single individual is something of a rarity in Archaeology. However, Mithen sees this as a methodological move, rather than as a search for the needle of the individual in the haystack of material cultural remains. The point is to use individuals struggling to fulfil their needs and requirements as the explanatory mechanism for the past. This is methodological individualism, not Archaeology in search of long dead individuals.

Nevertheless, Mithen cannot ignore the lessons of Middle Range Theory. His program needs to secure inferences from the archaeological record to past behaviours. In the case of a methodological individualism, that inference is from collective cultural remains to individuals. This is not to say that culture and groups are not important. Mithen does not deny that the Selectionist Archaeologists are right to think that the cultural ancestry places constraints on the individuals options. Individuals make decisions based upon "accumulated knowledge". However, accumulated knowledge includes knowledge gained by the individual as well as the culture.

Mithen wants to explore the proximate cues that serve ultimately biological goals.

\footnotetext{
${ }^{29}$ See section 3.2 .4
} 
To do this he needs as a component of any explanation a claim about the environmental cues that allow an individual to assess her options and to meliorate appropriately. This does not rule out the happy accident. Trial and error learning and the ability to take on board happenstance information should be included within the broad model of human decision-making capacities. Importantly, this does not rule out the horizontal transmission of information either. The idea that cultural information can pass across generations, from one individual to another, has been an important component of investigations of human cultures. Cavalli-Sforza and Feldman used the idea that cultural innovations could pass from one individual to another to build explanations of the spread of technologies through Europe. (Cavalli-Sforza \& Feldman, 1981) By suggesting that the capability of humans to take on board new information needs to be understood Mithen should be comfortable with such explanations. He is seeking to understand history by understanding the changing processes of information flow and use.

So, at the level of the individual, what cues is required to change behaviour? To adopt new technologies, to change their way of doing things, what information is required? Equally, what kind of information, what kind of capabilities is required to show individual initiative? This leads somewhat inevitably to what I've been calling selective agency. What is it?

The requirement seems to be the integration of a psychology of decision making into the archaeological project. There is a relationship between the environment and the perceived environment of humans. That relationship is mediated by Homo sapiens' ability to recognise relevant information and process it in a relevant way. To make sense of the evolution, the changes, the stability in some cases, of human material culture and the archaeological record it leaves behind, requires an understanding of the psychology of $H$. sapiens and their capability to change their behaviour.

Where this becomes crucial is in the study of human evolution. With the emergence of an identifiable material culture, we have the emergence of the Homo 
genus. However, there is a point in human evolution when material culture is partially the product of selective agents rather than being selected by Darwinian evolution. At that point we have the beginnings of some kind of an important transition that requires us to take account of a different kind of data, human cognitive abilities. Mithen seeks to understand these processes by including within his explanations explicit assumptions about psychological capacities. His methodological position is that it is only by including an understanding of human decision making strategies that we can understand the archaeological record.

Mithen is making a bet. Mithen's gamble is that psychology and related theories of mind can provide insight into the archaeological record on the one hand, and on the other, that the record is such that insights into individual decision-making is detectable. In making this explanatory bet, Mithen is relying on Psychology making a significant contribution to Archaeology. It is a psychology of a particular type. What he needs to identify is the proximal causes of behaviour, rather than the ultimate causes. A cognitively informed biology should be able to prescribe some kind of limits on those explanations; testable assumptions about what it is that human material culture can, and can't do. The conclusion is simply this. An understanding of human cognitive processes does not undermine our understanding of material culture as an adaptation. Rather it should be a part of our understanding of human adaptive behaviour. That in turn should aid our understanding of how cultures change. Mithen wants to avoid a behavioural ecology that cannot account for the process of change, by seeing every change as equally possible.

\subsubsection{The Problems of cognitive Archaeology}

On the surface at least, Mithen's position seems to make sense. By focusing on individuals, Mithen can acknowledge that part of an individual's environment is other members of a culture. Equally importantly, he deals with the concern we had when looking at the fitness of a tool or fitness of the behaviour that it facilitates. For Mithen's methodological individualism, both are important for the way in which they contribute to an individual's fitness. Mithen is consequently much closer to viewing 
tools as an extension of an organism's phenotype. In this regard, Mithen's position is probably most useful when cultural evolution and biological evolution are entwined. Especially when there is a relation between biological evolution and the cognitive elements associated with increased cultural elaboration.

Where Mithen stands out is viewing human cognitive mechanisms as crucial components of understanding cultural change. Mithen wants to include within archaeological practice the ability of humans to change strategies and behaviours given proximal cues, and the limits on those abilities. Where this starts getting a little odd is when we acknowledge that some cues for change are not found in the physical environment, but in the cultural environment. Mithen's bet will only have its payoff when we have a good understanding of how individuals influence each other.

The difficulty of Mithen's methodological individualism is going to arise when faced with explanations of collective endeavours. Hawkes Hierarchy is easier to collapse into the lower levels where humans are "more nearly like animals." The interrelations between survival, group organisation and ideology are much more opaque. Hawkes Hierarchy can be more difficult to ascend where increased efficiency of energy acquisition allows for the elaboration of social structures and ideological belief systems. Elaborate beliefs, ideologies and systems of information can stay in place because the costs can be born by a culture with "energy to burn". With all the confusing excesses of material remains that such expansion leaves the archaeologist, things are just that much harder to disentangle.

This elaboration in turn changes the cultural factors to which individuals need to adapt. This is particularly true of reproductive strategies. Social constraints such as punishment for infidelity and rules regarding resources and marriages influence directly an individual's opportunities and their social fitness. Consequently, what counts as "fit" in socially elaborate societies may well require a good understanding of that social elaboration. MRT may well find it hard to deliver this information from material remains.

Lets put this another way and reconsider the explanatory target of Archaeology. 
Take two distinct archaeological finds - a flint arrowhead and a large temple complex. One can perhaps make sense of the behaviour that produced the arrowhead by its contribution to an individual's fitness. In the case of a temple complex however, we are asking questions about why the environment has been manipulated the way it has by a group of people. Now Bettinger and Richerson note, "the emergent properties of groups should not be ignored." (Bettinger \& Richerson, 1996:p228) For a methodological individualist, this is true precisely because the "emergent properties" are part of the environment that an individual needs to adapt to. Group behaviours shape the adaptive landscape of individuals, and group behaviours therefore needs understanding in order to discern the fitness values of individuals.

The result is that methodological individualism of Mithen faces not only the standard problem of whether the behaviour of individual scale up to group behaviours in reliable ways. It also faces the problem that the group behaviour shapes the available strategies of the individual a theory of groups and the way that they construct the environment for individuals. This goes even for the simplest social system, and it is not clear that the reconstruction of the full complexities of social systems can be made from individual behaviour alone. 


\section{Chapter 8: Biological Explanations in A rchaeology}

This thesis has been explicitly looking at biological explanations in Archaeology. Now before we go into detail on the limits and problems of such explanations, it might be wise to step back a little and ask a few questions about biological explanations in general and our expectations of them.

In Archaeology, to explain a feature of material culture, some appeal to some biological principle needs to be invoked. Generally, these explanation involve an appeal to adaptation, either about some feature of material culture, or the way that it is used. Behavioural ecology uses just such appeals to fitness. Behaviours related to material culture were adaptive under certain conditions. These explanatory forms are those dictated by the research project of Darwinian biology, a biology that looks to evolution, natural selection and adaptation as unifying explanatory mechanisms that can account for biological phenomena.

Archaeology is in a strange position in its relations to the Darwinian program. The motivation for attempting to use Darwinian explanations is not always clear cut. For a start, it is not always clear that archaeologists have distinguished between a desire to "naturalise" their explanations and a desire to "biologise" their explanations. They are not the same things. Naturalised accounts of phenomena are accounts that make appeals to observable processes and observable phenomena. Real world things and forces that can be measured. These need not be biological phenomena. Biological accounts are merely one sort of naturalised explanation, not the only one. So why the appeal of biology?

The appeal is simply that human beings, Homo Sapiens, are just another biological 
entity. Therefore, explanatory forms that work on other biological entities should work on this one. Now at this point, we could bite a bullet when it comes to Archaeology. As we've noted, economic surplus allows for elaboration of culture beyond that which is immediately necessary for survival. We could say that biological explanations in Archaeology can only explain those features directly related to survival and reproduction. Any cultural superstructure built upon the economic surplus of a group is outside of the scope of strictly biological explanations. This argument has echoes within some of the debates within biology itself. Stephen Jay Gould and Richard Lewontin in particular have argued that the notion of adaptation and natural selection does not cover certain features of organisms. Some features are the by-products of developmental processes and contingent facts about a lineages history. (Gould \& Lewontin, 1979; Lewontin, 2000) So a strictly Darwinian and adaptationist line is incomplete in its explanatory scope.

Within Archaeology many of the arguments are in a similar vein. Darwinian explanations may have a limited scope for their applicability. The prospect of cultural elaboration due to an indirect relation between energy acquired and energy required for the reproduction of a lineage makes that a real possibility. Robert Dunnell's distinction between stylistic features of artefacts and those features subject to selection is a round about way of acknowledging these potential limits.

So the bullet to bite is that biological explanations are restricted to the lower levels of Hawkes Hierarchy. The level of subsistence strategies is the particular domain of its explanatory prowess. Any other levels will require different contributions from other sciences. Economics is one such, but Mithen's suggestion that the cognitive sciences have a role to play is at least partly an acknowledgement that adaptation and natural selection cannot do all the work in explaining the past. Other sciences, themselves based upon observable and measurable phenomena, have a role to play. There is something right about this view. Human beings and their cultures are the target of a large and diverse bunch of sciences and disciplines dedicated to studying their lifeways and cultural products. From Art History to 
Psychology and back to Anthropology, the diverse features of those biological oddities and their behavioural freak show get their own areas of study.

So on a less ambitious view of biological explanations of archaeological phenomena, biology plays its role alongside the other necessary sciences. Biology contributes a background understanding to the human past. Other disciplines and sciences contribute their explanations of certain features of the past. Theoretical arguments within Archaeology will take the form of turf wars, battling over which discipline contributes it explanatory power to where. The bullet to bite for Darwinian Archaeologies is the limited scope of biological explanations. The problem is that biological explanations are more ambitious than this.

\subsubsection{Beyond Subsistence}

Hawkes' Hierarchy is misleading. It suggests that the targets of archaeological explanations are a variety of cultural products. As we have frequently noted though, and in particular in relation to the work of Robert Dunnell, explaining the products of a culture isn't the only game in town. Archaeology also needs to be in a position to explain change. It needs to not only document the workings of different cultures, it also needs to explain the mechanisms that change one temporally located culture into one at a different temporal location. We would not think that a functional explanation of nineteenth century New Zealand would be in a position to account for the cultural detritus of the twentieth. Nor would we be satisfied with the claim that it was the same culture, only different. We would like, ideally, an explanation of the process of change from one to the other.

Biological explanations start looking more attractive and having much more scope with respect to the mechanisms of change. In particular the notion of evolution broadly conceived looks to have explanatory power beyond the lower levels of Hawkes Hierarchy. It seems at least plausible that even ideological systems may change due to processes similar or analogous to natural selection.

There are two ways we can go here however, analogy or application. Analogy is 
the approach favoured by Bettinger and Richerson. "...We need to keep very clear in our minds that culture is not exactly the same as any other natural system."(Bettinger \& Richerson, 1996:p229) The process of analogy is one where attempts to explain human cultures use the concepts and methods of Darwinian explanations. Debates about the unit of selection and the units of replication are arguments about what is the appropriate analogue to genes or individuals in applying evolutionary ideas. Most approaches to "biological" Archaeology take this form. The explanations appeal to natural selection and evolution-like processes, rather than specifically to biological evolution. This is borrowing theory, rather than applying it. (Murray, 2002)

The problem with analogy is its unclear foundations. What allows us to say that cultural products undergo something like natural selection? If we are using an argument form from another domain, we need to show that it is appropriate. Robert Dunnell attempts to get around this by saying that it is Darwinian biology that is the problem, not Archaeology.

"Evolutionary biology cannot, however, be applied unamended and uncritically to cultural phenomena, be they ethnographic or archaeological." (Dunnell, 1996a:p32)

Dunnell believes that an extension of Darwinian biology can take into account archaeological phenomena. Dunnell wants Darwinian science to include biology and culture within its explanatory gambit. For Dunnell, Darwinian evolution is an explanatory mechanism independent of any particular manifestation. Nevertheless, he is on shaky ground unless he can identify the unit of replication to which Darwinian processes apply.

Mithen and the behavioural ecologists are perhaps closer to actually applying biology to cultural remains. Strictly speaking though, they are using models derived from biology to explain artefacts and their related behaviours. It is also important to note here that when it comes to explaining changes in cultural remains, Mithen remedies behavioural ecology's weaknesses with appeals to a naturalised cognitive science, rather than biological processes per se. Evolved cognitive capacities explain 
cultural change, not natural selection.

The intuition that processes of change analogous to biological evolution are what are relevant changes the potential scope of such explanations. Dunnell, Mithen and the behavioural ecologists all accept this intuition to varying degrees. However, the research project changes at this point. Such a project is committed to discover the analogues to genes, individuals and traits in human culture, and make claims about the required properties for the process of natural selection, the topics we covered in chapter 5. The selectionist archaeologists failed in this regard by not accounting for the source theories for differential fitness, or the replicating units.

Some kind of joint effort, combining the selectionists' view, the behavioural ecologists' view, and the modifications of Mithen, seem to solve some of the problems. Selectionists need some methods of determining fitness, and determining when selective agency is operative. Behavioural ecologists need to acknowledge that human behaviour is not always flexible, and that sometimes mismatches between models and data are the result of poor models, and other times the result of historical and cognitive constraints. Selectionist Archaeology, and Mithen's cognitive Archaeology, can provide insights into these problems.

What is happening here is that the other naturalised sciences are supplying the source laws, the understanding of differential fitness, that natural selection requires. However There is no need to restrict source laws to biology. Just as engineering can provide insights into the differential fitness of alternative biomechanical structures, it is more than likely that other sciences can provide insights into the origins of differential fitness. So again, the prospect of including multiple disciplines in our understanding of human cultures seems inevitable. We need economics to take account of different fitness of individuals in relation to different economic positions; engineers, in conjunction with behavioural ecologists, to explain the different contribution to fitness of differing modes of manufacture. Selectionists to provide the mechanisms for changes. And so on.

For an integrated approach to work, the various disciplines must provide an 
understanding of what features of a past culture are adaptive, and how they contribute to enhancing the fitness of individuals. Then, a combination of cognitive mechanisms and natural selection can provide the mechanisms of change.

At this point, we come to the final problem: Intent. The problem of intent has been ticking away in the background in this entire thesis. It was unconstrained speculation about human intent that caused problems for the early professional archaeologists, the cultural historians. Binford tried to get rid of it by using the idea that cultures are a "systemic, integrated adaptation" to the environment. The "New Archaeology" attempted to eliminate intent from explanations of the past. Dunnell too tried to sideline intent. For Dunnell and the Selectionist Archaeologists, intent was a generator of novelty. Natural selection shaped our past, not human minds. Archaeologists who look to behavioural ecology suggested that human minds direct decisions towards ultimately biological ends. In doing this, they ignored the mundane day to day realities of human decision making. Humans make decisions based upon the information they possess at an isolated point in time. Mismatches between the formal models of behavioural ecology and actual behaviour may be because of some information failure. Maybe no one noticed the better option. Maybe they could never see it. Human minds are not perfect decision making machines.

Mithen's bet, that including intent within archaeological explanations will solve some of Archaeology's problem is I believe a good one. His gamble is that the cognitive sciences and related disciplines will aid our understanding of the past. The human past is the result of millions of small decisions made by millions of individuals. The shape of the archaeological record, the raw data, is partly the result of those decisions, and should provide an insight into those decisions if we can sift out the non-human factors in site formation. Cognitive science, and the understanding of the decision making process, will provide insights into the past. Unfortunately, the cognitive sciences are still a hotly contested area. Mithen himself found this out after the release of his book "The prehistory of the Mind". (Mithen, 1996) The basis for much of the criticism of his work was the use of a particular model of how the mind 
works. There was no problem with his archaeological evidence, the raw data. His reconstructions and explanations of Homo's evolutionary past using a controversial theory of mind were problematic.

The other problem is that the cognitive sciences, no matter how good they are, are in no position to predict the behaviour of individuals. They are in a similar position to biology and other sciences in this regard. No sciences predict or explain the behaviour of an individual. We can document, with some precision, an individual's behaviour, and provide a detailed history of their actions. But such a documentation is out of the question for Archaeology. We cannot see the behaviours to catalogue them. So it seems unlikely that Darwinian Archaeology, nor indeed any naturalised Archaeology, would ever be in the position to explain a unique data point. The unique individual finds of Archaeology will never be explicable by the broad laws of science.

Instead we have to rely on what Sterelny calls "robust process" explanations to provide insights in the past. (Sterelny, 2001) Robust process explanations are what they sound like. They are an appeal to a process that can be realised in multiple circumstances. They are explanations that are robust, in that they do not rely on a precise sequence of particular events. Rather, they rely upon a set of conditions, and make the claim that whenever those conditions are met, certain types of events will entail. Much of biology, psychology and other sciences to do with the study of organisms relies on robust process explanations. Such explanations have advantages. While we can explain something like the spread of a noxious weed by an account of the individual seeds spread from an initial plant, such an explanation is dependent upon specific and numerous variables. Now an explanation of this type might be able to explain why a member of this species of noxious weed has made it into my plant pot. It can point to a particular seed, and a particular confluence of events that explain the seed being deposited in precisely that place. But this style of explanation cannot explain why a similar species of weed has made it into someone else's plant pot. A robust process explanation can, even if the details of the individual event leading to 
infestation are never precisely documented. By determining what factors are fixed, and working out what factors affect variables in a meaningful way, we can begin to use robust process explanations to make claims with a broader applicability. We can use such explanations more than once. The reason for the weed in plant pots is the dispersal of seeds by air currents at a time of the year when people tend to have their windows open.

These robust process explanations are necessary for Archaeology and the study of pre-history. We cannot see the individual events of the past. But we may be able to explain the past with robust explanations, if we can show that they are applicable. Such explanations however are not good at predicting the finer details of events. But so long as we can determine their limitations, we can use them whenever the circumstances warrant it. Binford's instinct that Archaeology needed laws was not entirely off track. Archaeology does need the broad understanding that robust explanations can provide to make sense of the past. It just didn't need the formal rigour of the Hypothetico-deductive conception of science.

What this means for Archaeology and Hawkes Hierarchy, is that we may be able to give robust process explanations for all levels of Hawkes Hierarchy, only so long as the levels have features in common across cultures. The applicability and repeatability of robust process explanations depends on regularities existing across cultures. One of the strengths of the appeal to biology for Archaeology is the fact that all people, in all places and times, get hungry. We can use the basic biological needs of homo sapiens to provide us with explanations that can make sense of multiple situations.

This is a part of Mithen's gamble as well. Mithen is relying on the commonality of human cognitive abilities to provide him with the robust explanations that Archaeology requires. What the reliance on broader laws or explanatory forms does mean is that some features of the past may not be explicable. We may be able to provide a robust explanation for the presence of a religious cult as an adaptation for group living. However, we may not be able to explain why a particular group's cult 
did cave paintings featuring animals that they did not hunt.

Despite the problems, cognitive science, biology and other sciences are necessary to Archaeology. Their most important contributions is to provide constraints. As archaeologists build their scenarios for what has happened in the past, we can constrain those scenarios to what is possible. Engineering constraints, environmental constraints, cognitive constraints and the limits placed on organisms by biological processes should restrict scenarios to plausible hypotheses. The irony in all of this is that Archaeology does not look to have a theory of its own. The closest it gets is in the middle range theory of Binford. As we saw, MRT was not a theory about the past, rather it is a theory about how to do Archaeology, and get the data necessary for theories about the past, the scenarios about particular behaviours and groups.

Once we have those scenarios, we can begin to understand the bigger picture of the past. Our hypotheses about that bigger picture, including hypotheses about extinct peoples' political and ideational lives, will be constrained by our understanding of how humans behave, as individuals and as groups. The scope and limits on our understanding of the past will be the limits of our understanding of human beings generally; the more we can show to be unlikely or impossible, the more we can understand. Our ascent of Hawkes' Hierarchy is constrained by the limits of naturalised robust explanations of each of its levels. 


\section{Bibliography}

Avery, G., Cruz-Uribe, K., Goldberg, P., Grine, F. E., Klein, R. G., Lenardi, M. J., Marean, C. W., Rink, W. J., Schwarcz, H. P., Thackeray, A. I., \& Wilson, M. L. (1997). The 1992-1993 Excavations at the Die Kelders Middle and Later Stone Age Cave Site, South Africa. Journal of field archaeology, 24(3), 263.

Bettinger, R. L., \& Richerson, P. J. (1996). The State of Evolutionary Archaeology: Evolutionary Correctness, or the Search for the Common Ground. In H. D. G. Maschner (Ed.), Darwinian Archaeologies (pp. 221-232). New York: Plenum Press.

Binford, L. R. (1962). Archaeology as Anthropology. American Antiquity, 28, 217-225.

Binford, L. R. (1965). Archaeological Systematics and the Study of Culture Process. American Antiquity, 31, 203-210.

Binford, L. R. (1972). An Archaeological Perspective. New York: Seminar Press.

Binford, L. R. (1981). Bones: Ancient Men and Modern Myths. New York: Academic Press.

Binford, L. R. (1982). Objectivity-Explanation-Archaeology 1981. In C. Renfrew \& M. J. Rowlands \& B. A. Segraves (Eds.), Theory and Explanation in Archaeology : The Southampton Conference (pp. 125-138). New York: Academic Press.

Binford, S. R., \& Binford, L. R. (Eds.). (1968). New Perspectives in Archaeology. Chicago: Aldine.

Boone, J. L., \& Smith, E. A. (1998). Is It Evolution Yet? A Critique of Evolutionary Archaeology with Ca* Comment. Current Anthropology, 39(/Supp), S141.

Boyd, R., Gasper, P., \& Trout, J. D. (Eds.). (1991). The Philosophy of Science. Cambridge, Mass.: MIT Press.

Cavalli-Sforza, L. L., \& Feldman, M. W. (1981). Cultural Transmission and Evolution: A Quantitive Approach.: Princeton University Press.

Childe, V. G. (1979). Man Makes Himself. N.Y.: New American Library.

Daniel, G. E. (1967). The Origins and Growth of Archaeology.: Penguin.

Daniel, G. E. (1975). A Hundred and Fifty Years of Archaeology ( 2nd ed.). London: Duckworth.

Daniel, G. E. (1981). A Short History of Archaeology. London: Thames and Hudson.

Dunnell, R. C. (1971). Systematics in Prehistory. New York: The Free Press.

Dunnell, R. C. (1996a). Evolutionary Theory and Archaeology. In M. J. O'Brien (Ed.), Evolutionary Archaeology: Theory and Application (pp. 30-67). Salt Lake City: University of Utah Press.

Dunnell, R. C. (1996b). Natural Selection, Scale, and Cultural Evolution: Some Preliminary Considerations. In M. J. O'Brien (Ed.), Evolutionary Archaeology : Theory and Application (pp. 24-29). Salt Lake City: University of Utah Press.

Fagan, B. M. (1996). The Oxford Companion to Archaeology. New York: Oxford University Press.

Flannery, T. F. (1994). The Future Eaters : An Ecological History of the Australasian Lands and People. Chatswood, N.S.W.: Reed Books.

Foley, R. A., \& Lee, P. C. (1989). Finite Social Space: Evolutionary Pathways and Re-Constructing Hominid Behaviour. Science, 243, 901 - 906.

Gibbon, G. E. (1989). Explanation in Archaeology. Oxford [England] ; New York, NY, USA: Blackwell.

Gordon, J. E. (1978). Structures, or, Why Things Don't Fall Down. New York: Da Capo Press.

Gould, S. J., \& Lewontin, R. C. (1979). The Spandrels of San Marco and the Panglossian Paradigm: A Critique of the Adaptionist Programme. The Proceedings of the Royal Society London (Series $B)$.

Green, S. (1981). Prehistorian : A Biography of V. Gordon Childe. Bradford-on-Avon: Moonraker. 
Hawkes, C. F. (1954). Archaeological Theory and Method: Some Suggestions from the Old World. American Anthropologist, 56, 155-168.

Honderich, T. (1995). The Oxford Companion to Philosophy. Oxford ; New York: Oxford University Press.

Kimura, Y. (1999). Tool-Using Strategies by Early Hominids at Bed Ii, Olduavai Gorge, Tanzania. Journal of Human Evolution, 37(6), 807-831.

Kitcher, P. (1991). Explanatory Unification. In R. Boyd \& P. Gasper \& J. D. Trout (Eds.), The Philosophy of Science (pp. 329-348). Cambridge, Mass.: MIT Press.

Kohn, M. (2000). As We Know It: Coming to Terms with an Evolved Mind. London: Granta Books.

Lewin, R. (1997). Bones of Contention : Controversies in the Search for Human Origins ( 2nd, with a new afterword. ed.). Chicago, Ill.: University of Chicago Press.

Lewontin, R. C. (2000). The Triple Helix : Gene, Organism, and Environment. Cambridge, MA: Harvard University Press.

Lyman, R. L., \& O'Brien, M. J. (1998). The Goals of Evolutionary Archaeology. Current Anthropology, 39(5), 615-652.

Lyman, R. L., \& O'Brien, M. J. (2001). On Misconceptions of Evolutionary Archaeology: Confusing Macroevolution and Microevolution. Current Anthropology, 42(3), 408-409.

Martin, M., \& McIntyre, L. C. (1994). Readings in the Philosophy of Social Science. Cambridge, Mass.: MIT Press.

Maschner, H. D. G., \& Mithen, S. J. (1996). Darwinian Archaeologies: An Introductory Essay. In H. D. G. Maschner (Ed.), Darwinian Archaeologies (pp. 3-16). New York: Plenum Press.

Mithen, S. J. (1990). Thoughtful Foragers : A Study of Prehistoric Decision Making. Cambridge [England] ; New York: Cambridge University Press.

Mithen, S. J. (1996). The Prehistory of the Mind: A Search for the Origins of Art, Religion and Science. London: Thames and Hudson.

Murray, T. (2002). Evaluating Evolutionary Archaeology. World archaeology, 34(1), 47-59.

O'Brien, M. J., Darwent, J., \& Lyman, R. L. (2001). Cladistics Is Useful for Reconstructing Archaeological Phylogenies: Palaeoindian Points for the Southeastern Unitied States. Journal of Archaeological Science, 28, 1115-1136.

Raab, L. M., \& Goodyear, A. C. (1984). Middle Range Theory in Archaeology: A Critical Review of Origins and Applications. American Antiquity, 49(2), 255-268.

Renfrew, C. (1973). Before Civilization : The Radiocarbon Revolution and Prehistoric Europe. London: Cape.

Renfrew, C. (1982). Explanation Revisited. In C. Renfrew \& M. J. Rowlands \& B. A. Segraves (Eds.), Theory and Explanation in Archaeology: The Southampton Conference (pp. 5-24). New York: Academic Press.

Renfrew, C., Rowlands, M. J., \& Segraves, B. A. (1982). Theory and Explanation in Archaeology: The Southampton Conference. New York: Academic Press.

Roberts, D. (1993). The Ice Man: Lone Voyager from the Copper Age. National Geographic, 183(6).

Rudwick, M. J. S. (1972). The Meaning of Fossils : Episodes in the History of Palaeontology. London: Macdonald.

Salmon, M. H. (1982). Philosophy and Archaeology. New York, N.Y.: Academic Press.

Salmon, W. C. (1989). Four Decades of Scientific Explanation. Minneapolis: University of Minnesota Press.

Schick, K. D. (1994). The Movius Line Reconsidered: Perspectives in the Earlier Paleolithic of Eastern Asia. In R. Corruccini \& R. L. Ciochon (Eds.), Intergrative Paths to the Past: Paleoanthropological Advances in Honour of F. Clark Howell (pp. 429-450). Englewood Cliffs, NJ: Prentice Hall.

Schick, K. D., \& Toth, N. P. (1993). Making Silent Stones Speak : Human Evolution and the Dawn of 
Technology. New York: Simon \& Schuster.

Schiffer, M. B. (1976). Behavioral Archeology. New York: Academic Press.

Schiffer, M. B. (1996). Some Relationships between Behavioural and Evolutionary Archaeologies. American Antiquity, 61(4), 643-662.

Schiffer, M. B., \& Miller, A. R. (1999). The Material Life of Human Beings : Artifacts, Behavior, and Communication. London: Routledge.

Shennan, S. (1996). Foreword to "Darwinian Archaeologies". In H. D. G. Maschner (Ed.), Darwinian Archaeologies (pp. 3-16). New York: Plenum Press.

Sober, E. (1984). The Nature of Selection : Evolutionary Theory in Philosophical Focus. Cambridge, Mass: Mit Press.

Solecki, R. S. (1971). Shanidar, the First Flower People ( [1st ] ed.). New York,: Knopf.

Sterelny, K. (2001). Explanatory Pluralism in Evolutionary Biology, The Evolution of Agency and Other Essays (pp. 129-151). Cambridge, UK ; New York: Cambridge University Press.

Stiebing, W. H. (1993). Uncovering the Past : A History of Archaeology. Buffalo, N.Y: Prometheus Books.

Stiner, M. C., Munro, N. D., \& Surovell, T. A. (2000). The Tortoise and the Hare: Small-Game Use, the Broad Spectrum Revolution, and Paleolithic Demography. Current Anthropology, 41(1).

Stiner, M. C., Munro, N. D., Surovell, T. A., Tchernov, E., \& Bar-Yosef, O. (1999). Paleolithic Population Growth Pulses Evidenced by Small Animal Exploitation. Science, 283(5399), 190.

Taylor, W. W. (1948). A Study of Archeology. Menasha, Wis.: American Anthropological Assn.

Toth, N. (1985). The Oldowan Reassessed: A Close Look at Early Stone Artifacts. Journal of Archaeological Science, 12, 101-120.

Trigger, B. G. (1980). Gordon Childe, Revolutions in Archaeology. London: Thames \& Hudson.

Trigger, B. G. (1990). A History of Archaeological Thought. Cambridge ; New York: Cambridge University Press.

Ucko, P. J. (1995). Theory in Archaeology: A World Perspective. London ; New York: Routledge.

Winterhalder, B., \& Smith, E. A. (2000). Analyzing Adaptive Strategies: Human Behavioral Ecology at Twenty-Five. Evolutionary Anthropology, 9(2), 51-72. 